\title{
Perovskite and Organic Solar Cells fabricated by Inkjet Printing: Progress and Prospects
}

Xiaojin Peng, Jian Yuan, Shirley Shen, Mei Gao, Anthony S. R. Chesman, Hong Yin, Jinshu Cheng, Qi Zhang and Dechan Angmo*

X. Peng, Dr. J. Yuan, Prof. J. Cheng

State Key Laboratory of Silicate Materials for Architectures, Wuhan University of

Technology, Wuhan, 430070, Hubei, People's Republic of China.

Prof. Q. Zhang

School of Aerospace, Transportation and Manufacturing, Cranfield University, Cranfield, Bedfordshire, MK430AL, UK

X. Peng, Dr. S. Shen, Dr. M. Gao, Dr. A. S. R. Chesman, Dr. H. Yin, Dr. D. Angmo CSIRO Manufacturing, Clayton, VIC 3168, Australia.

E-mail: Dechan.Angmo@,csiro.au

Keywords: inkjet printing, perovskite solar cells, organic solar cells, roll-to-roll manufacturing, scale up

\footnotetext{
Abstract

Inkjet printing (IJP) technology, adapted from graphics and newspaper printing, has proven to be an essential research tool and industrial manufacturing technique in a wide range of printed electronic technologies, including optoelectronics. Its primary advantage over other deposition methods is it's low-cost and mask-less on-demand patterning, which offers unmatched freedom-of-design. Additional benefits include the efficient use of materials, contactless high-resolution deposition and scalability, enabling rapid translation of learning from small-scale, laboratory-based research into large scale industrial roll-to-roll (R2R) manufacturing. In the development of organic solar cells (OSCs), IJP has enabled the printing of many of the multiple functional layers which comprise the complete cell as part of an additive printing scheme. Although IJP has only recently been employed in perovskite solar
} 
cell (PeSC) fabrication, it is already showing great promise and is anticipated to find broader application with this class of materials. As OSCs and PeSCs share many common functional materials and device architectures, this review presents a progress report on the IJP of OSCs and PeSCs in order to facilitate knowledge transfer between the two technologies, with critical analyses of the challenges and opportunities also presented.

\section{Introduction}

Solar cells account for only $2 \%$ of global electricity production, ${ }^{[1]}$ although it has the potential to generate total global electricity production by several folds through the use of currently available technologies such as silicon solar cells. ${ }^{[2]}$ The lack of cost-competitiveness has hindered the wider adoption of solar cells and improvement in power-to-cost ratio remains key to increasing their contribution to global electricity supply. This fact has driven the development of solar cells from the first-generation silicon-based solar cells to the second-generation thin film-based solar cells. However, progress achieved in thin-film solar cells has been incremental and insufficient to break the market dominance of silicon let alone breaking beyond $2 \%$ in the global electricity supply. Clearly, dramatic improvements in the power-to-cost ratio are required if solar cells are to make a more substantial contribution to global electricity supply.

Organic solar cells (OSCs) promised to break through the cost barrier due to their significantly lower material consumption and their compatibility with low-temperature solution-based processing than the second generation solar cells. With these merits, less capital-intensive, high-throughput manufacturing methods with roll-to-roll (R2R) printing/coating techniques, such as those used in the printing of newspapers and magazines, were envisioned. Significant developments have already been made in the manufacturing 
arena evidenced by the demonstration of OSCs fabricated using a plethora of fast R2R printing and coating techniques ${ }^{[3-5]}$ However, power conversion efficiencies (PCEs) of $13 \%{ }^{[6]}$ and $4-5 \%{ }^{[7]}$ in laboratory-scale devices and large-area modules, respectively, have been achieved for OSCs. These efficiencies remain far lower than for the previous generations of solar cells. For example, silicon solar cells have a record PCE of $26 \%$ on small area and $19.6 \%$ on large-area. ${ }^{[8]}$

Organic-inorganic hybrid perovskite solar cells (PeSCs) have emerged recently as a breakthrough technology. These make use of a class of materials that can be processed using solution-based deposition techniques but offer greater efficiencies than OSCs. Within a short period, PCEs have climbed to $22.1 \%{ }^{[9]}$ from the first reported PCE of $3.8 \%$ in $2009 .{ }^{[10]}$ The challenge now lies in translating such efficiencies to commercially-feasible forms produced through industrial fabrication methods.

A large number of film deposition methods are applicable for the solution-based fabrication of the various layers of a solar cell ${ }^{[11,12]}$. Among them, inkjet printing (IJP) is one of the most frequently used methods on a laboratory scale. ${ }^{[13]} \mathrm{IJP}$ is a material-conserving technique used for the controlled deposition of different suspensions or solutions, enabling rapid and easy formation of functional material layers on various substrates. ${ }^{[14]}$ It also allows for the formation of fine patterns of printed inks at high resolution under ambient conditions. With a digital motif, print images can be made and modified on-demand with little delay between ordering and delivery. This flexibility is a big improvement on the limited flexibility offered by traditional printing methods such as flexographic or gravure printing in which printing plates are limited in resolution and costly and time-consuming to produce. In addition, IJP offers unmatched print resolutions of up to $5000 \mathrm{DPI}$ as the method relies on ejecting a single drop or drops of ink through very fine nozzles with diameters in the range of 20-100 $\mu \mathrm{m}$. Furthermore, the main processing advantage of IJP is its scalability from laboratory scale to 
larger-scale sheet-to-sheet or R2R processes without requiring contact to the substrate ${ }^{[15,16]}$ using functionally the same equipment. Based on these merits, IJP is anticipated to find application in the high-speed commercial manufacture of various printed electronics and solar cells.

A number of existing reviews address IJP utilization in various applications including optoelectronic fields, but none comprehensively examine its use in the fabrication of OSCs and PeSCs. Schubert et al. published the earliest reviews of the use of IJP in non-traditional applications in 2004 and 2008 - both of which remain excellent guides to understanding the process of droplet generation in IJP. These reviews particularly delve into the relationships between inkjet printability and ink and printing parameters including polymer structure, molecular weight, ink concentration, solvents, inkjet voltage driving conditions and present advances in PLED, OLED, TFTs, ceramics, and waxes. ${ }^{[15,17]}$ Similarly, Derby et al. and Friend et al. review the basic principles of inkjet printability. ${ }^{[18,19]}$ Other reviews outline the use of IJP for general optoelectronic application but provide little emphasis on solar cells. $^{[14][20][21]}$ To date, only Fang et al. reviewed IJP in OSCs, but chose to focus mostly on the active polymer blend in the OSC. ${ }^{[22]}$

A plethora of studies have focused on evaluating IJP for the fabrication of various functional materials in OSCs from laboratory to semi-industrial scales fabrication while several reports of IJP use in PeSCs have emerged recently. By addressing both OSCs and PeSCs, the aim of this review is two-fold: firstly, to comprehensively assess IJP developments across both the fields and secondly, to highlight the developments and lessons from the use of IJP in OSCs that could be directly applied and adapted to PeSCs as both technologies share several similar functional materials and device structures. To accomplish this, following an introduction to IJP technology, we find it pertinent to dedicate a section delving into the different geometries and materials used in OSCs and PeSCs. We then review IJP in the fabrication of numerous 
layers of OSCs and PeSCs. Finally, we highlight current challenges and present an outlook on the IJP technique to OSCs and PeSCs fabrication.

\section{Inkjet Printing Technology}

Inkjet printing is a versatile method for fabricating functional layers from homogenous or colloidal liquid phase inks. The operating principle behind various forms of IJP is based on the ejection of fixed quantities of inks in the form of droplets from nozzles. The mechanism of droplet formation varies in different inkjet systems and has evolved over the course of IJP development (Figure 1).

The beginnings of IJP can be attributed to early studies into the generation of droplets from jets. Felix Savart in 1833 was the first to make this a subject of theoretical study, with his work leading to a series of efforts in the mid-to-late 1800 s to understand the laws governing the break-up of jets into small droplets. Plateau explained theoretically the constitution of jets in a cylindrical column issuing from a circular orifice without any outside perturbations and with the application of vibration to the liquid. ${ }^{[23,24]}$ His work was followed by Lord Rayleigh, who described the breaking up of inviscid liquid jets into streams of droplets by the application of a transient pressure pulse to the nozzle. ${ }^{[25]}$ The phenomenon that was the focus of Plateau and Rayleigh's collective work, namely the instability of liquid jets in a column to outside perturbations, which causes the stream to breakup into droplets, is known as PlateauRayleigh instability. This understanding has underpinned the subsequent development of IJP. During the theoretical and empirical investigations into how to control jets breaking up into droplets, the first inkjet-like device was developed by Lord William Kelvin (1870), who patented a method of automatically recording telegraphic messages by using electrostatic force to direct a stream of ink. ${ }^{[26]}$ However, it was not until 1951 that the first inkjet integrated monograph was patented by Rune Elmquist while working for Siemens (née Siemens-Elema). ${ }^{[27]}$ Subsequently, IJP underwent an explosive development with the 
emergence of computer technology in the period of 1960-1980 leading to the development of the several IJP methods that are available today. The most common IJP methods today are Continuous Inkjet (CIJ) printing and Drop-on-Demand (DOD) printing.

\subsection{Continuous Inkjet Printing}

In continuous inkjet printing $(\mathrm{CIJ})$, the printed materials are generated in a continuous stream under pressure and then ejected through a small nozzle, which is placed at a potential relative to the ground. As the steam ejects out of the nozzle, it breaks down into small droplets that fall towards the substrate under the influence of gravity. While descending, the droplets pass through electrodes that impart a small charge on each of the droplets. The charged droplets then pass between deflection plates, which steer the direction of the droplets by a distance that is controlled by the input signal of the electric field, before being deposited on a stationary or moving substrate. A piezoelectric transducer is often used to subject the liquid behind the nozzle to a small pressure fluctuation, which is used to synchronize droplet formation (Figure 2).

The major advantage of continuous- and other IJP systems is the absence of physical contact or a critical spacing between the nozzle and the substrate, thus making it suitable for printing on rougher surfaces, curved surfaces, and surfaces sensitive to pressure. Additionally, the method is suitable to print any material that is sufficiently fluid and conductive, or any solute that is soluble in a conducting fluid vehicle.

However, the major disadvantage of the CIJ process is the inevitable waste of inkjet material during deposition. Although unwanted droplets of printing material can be collected in a gutter and recycled to become part of the printing ink, this recycled ink may be contaminated. ${ }^{[28]}$ For example, in Sweet's system, approximately only $2 \%$ of printing materials were used for the printing task. ${ }^{[29]}$ Additionally, CIJ technology is low-resolution compared to more advanced systems like DOD IJP, in which resolutions of up to 5000 DPI 
can be achieved. Hence, CIJ has found greatest use in labelling applications, whereas DOD is used in print and graphics where high-resolution printing is required.

\subsection{Drop-on-Demand Inkjet Printing}

Drop-on-demand inkjet printing, by definition, enables the generation of a single drop when required, hence enabling large materials savings in comparison with CIJ. In a DOD system, either the printer head moves and accurately settles on the desired location as controlled by a computer program, or the substrate is in motion. A series of events leads to the ejection of the liquid (Figure 2). The ejection of printing materials is related to a regular pressure pulse in the printing nozzles that is generated by a sudden contraction in the chamber volume, which forces the ink out of the nozzles. This pressure pulse is generated by one of two mechanisms; the mechanical deformation of a piezoelectric transducer (PZT), or the collapse of thermal bubbles, which involves resistive localized heating in the ink chamber. Accordingly, DOD IJP is divided into piezoelectric DOD and thermal DOD printing, respectively. In thermal DOD printing, a small resistive-heater thin film is set in the fluid chamber. A current is passed through the heater, causing the fluid to be heated above its boiling temperature, resulting in a small bubble to form due to vapour entrapment. When the current is removed, the bubble rapidly collapses due to heat transfer to the surrounding ink, which is at a lower temperature. The rapid expansion and collapse of the bubbles generate the required pressure pulse for droplet injection. Thermal DOD printing systems have found restricted use in only desktop or domestic printers. Alternatively, the pressure pulse for piezoelectric DOD printing arises from the mechanical deformation of a PZT. An impulse current is applied to a piezoelectric transducer, resulting in its cyclic deformation, which causes droplets to be ejected from the nozzle. Currently, the majority of industrial printers in ceramic or functional 
materials production use piezoelectric DOD technology instead of thermal DOD technology due to two main reasons. Firstly, it is difficult to generate vapour bubbles in a high-vapour pressure fluid. Secondly, a piezoelectric DOD printing system permits control over drop size and the velocity of any fluid through the simple adjustment of the actuation pulse. ${ }^{[28]}$ An in-depth review of different types of inkjet printers has been given elsewhere (see Basaran et al.). ${ }^{[30]}$ In 2005, Derby reported that drops in a DOD printing mode are produced at a typical frequency of $1-20 \mathrm{kHz},{ }^{[31]}$ which is an enhanced frequency range compared with Sweet's DOD system (2 $\mathrm{kHz}),{ }^{[30]}$ and the resonances within the chamber behind the nozzle strongly influence pressure pulse propagation and drop generation.

\subsection{Properties of Inks for Inkjet Printing}

While inkjet printing has been widely used in OSCs and somewhat in PeSCs, the properties of the inks, whether in-house formulated or commercially available, are seldom characterized. The ink properties play a crucial role in IJP, which relies on the generation of stable droplets. Significant work on characterizing "jettable" inks are published elsewhere, ${ }^{[32]}$ and such an approach needs to be adopted when reporting the IJP of new materials. Here we present a brief summary of some key parameters that ought to be considered.

Fromm extensively studied the mechanism of drop generation and attempted to relate this to ink physical properties. ${ }^{[32]}$ He formulated a dimensionless parameter, $Z$, which is the inverse of the Ohnesorg number $(\mathrm{Oh})$, to characterize if a stable drop could be generated from an ink (Equation 1). He proposed $Z>2$ for stable drop formation. This work was extended by Reis and Derby. Through the numerical simulation of drop formation, they postulated stable droplets are possible between $10<Z<1^{[30]}$. The $O h$ in-turn relates two key dimensionless parameters - Reynolds number $(R e)$ and Weber 
number $(\mathrm{We})$. These two dimensionless parameters incorporate all parameters that relate to fluid flow properties. $R e$ is the ratio of inertial forces to viscous forces within a fluid that is subjected to relative internal movement due to different fluid velocities, in what is known as a boundary layer in the case of a bounding surface, such as the interior of a pipe (Equation 2). The $W e$ relates to the competition between fluid inertia and surface tension (Equation 3). The $O h$ number simply combines these two works and relates viscosity to surface tension (Equation 4).

$$
\begin{aligned}
& Z=\frac{1}{O h} \\
& O h=\frac{\sqrt{W e}}{R e}
\end{aligned}
$$

where

$$
\begin{aligned}
& W e=\frac{v^{2} \rho a}{\gamma} \\
& \operatorname{Re}=\frac{v \rho a}{\eta}
\end{aligned}
$$

Here $\eta$ is the dynamic viscosity, $\rho$ is the density, $\gamma$ is the surface tension, $a$ is the characteristic length, and $v$ is the velocity.

Therefore, $Z$ from equation 1 can be used to express the relationship between surface tension and viscosity:

$$
Z=\frac{1}{O h}=\frac{R e}{\sqrt{W}}=\frac{(\rho a \gamma)^{\frac{1}{2}}}{\eta}=\frac{\rho a \gamma}{\eta^{2}}
$$

Thus, “jettability” has a geometric dependence on viscosity and a proportionate dependence on surface tension. At low $Z$ values, viscosity prevails and prevents drop 
ejection, whereas unstable drops accompanied by a large number of satellite drops can be experienced at high $Z$ values when surface tension dominates.

Derby et al. identified a minimum velocity that is necessary to trigger droplet ejection at the nozzle to overcome the fluid/air resistance. This velocity is achieved in all fluids with $W e>4$. Another critical process relates to the properties of the inks and the surface properties on to which the ink is intended to be deposited. It is critical that the drops land on the surface as a single drop with some degree of spreading. However, certain ink drops can splash upon impact with the surface, causing the breakdown of the main drops into a number of undesirable scattered satellite drops. An empirically verified parameter first proposed by Stow and Hadfield enables a first hand prediction of the onset threshold for splashing to occur: $f(R)<W e^{1 / 2} \operatorname{Re}^{1 / 4}$, where $f(R)$ is a function of surface roughness. A 2D Cartesian graph, as shown in Figure 3, with We and $\mathrm{Re}$ as $\mathrm{x}$ and $\mathrm{y}$ coordinates, respectively, as proposed by Derby can provide a useful guide to develop inks suitable for DOD inkjet systems. ${ }^{[28]}$ Additionally, the success of IJP depends on the processes that follow a successful drop landing on a substrate. These include substrate and droplet interactions, which determine drop spreading, coalescing, solidification, and ultimately film uniformity during drying processes, leading to continuous-film formation. The interplay of substrate surface properties and ink drop properties via parameters such as the contact angle of the drop on the substrate and surface roughness determine the process of film formations.

An important effect that is often cited as an impediment to uniform film formation is the "coffee-ring effect." The term is used to describe the propensity of the deposited solutes in the ink to migrate to the boundaries of a printed feature, resulting in layer non-uniformity. This is caused by the higher evaporation rate at a droplet's pinned 
contact line than at its centre, which causes material to be transported to the boundary by a replenishing flow from the centre. Controlling printing parameters can enable effective control of printing quality. For example, IJP of PEDOT:PSS was thoroughly investigated and printing parameters, including delay time and drop spacing, were found to be critical to uniform film formation. ${ }^{[33]}$ Additionally, the deposition temperature effectively allows suppression of the coffee-ring effect. Similarly, viscous fingering instabilities (Saffman-Taylor) can cause an uncontrollable ink flow on a substrate, resulting in dendrimer-like structures. Viscous fingering instability originates from a complex interplay between several parameters, including capillary, viscous, and gravitational forces, wettability effects, and the underlying heterogeneous pore geometry (roughness of the substrate), leading to preferential flow paths in ramified networks or "fingering". ${ }^{[34,35]}$ Successful IJP requires optimization of various printing parameters that can affect drop formation and subsequent film formation. This topic is treated in great length by Derby et al. and interested readers are advised to consult their publication. ${ }^{[28]}$

\section{Organic and Perovskite Solar Cells}

\subsection{General Functional Layers}

Both OSCs and PeSCs are multi-layered structures that typically comprise a minimum of six functional layers: substrate, front electrode, first intermediate layer, active layer, second intermediate layer and back electrode. Except for the active layer material, both OSCs and PeSCs employ similar materials for the other functional layers. The active layer is the charge generating material - the photoactive material. The photoactive material in OSCs is a mixture of organic materials whereas an inorganicorganic metal halide forms the active layer in PeSCs. 
Substrates are generally transparent and can be rigid or flexible, depending on the requirements of the final device. To date, glass is the most used rigid substrate because of its low cost and thermal and chemical durability. However, when considering the goal of creating low-cost manufacturing through continuous $\mathrm{R} 2 \mathrm{R}$ processing, thin and flexible substrates are required. Polymer substrates, such as polyethylene terephthalate (PET) and polyethylene naphthalate (PEN), are the best alternatives for glass substrates, as they are relatively inexpensive and transparent. These have been utilised in OSCs with much success, ${ }^{[36,37]}$ and early reports of a PeSC using PEN achieving a PCE of $15.6 \%$ suggest they are equally suitable for solar cells using that class of photoactive materials. ${ }^{[20,36,38]}$ Indium tin oxide (ITO) often acts as the transparent conducting electrode (TCE) that lies on top of a transparent substrate. The active layer - the photoactive charge generating material - is sandwiched between the front TCE and the back electrode. Al, Ag and Au are the most common metals used as back electrodes, with the metal choice depending on the device configuration. One of the electrodes collects holes and the other gathers electrons. A work function difference between the front and the back electrodes maintains an effective electric field in the device.

The direction of charge transport is determined by the positioning of the intermediate layers - namely the hole transport layer (HTL) and the electron transport layer (ETL) - which are located between the active layer and either of the electrodes (Figure 4). Poly(3,4-ethylenedioxythiophene)-poly(styrenesulfonate) (PEDOT:PSS) is the most widely used HTL material in both OSCs and PeSCs, particularly in certain device configurations where PEDOT:PSS is deposited on top of ITO. In OSCs, PEDOT:PSS is also used on top of the active layer. Similarly, several metal oxides, such as $\mathrm{TiO}_{\mathrm{x}}{ }^{[39,40]}$ and $\mathrm{ZnO},{ }^{[41,42]}$ are ideal candidates for ETLs. In addition to these, a plethora 
of other materials have been investigated as ETL and HTL layers, particularly in PeSCs. Several reviews address these intermediate layers in both $\mathrm{OSCs}^{[43]}$ and PeSCs. ${ }^{[44-47]}$

Each intermediate layer plays an important role in the photovoltaic process. Firstly, the intermediate layers selectively extract one type of charge (hole or electron), transport the charges to the collecting electrodes, and prevent charge recombination. Secondly, an intermediate layer can sometimes be used to bridge a mismatch of energy levels between the active layer and an electrode. Furthermore, an intermediate layer can compensate for roughness and remove some of the shunts resulting from nonuniformity in the electrode film. Both ETL and HTL have a similar operating mechanism but the opposite purpose. If the first intermediate layer is an ETL (alternatively known as the hole-blocking layer), then the second intermediate layer would be the HTL (alternatively known as the electron-blocking layer), and vice versa. The placement of different functional layers determines the direction of current flow in the device and has led to classification of device configurations in both OSCs and PeSCs in several categories.

\subsection{Organic Solar Cells}

OSCs are based on a mixture of conjugated polymers (molecular weight of $10-100$ $\mathrm{kDa})$ or discrete small molecules $(1-1000 \mathrm{Da})^{[48]}$. Due to a high exciton binding energy, solely employing one of these materials in a solar cell leads to very poor power conversion efficiencies $(0.001 \%) .{ }^{[49]}$ To overcome this, the bulk heterojunction (BHJ) concept evolved by blending one of these polymers or molecules (donor) with another molecule or polymer that has a higher electron affinity (acceptor). When the two are intermixed in a thin film on a nanoscale efficient exciton dissociation and charge transport is achieved. ${ }^{[49,50]}$ As conjugated polymers and molecules can be 
chemically engineered, a range of both donor and acceptor materials have been synthesized, driving PCEs up to $13 \%{ }^{[6]}$. These have been integrated in different device configurations.

\subsubsection{Normal Device Structure of OSCs}

In the normal geometry, devices start with a transparent substrate, often glass or PET substrates, and a semi-transparent front TCE, either ITO or ITO-free electrodes (Figure 4). As these cells are exposed to the sunlight, the incident light will pass through the transparent substrate and TCE to be absorbed in the active layer. Here, excitons - electron-hole pairs - are generated and dissociated into free charge carriers as holes and electrons. ${ }^{[51]}$ Holes pass through the HTL and are collected at the front TCE (anode), while the electrons pass through the ETL and reach the back electrode (cathode). Although this traditional OSC structure can deliver relatively high efficiencies and is relatively easy to manufacture, ${ }^{[52,53]}$ it has the disadvantage of low stability. As the ITO always acts as an anode, the cathode needs to be a low workfunction metal, with the combination of $\mathrm{Ca} / \mathrm{Al}$ as the ETL/back electrode commonly used. However, calcium is highly hygroscopic and aluminium oxidizes rapidly, leading to poor stability in the normal device structure of OSCs. ${ }^{[54]}$

\subsubsection{Inverted Device Structure of OSCs}

The poor stability of normal-geometry OSCs was addressed by reversing the device structure to give an inverted geometry, which carries the opposite arrangement of layers in comparison (Figure 4). Hence, the front TCE on the substrate acts as the cathode, with an ETL layer between the cathode and the active layer, and the back electrode becomes the anode with an HTL layer between this anode and the active layer. With the charge selective layers switched in comparison to the normal geometry, the back electrode can be set as a high work-function metal, such as Ag or 
$\mathrm{Au}$, which are more stable than calcium and aluminium. Thus, the inverted OSC has proven to be a better choice to address the poor stability encountered in normal structure OSCs. Furthermore, the inverted geometry enables vacuum-free manufacture of complete OSCs as the back Ag electrode can be printed under ambient conditions using a plethora of printing methods.

\subsection{Perovskite Solar Cells}

The term "perovskite" is a description of a crystal structure of calcium titanate $\left(\mathrm{CaTiO}_{3}\right)$, with a stoichiometry formula of $\mathrm{ABX}_{3}$. It was discovered by Russian mineralogist Gustav Rose in 1839 and was named after another Russian mineralogist, Lew A. Perovski. ${ }^{[55]}$ However, in the field of solar cells, the term perovskite is applied to a class of photoactive materials comprising several organic inorganic hybrid metal halides with the formula $\mathrm{ABX}_{3}$, as shown in Figure 4. Here, the A sites are typically replaced by organic cations of methylammonium $\left(\mathrm{MA}, \mathrm{CH}_{3} \mathrm{NH}_{3}{ }^{+}\right.$) or formamidinium $\left(\mathrm{FA}, \mathrm{CH}\left(\mathrm{NH}_{2}\right)_{2}{ }^{+}\right)$, while the smaller divalent metal cations $\left(\mathrm{Pb}^{2+}, \mathrm{Sn}^{2+}\right.$ and $\left.\mathrm{Cu}^{2+}\right)$ occupy octahedral B sites. The $\mathrm{X}$ sites are occupied by halide anions, such as $\mathrm{I}^{-}, \mathrm{Cl}^{-}$ and $\mathrm{Br}^{-}$. Hence, a large range of organic inorganic hybrid metal halide materials are realized by combining these components in diverse ratios, such as $\mathrm{MAPbI}_{(3-\mathrm{x})} \mathrm{Cl}_{\mathrm{x}}{ }^{[56]}$, $\mathrm{MAPbI}_{(3-\mathrm{x})} \mathrm{Br}_{\mathrm{x}}{ }^{[57]}, \mathrm{MAPbBr}_{(3-\mathrm{x})} \mathrm{Cl}_{\mathrm{x}}{ }^{[58]}, \mathrm{FAPbI}_{(3-\mathrm{x})} \mathrm{Cl}_{\mathrm{x}}{ }^{[59]},(\mathrm{MA})_{\mathrm{x}}(\mathrm{FA})_{1-\mathrm{x}} \mathrm{PbI}_{3}{ }^{[60]}$, $\operatorname{MASn}_{\mathrm{x}} \mathrm{Pb}_{(1-\mathrm{x})} \mathrm{I}_{3}{ }^{[61]}$, which show outstanding $\mathrm{PV}$ properties and make ideal active materials. A number of outstanding reviews provide greater detail into the materials and properties of PeSCs ${ }^{[62-64]}$. Owing to PeSCs' origin in DSSCs, and their subsequent development borrowing from the field of OSCs, several device structures 
of the PeSCs have evolved. These structures can be divided into conventional (n-i-p) and inverted (p-i-n) structures.

\subsubsection{Conventional n-i-p Structures}

The conventional n-i-p structure can adopt one of two different device configurations: a mesoporous n-i-p structure or a planar n-i-p structure. The former structure was the first structure of a reported PeSC, which is a direct adaptation from DSSC device architecture. A typical example of a mesoporous n-i-p structure consists of a base of a TCE on a transparent substrate, an ETL (such as compact $\mathrm{TiO}_{2}$ ), a mesoporous metal oxide (mp- $\mathrm{TiO}_{2}$ or mp- $\left.\mathrm{Al}_{2} \mathrm{O}_{3}\right)$ layer filled with perovskite material, followed by a HTL, and a metal anode (e.g. Au or Ag) (Figure 4). The layer arrangement and charge transport in the device are analogous to the inverted structure in OSCs. The first mesoporous solid-state PeSC with a recorded PCE of 9.7\% was reported by Kim et al. in 2012. ${ }^{[65]}$ The perovskite $\mathrm{MAPbI}_{3}$ nanocrystal was adopted as the photoabsorber and the mp- $\mathrm{TiO}_{2}$ layer was used as a scaffold.

The mesoporous layer in this structure enhanced charge collection performance by decreasing the carrier transport distance, preventing direct current leakage between the two selective contacts, and increasing photon absorption through light scattering. ${ }^{[64]}$ However, grain growth of the thick perovskite layer was restrained by the pore size in the structure, leading to a disordered and amorphous phase, resulting in a relatively low $\mathrm{V}_{\mathrm{OC}}$ and $\mathrm{J}_{\mathrm{SC}}{ }^{[66,67]}$ Interestingly, fabricating a thinner layer of the perovskite can overcome this obstacle and promised an improved device efficiency, as the crystallinity of the thinner layer is greater than the thick analogue,${ }^{[64]}$ and it offered an improvement in the pore filling fraction and morphology. ${ }^{[68,69]} \mathrm{A}$ thin layer with a complete pore filling fraction enabled relatively high charge transport rates and collection efficiencies at the $\mathrm{TiO}_{2}$ interface. Consequently, the mesoporous n-i-p 
structure has enabled high efficiency devices, with a PCE of $22.1 \%$ recently reported $^{[70]}$.

Early in the development of these materials, it became evident that $\mathrm{TiO}_{2}$ only provided a passive structural scaffold and did not play an active part in the exciton separation process as it did in DSSCs. This understanding led to the complete elimination of the mesoporous $\mathrm{TiO}_{2}$ layer to give a planar n-i-p structure (Figure 4). The first planar n-i-p PeSC was briefly touched upon by Snaith et al. in their publication deconstructing the role of $\mathrm{TiO}_{2}$ in PeSCs and achieved a PCE of $1 \% .{ }^{[71]}$ Subsequently, they focused on making planar devices only, and achieved PCEs of $15.4 \%$ and $8 \%$ via vapor and solution deposition, respectively. ${ }^{[72]}$ Also, a planar heterojunction PeSC with a recorded PCE of $11.4 \%$ was demonstrated by Eperon et al. ${ }^{[69]}$ Further enhancements in the performance of planar n-i-p solar cells was achieved by carefully controlling the formation of the perovskite absorber layer, and the interfaces between the perovskite, carrier transport layers, and electrodes. ${ }^{[73]}$ A planar solar cell reported by Liu and Kelly had a PCE of $15.7 \%$ and was fabricated via a sequential deposition method. ${ }^{[74]}$ This cell featured $\mathrm{MAPbI}_{3}$ as an active layer and low-temperature solution-fabricated $\mathrm{ZnO}$ as an ETL. It is worth noting that this low-temperature fabrication method can not only reduce the manufacturing cost but can also increase the potential for depositing these layers on temperature-sensitive organic substrates. ${ }^{[75]}$ Although planar n-i-p PeSCs exhibited higher PCEs compared with their mesoporous analogues that incorporated the same materials, much work needs to be done to reduce their manufacturing cost, increase their stability, and scale-up their industrial production.

\subsubsection{Inverted $p$-i-n Structure}

An inverted p-i-n perovskite solar cell has the opposite arrangement in device structure compared to conventional n-i-p structures. For inverted p-i-n structures, the HTL 
becomes the first layer to be deposited on the surface of glass/ITO substrate. The perovskite material is then deposited onto the HTL, followed by an ETL, such as a fullerene derivative, e.g., $\mathrm{PC}_{61} \mathrm{BM}$ or $\mathrm{PC}_{71} \mathrm{BM}$. The device is then completed by depositing a back electrode, such as Al or Au (Figure 4).

The first p-i-n PeSC with a device structure of Glass/ITO/PEDOT:PSS/MAPbI $3 /$ C60/bathocuproine/Al was reported by Jeng et al., with a PCE of $3.9 \%$ achieved in 2013. ${ }^{[76]}$ The efficiency of the planar p-i-n device has been significantly improved upon through the use of more advanced materials and preparation methods, such as a multistep solution coating process ${ }^{[77]}$. A solutionprocessed mixed-halide $\mathrm{MAPbI}_{3-\mathrm{x}} \mathrm{Cl}_{\mathrm{x}}$ active layer in a planar $\mathrm{p}-\mathrm{i}-\mathrm{n}$ device was demonstrated by Docampo et al. and a PCE of 9.8\% was realized in 2013. ${ }^{[78]}$ To date, $p-i-n$ structures have demonstrated similar record efficiencies as other structures, with PCEs approaching 20\%. A recent review provides a comprehensive overview of advances in $p-i-n$ structure. ${ }^{[64,79]}$

\section{Applications of Inkjet Printing in OSC Fabrication}

There are a number of film-forming techniques for SC fabrication, including casting, ${ }^{[11]}$ spin-coating, ${ }^{[80]}$ doctor blading, ${ }^{[81]}$ screen printing, ${ }^{[82]}$ flexographic printing, ${ }^{[83]}$ gravure printing, ${ }^{[84-87]}$ reverse gravure coating, ${ }^{[88]}$ spray-coating, ${ }^{[89,90]}$ and IJP. ${ }^{[91,92]}$ Among these methods, only the printing methods enable the ability to transfer a layer of ink to a substrate according to a motif, thus allowing 2-dimensional freedom-of-design. Coating methods are limited in patterning and require a flow-mask or a shadow mask to achieve some patterning. Slot-die and reverse gravure coating only allow stripe shapes to be coated in the flow direction of the ink, whereas a shadow mask used in spray-coating can allow 2-dimensional design, but with extremely low-resolution and high material wastage. Alternatively, these methods 
require post-patterning with subtractive techniques such as laser scribing, which adds to processing complexity and limits throughput. Printing methods involve a carrier (a printing plate) with a positive or negative image of the motif that is reproduced upon contact with the substrate and the printing plate. In flexographic or gravure printing, these images are made on printing plates made of stainless steel coated with chromium, thus limiting the freedom to change the design, due to increased cost and time requirements. Screen printing involves the use of a screen made of thread or steel mesh which carries the print image and is suitable for pastes or highly viscous inks. IJP techniques combine the merits of both printing and coating technologies. Like coating techniques, no physical contact between the print head and the substrate is needed in IJP; and like printing techniques, 2-dimensional designs can be achieved with IJP. Additionally, the printing motif is present in a digital form, permitting unmatched freedom-of-design and accessibility. Above all, IJP allows extremely highresolution printing with 5000 DPI possible. Also, some industrial inkjet printers with the ability to choose different solvents and nozzles to increase resolution have already been commercialized, benefiting functional materials manufacturing in industry. ${ }^{[92]}$ IJP is gradually being applied to fabricating solar cells and has the potential to be a powerful method for large-area manufacture.

\subsection{Inkjet Printing of Single Layers in Organic Solar Cells}

\subsubsection{Front Electrode}

ITO is the most commonly used TCE for the front electrode in organic solar cells. ${ }^{[93]}$ However, ITO incurs large materials and processing cost, and its brittle nature limits processing, handling, and application in flexible products. ${ }^{[94]}$ The relatively low conductivity of ITO on flexible substrates $(60 \Omega / \mathrm{sq})$ also creates a great demand for an 
alternative TCE, as high resistance leads to large power losses in large area modules. ${ }^{[95]}$ In this regard, the replacement for the ITO electrode has been investigated extensively. ${ }^{[96,97]}$ Composite electrodes comprising Ag grids superimposed by PEDOT:PSS is a robust substitute for ITO. Silver grid/PEDOT:PSS is flexible, highly conductive and semi-transparent, and fulfils the requirements for a front electrode in OSCs. Moreover, a sliver grid can also be fabricated under ambient conditions via a variety of printing methods, including IJP. PEDOT:PSS usually has a high sheet resistance above $100 \Omega /$ sq. While in laboratory cells with a small area this may be a feasible replacement of ITO, increasing the cell dimensions leads to a proportional decrease in solar cell performance due to power losses $\left(\mathrm{P}_{\text {loss }} \approx \mathrm{R}_{\mathrm{s}} \mathrm{I}^{2}\right)$. Such power losses also occur in ITO, which limits the scaling of cell area in modules. ${ }^{[98]}$ A Ag grid used in conjunction with the conductive polymer PEDOT:PSS ${ }^{[99-102]}$ results in high-conductivity thin film with a sheet resistance below $1 \Omega /$ sq. Thus, devices can be scaled from laboratory-scale cells to modules that are hundreds of meters long with no loss in performance. ${ }^{[3,98]}$ The design of the grid has to be tuned, however, to enable maximum conductivity and minimum shadow loss. Additionally, the roughness and spikes in the grid lines can create shunt paths in thin films of the OSCs as the opposite electrodes are separated by a photoactive layer that is only between $200-400 \mathrm{~nm}$. Therefore, grid design and processing has to be carefully optimized. Galagan et al. employed a simple numerical model to optimize grid design for solar cell performance by taking into account shadow losses from the Ag grid, the series resistance of the grid, and the resistive loss of PEDOT:PSS. ${ }^{[103,104]}$ With this model, lithographically fabricated Mo/Ag/Mo grids and inkjet printed grids were assessed. Both methods led to similar efficiencies, albeit with different optimized design conditions. IJP fingers with a grid width of $325 \mu \mathrm{m}$ were found to be optimal for a 
pitch width (the horizontal distance between two grid lines) of $2.5-3.3 \mathrm{~cm}$, giving a uniform distribution of electric potential while optimising the trade-off between shadowing losses and Ohmic losses. Above this pitch width, shadow losses dominated and the device efficiency rapidly declined. At the optimized value, an efficiency of $1.5 \%$ for a P3HT:PCBM based cell with a $4 \mathrm{~cm}^{2}$ active area was achieved. The device employed PEDOT:PSS with a thickness of $100 \mathrm{~nm}$ and a conductivity of $200 \mathrm{~S} / \mathrm{cm}$ $(500 \Omega / \mathrm{sq})$.

Subsequently, Neophytou et al. ${ }^{[105]}$ investigated the effect of varying the conductivity of PEDOT:PSS on inkjet printed Ag grids on the overall device performance of ITOfree OSCs (Glass/Ag-grids(IJP)/PEDOT:PSS/P3HT:PCBM/Al). Two different PEDOT:PSS materials with conductivities of $0.002 \mathrm{~S} / \mathrm{cm}$ and $10 \mathrm{~S} / \mathrm{cm}$ were used with an inkjet printed $\mathrm{Ag}$ grid, which featured a line width of $40 \mu \mathrm{m}$ and a pitch size (of $700 \mu \mathrm{m}$. The higher conductivity PEDOT:PSS enabled a PCE of $1.96 \%$ with $\mathrm{V}_{\mathrm{oc}}=510$ $\mathrm{mV}, \mathrm{J}_{\mathrm{sc}}=10.35 \mathrm{~mA} / \mathrm{cm}^{2}$, and $\mathrm{FF}=36.8 \%$ under 1 sun $\mathrm{AM} 1.5 \mathrm{G}$ illumination. This was a 30\% gain in PCE over the lower conductivity PEDOT:PSS, thus demonstrating that PEDOT:PSS not only acts as a HTL, but also functions as a conductivity enhancer for the Ag grid. Therefore, the PEDOT:PSS/Ag grid acted as a composite electrode. In a subsequent study, Huang et al. achieved an even higher PCE of $2.86 \%$ on a device with an area that was 3 times larger than that used by Neophytou and another group. ${ }^{[106]}$ This efficiency is very close to that achieved with similar devices incorporating ITO electrodes $(\mathrm{PCE}=3.04 \%)$. Nonetheless, these devices had areas less than $0.3 \mathrm{~cm}^{2}$ and served as proof-of-concept optimization.

Huang et al. achieved an average PCE of $2.34 \%$ with ITO-free OSCs (Glass/Ag-grids (IJP)/PEDOT:PSS/P3HT:PCBM/Ca-Al) with large electrode areas of $8 \mathrm{~cm}^{2}{ }^{2}{ }^{[106]}$ In their study, ITO-free OSCs with different areas were first fabricated by replacing the 
ITO with highly conductive PEDOT:PSS (PH 1000). Initial results indicated that the PCE of the ITO-free devices was dramatically reduced from $1.93 \%$ to $0.17 \%$ with device areas increasing from $0.3 \mathrm{~cm}^{2}$ to $4 \mathrm{~cm}^{2}$ owing to the large sheet resistance of PEDOT:PSS. Therefore, the PEDOT:PSS (PH 1000) layer was reinforced with inkjet printed Ag-grids. With an optimized pitch width of $2 \mathrm{~mm}$, the performance of the ITOfree cells with a device area of $4 \mathrm{~cm}^{2}$ increased to $2.47 \%$. Huang et al. further probed the impact of scaling up by comparing ITO-based and Ag-grid/PH1000-based devices across a range of device areas $\left(0.3 \mathrm{~cm}^{2}, 4 \mathrm{~cm}^{2}\right.$ and $\left.8 \mathrm{~cm}^{2}\right)$. The results illustrated that both the ITO-based and the Ag-grid-based devices gave similar PCEs of ca 3\% in small area $\left(0.8 \mathrm{~cm}^{2}\right)$ devices. On scaling up from $0.8 \mathrm{~cm}^{2}$ to $8 \mathrm{~cm}^{2}$ area, however, the PCE in ITO-based devices declined by ca. 35\% (3.04 to $1.97 \%)$, whereas the decline was only $20 \%$ in the Ag-grid based devices (2.86 to $2.34 \%$ ).

Yu et al. compared three different R2R methods for the printing of Ag grids in an allR2R-processed OSC. IJP, flexographic printing, and thermal imprinting were compared by fabricating large area $\left(6 \mathrm{~cm}^{2}\right) \mathrm{R} 2 \mathrm{R}$-produced ITO-free OSCs on flexible PET substrates in a typical inverted structure: PET/AgGrid(IJP)/PEDOT:PSS/ZnO/P3HT:PCBM/PEDOT:PSS/Ag-Grid ${ }^{[83]}$ (Figure 5). Thermal imprinting and filling with Ag nanoparticles led to the most ideal structure, as the method offered excellent control over the line width (which is predefined during imprinting) and topology (because Ag lines are embedded in the substrate), leading to high transmittance, a low sheet resistance of $10 \Omega /$ sq, and a uniform topology with spikes of less than $20 \mathrm{~nm}$. In comparison, IJP grids had an irregular structure in the grid lines and some misfired ink droplets, resulting in a sheet resistance of $60 \Omega /$ sq and spikes in topology of $50 \mathrm{~nm}$. Flexographic printing of a Ag grid gave a similar resolution to IJP and was the fastest printing technique, allowing a web-speed of 25 
$\mathrm{m} / \mathrm{min}$. Nevertheless, it can be argued IJP was the best technique for the R2R production of Ag-grid TCE front electrode. In comparison with the thermal imprinting process, which involved two discrete processing steps with a very slow speed of 0.48 $\mathrm{m} / \mathrm{min}$, IJP was carried out at four times faster speed of $2 \mathrm{~m} / \mathrm{min}$. While flexographic printing leads to the fastest deposition speed of $25 \mathrm{~m} / \mathrm{min}$, the topology of the Ag grid was irregular, with spikes exceeding $1 \mu \mathrm{m}$, leading to shunts in the solar cells as the opposite electrodes were separated by the photoactive layer with a maximum thickness in the range $200-500 \mathrm{~nm}$. The spikes were a consequence of flexographic printing being a contact-based printing method. ${ }^{[12]}$ In contrast, the spikes in IJP were $50 \mathrm{~nm}$ in height - a positive consequence of the contact-less nature of IJP. The high sheet resistance of the IJP Ag grids was a consequence of unoptimized sintering and was improved upon in a subsequent report by the same group. ${ }^{[4]}$ Table 4 presents the comparison made by $\mathrm{Yu}$ et al. of the three techniques for printing Ag grids on a semiindustrial scale.

Sintering/drying processes are as important as the IJP process itself. The sintering process always follows the printing of Ag-grids or other metals during TCE fabrication. Often a sintering temperature of $200{ }^{\circ} \mathrm{C}$ is reported. ${ }^{[106,107]}$ However, such a temperature exceeds the thermal tolerance of plastic substrates like PET $\left(140^{\circ} \mathrm{C}\right)$. An alternative approach to overcome this limitation is photonic sintering as demonstrated by Angmo et al. and Galagan et al., which is also compatible with largescale manufacturing. ${ }^{[4,108]}$ Angmo et al. applied photonic sintering to flash sinter R2RIJP Ag grids on PET. ${ }^{[4]} 16$ serially connected OSC modules were fabricated with the device structure of PET/Aggrids(IJP)/PEDOT:PSS/ZnO/P3HT:PCBM/PEDOT:PSS/Ag. By varying the degree of photonic sintering by controlling the number of flashes $(0,1,2$ or 4$)$, the sheet 
resistance of the Ag grid was halved from $20 \Omega /$ sq with no flashes to $9-12 \Omega /$ sq with 4 flashes. The IV curves indicated slightly enhanced performance from a PCE of $1.5 \%$, $\mathrm{V}_{\mathrm{oc}}=8.1 \mathrm{~V}, \mathrm{~J}_{\mathrm{sc}}=5.3 \mathrm{~mA} / \mathrm{cm}^{2}, \mathrm{FF}=50 \%$ to a PCE of $1.7 \%, \mathrm{~V}_{\mathrm{oc}}=8.2 \mathrm{~V}, \mathrm{~J}_{\mathrm{sc}}=5.7 \mathrm{~mA} / \mathrm{cm}^{2}$, $\mathrm{FF}=51 \%$, when comparing devices that had Ag grids that were exposed to 4 flashes to those that did not undergo flash sintering. Although the improvement in PCE was marginal, the photonic sintering process led to a significant improvement in the adhesion of the Ag grid to the PET substrate. In summary, studies on laboratory- and large-scale semi-industrial processes demonstrate that a fully IJP Ag-grid combined with a conductive polymer is a feasible alternative for ITO-free optoelectronic applications in general, and for OSCs in particular. Process optimization is key to enabling highly conductive and topologically uniform print lines.

\subsubsection{Hole Transporting Layer (HTL)}

Water-based PEDOT:PSS from Sigma-Aldrich is a common HTL used in typical structures of OSCs and OLEDs, and as an antistatic coating. Soltman et al. published an acclaimed paper on the IJP of PEDOT:PSS that detailed the impact of three key printing variables; substrate temperature, drop spacing, and drop frequency. ${ }^{[33]}$ This publication remains one of the guiding tools for IJP in general. PEDOT:PSS was printed on PVP dielectric coated glass, and had a contact angle of $82.7^{\circ}$ and an RMS roughness of $3.34 \AA \AA^{[33]}$ Firstly, they demonstrated there is a critical drop spacing (distance between adjacent drops) to give a uniform printed line. Having a drop spacing lower than the critical spacing can lead to disconnected individual drops or scalloped lines, while drop spacing higher than the critical spacing leads to bulging or even stacked coins. Stacked coins also result if the evaporation time for the single drops is less than the drop jetting period, such that the landing drop is nearly dried before the next drop lands. Hence, they outlined that the ideal line avoids bulging by 
slowing down the drop frequency until the advancing contact angle is never exceeded, but is not so slow that drops dry within the period of one or two drops landing, avoiding stacked coins. It has a low enough drop spacing to avoid scalloping, and the delay is not so slow that the dropping frequency is comparable to the time it takes for the orifice to form a skin, thereby avoiding unpredictable drop trajectories (Figure 6). Additionally, Soltmann et al. demonstrated control over the coffee-ring effect in the printed droplets by controlling the deposition temperature (Figure 6).

Subsequently, inkjet-printed PEDOT:PSS as a HTL in OSCs was reported. Eom et al. explored the roles of additives in the printing of PEDOT:PSS and the influence on OSCs with a device structure of Glass/ITO/PEDOT:PSS (IJP)/P3HT:PCBM/Li-A1. ${ }^{[109]}$ In their study, the printed PEDOT:PSS inks were dispersed in a mixed solvent system with different ratios of glycerol and ethylene glycol butyl ether (EGBE). Among all the tested ratios, a PEDOT:PSS ink with $6 \mathrm{wt} \%$ of glycerol and $0.2 \mathrm{wt} \%$ EGBE exhibited the best uniform film thickness and density, generating a promising performance of PCE $3.16 \%, \mathrm{~V}_{\mathrm{oc}}=0.595 \mathrm{~V}, \mathrm{~J}_{\mathrm{sc}}=9.593 \mathrm{~mA} / \mathrm{cm}^{2}, \mathrm{FF}=55.28 \%$. This is attributed to the $0.2 \mathrm{wt} \% \mathrm{EGBE}$ in the dispersion being able to minimize the interfacial tension between PEDOT:PSS and glycerol. Printing ink droplets with a smaller size was easily achieved, which generated a uniform PEDOT:PSS film. Later, the drop spacing and substrate temperature were also found to have an important effect on the PEDOT:PSS layer. To illustrate this, OSCs with a typical structure of Glass/ITO/PEDOT:PSS(IJP)/P3HT:PCBM/Ca-Al were fabricated by Steirer et al. ${ }^{[10]}$ In their experiments, a drop spacing of $25 \mu \mathrm{m}$ and the lowest temperature of $28^{\circ} \mathrm{C}$ enabled the best uniformity of a PEDOT:PSS film, and resulted in a PCE of $3.31 \%$. Moreover, the subsequent annealing process also contributed to optimizing the performance of an inkjet-printed PEDOT:PSS film, as demonstrated by Xiong et al. in 
2012. ${ }^{[111]}$ Both thermal and solvent annealing processes were investigated in this study. Thermal annealing was found to be relatively ineffective in improving the conductivity and transparency of the films in comparison to solvent annealing. Combining solvent annealing and thermal annealing resulted in a further increase in conductivity of the PEDOT:PSS thin film.

Unlike Ag-grids, which require the 2-dimensional freedom of design offered by IJP to form high-resolution patterns, PEDOT:PSS in OSCs are usually present as uniform thin-films, rendering alternative techniques, such as spin-coating on a laboratory scale and numerous fast and facile printing methods such as slot-die coating, ${ }^{[11,88]}$ the preferred deposition techniques for that material on a larger scale. Conversely, IJP offers the freedom to directly pattern irregular shapes on large-scale modules, without the need for post-deposition subtractive processes that may be required for equivalent shapes deposited via screen printing and slot-die coating. Thus, research to date has shown the IJP of PEDOT:PSS is feasible for all module geometries and permits the fabrication of aesthetically pleasing $2 \mathrm{D}$ solar cells designs with fine features. ${ }^{[12]}$

\subsubsection{Photoactive Layer}

Early research into the inkjet printing of $\mathrm{P} 3 \mathrm{HT}$ :PCBM as a photoactive layer was published by Hoth et al. in $2007,{ }^{[91]}$ who employed a device structure of Glass/ITO/PEDOT:PSS/P3HT:PCBM(IJP)/Ca-Ag. The solvent used for IJP P3HT:PCBM was found to have a profound impact on the morphological and interfacial properties of the film. A high boiling point solvent was found to be essential to give a polymer blend that could be deposited via IJP. 1,2-Dichlorobenzene (o-DCB) (b.p. $180{ }^{\circ} \mathrm{C}$ ) and tetralene (BP $207^{\circ} \mathrm{C}$ ) were first compared. The o-DCBbased ink led to inhomogeneous film formation with high thickness variation in the 
micrometer scale range, as well as de-wetting of the film. This was attributed to the high surface tension of o-DCB (37 dynes/cm). Alternatively, tetralene has a lower surface tension (34.9 dynes/cm), which can lead to uniform printing. However, the surface of the printed film was rough (RMS roughness $21 \mathrm{~nm}$ ) and large phase separation between P3HT and PCBM was observed. This was attributed to the slow drying of the tetralene-based ink, as tetralene has a significantly lower vapor pressure (0.18 $\mathrm{mm} \mathrm{Hg})$ compared to o-DCB (1.20 mm Hg). A mixed solvent formulation comprising 68 vol\% high boiling point o-DCB and 32 vol\% low boiling point mesitylene $\left(165^{\circ} \mathrm{C}\right)$ led to the best film, with an RMS of $2.6 \mathrm{~nm}$ and a uniformly intermixed phase in the final film. Thus, a high-quality IJP photoactive layer could be deposited and the resulting device showed a PCE of $2.9 \%$, similar to ITO-based devices (Figure 7). ${ }^{[91]}$ This significant study demonstrated that while o-DCB - the most common solvent for most OSCs polymer blend inks - enabled intimate mixing between the polymer and PCBM in solution, it also imposes limitations on the spreading and wetting of the ink on the substrate. Additionally, its high vapor pressure allows a significant time for drying of the ink leading to coffee-ring inducing film nonuniformity. The incorporation of a second low-boiling point and lower vapor pressure solvent, such as mesitylene $(1.80 \mathrm{~mm} \mathrm{Hg})$, enabled the deposition of a uniform thin film. Upon deposition, mesitylene vaporizes fast, increasing the concentration and the viscosity of the deposited drying film and in turn, reducing material migration to the film edges, consequently inhibiting coffee-ring formation.

Hoth et al. also reported how to improve the morphological properties of an inkjetprinted film by modifying the film formation and drying conditions. ${ }^{[113]}$ The combination of regioregular (RR)-96\%-P3HT with a solvent mixture of o-DCB/MT was used to control the drying and film formation. A suitable gelation time was 
determined using the same device structure they subsequently used in 2016 to achieve an enhanced PCE of $3.5 \%$.

The effects of varying the viscosity and surface wetting of inks on photoactive thin film morphology was investigated by Aernouts et al., ${ }^{[92]}$ who used different ratios of P3HT:PCBM in a 1:1 tetralene:CB (v/v) solution to control the inks' viscosity and surface tension. These mixtures were inkjet printed in the device structure Glass/ITO/PEDOT:PSS/P3HT:PCBM(IJP)/Al, with careful optimisation of the inks' properties giving a smooth P3HT:PCBM layer with minimal surface roughness. A continuous, pinhole-free, smooth film was incorporated into a device that had a PCE of $1.4 \%$ under simulated 1 sun AM1.5 illumination.

The impact of the regioregularity of $\mathrm{P} 3 \mathrm{HT}$ on the performance of bulk heterojunction solar cells with an IJP P3HT:PCBM layer was discussed by Hoth et al. in 2009. ${ }^{[14]}$ A similar device architecture of Glass/ITO/PEDOT:PSS/P3HT:PCBM(IJP)/Ca-Ag was used. The results revealed that RR (98\%)-P3HT was not suitable for IJP at room temperature, while RR (96\%)-P3HT:PCBM dissolved in a mixed solution of oDCB/MT could be well inkjet printed under the same conditions. The best performance for the devices was 3.5\% PCE, $\mathrm{V}_{\mathrm{oc}}=0.54 \mathrm{~V}, \mathrm{~J}_{\mathrm{sc}}=10.1 \mathrm{~mA} / \mathrm{cm}^{2}$, and $\mathrm{FF}=$ $64 \%$.

Different solvent mixtures suitable for IJP were subsequently demonstrated. Lange et al. prepared a P3HT:PCBM ink in a 55:45 (wt/wt) $\mathrm{CB}: \mathrm{TCB}(\mathrm{TCB}=$ trichlorobenzene $)$ solvent mixture, with a $0.30 \mathrm{wt} \%$ concentration of P3HT in a $1: 1(\mathrm{wt} / \mathrm{wt})$ P3HT:PCBM ratio. ${ }^{[115]}$ When this solution was inkjet printed on passive layers in a device structure of Glass/ITO/passive layer/P3HT:PCBM/Al where the passive layer comprised PEDOT:PSS mixed with $25 \mathrm{wt} \%$ isopropanol and $25 \mathrm{wt} \%$ ethylene glycol, a PCE of $1.5 \%$ was achieved from the devices. 
In later studies, IJP was applied to the high efficiency donor polymers and acceptors that started to become more readily available. PCPDTBT and PSBTBT have been widely used as donor materials in bulk heterojunction solar cells, while mono-PCBM and the higher substituted fullerene derivative bis-PCBM have been frequently adopted as acceptor materials due to their high electron affinity. Mixed active materials comprising the two polymers (PCPDTBT and PSBTBT) and two fullerene derivatives (mono-PCBM and bis-PCBM) were designed and investigated by Teichler et al. by varying the blend ratios, concentrations, and solvent mixtures. ${ }^{[16]}$ The device structure was Glass/ITO/PEDOT:PSS/Active layer(IJP)/LiF-Al, with maximum PCEs of $0.64 \%$ and $1.48 \%$ obtained for the 1:2 PSBTBT:mono-PCBM $(190 \mathrm{~nm})$ and $1: 3.4$ PCPDTBT:mono-PCBM (169nm) systems, respectively.

Subsequent work on the IJP of the photoactive layer using different solvent systems was explored in the normal device structure Glass/ITO/PEDOT:PSS(IJP)/P3HT:PCBM(IJP)/LiF-Al. Eom et al. deposited both PEDOT:PSS and P3HT:PCBM with the IJP method. ${ }^{[117]}$ To optimize the solvent systems used for the IJP of the photoactive materials, the high boiling point additives 1,8-octanedithiol $(\mathrm{ODT})\left(\right.$ b.p. $\left.=269^{\circ} \mathrm{C}\right)$, o-DCB $\left(179^{\circ} \mathrm{C}\right)$, and chloronaphthalene $(\mathrm{Cl}$ naph) (b.p. $\left.=259^{\circ} \mathrm{C}\right)$ were mixed with chlorobenzene $\left(\right.$ b.p. $\left.=132^{\circ} \mathrm{C}\right)$ in different volume ratios. The PEDOT:PSS was mixed with glycerol and EGBE. Ultimately, the OSC made from the photoactive ink of $\mathrm{P} 3 \mathrm{HT}$ :PCBM in a solution containing $\mathrm{CB}$ with 5 vol $\%$ ODT additive exhibited the best performance with $\mathrm{PCE}=3.7 \%, \mathrm{~V}_{\mathrm{oc}}=0.628 \mathrm{~V}$, $\mathrm{J}_{\mathrm{sc}}=10.68 \mathrm{~mA} / \mathrm{cm}^{2}, \mathrm{FF}=55.27 \%$. Such a good result was attributed to the higher level of P3HT crystallinity and distinct nano-scaled phase separation morphology resulting from the use of 5 vol\% ODT additive. 
The prospect of using IJP also creates the potential to revolutionize the transition to commercial scale manufacturing by requiring equipment with lower capital costs than vacuum-based deposition methods. Air-processed OSCs were first fabricated and measured by Jung et al. in 2014. ${ }^{[118]}$ A series of device structures fabricated by different deposition techniques were used to optimize the OSC performance. The highest PCE of $4.85 \%$ was achieved by IJP a P3HT:PC ${ }_{70} \mathrm{BM}$ active layer with a tailored ternary solvent comprising chorobenzene:mesitylene:chloroform. This performance was comparable to devices fabricated using spin-coating. The typical device structure of this OSC was Glass/ITO/PEDOT:PSS (IJP)/P3HT:PC70BM (IJP)/Al.

With the increasing application of IJP to OSCs and other organic-based optoelectronic products, it is critical to consider how film morphology is affected by various printing parameters. Haldar at al. printed P3HT:PCBM in different printing modes; single layer and multilayer arrays, as shown in Figure $8 .^{[119]}$ In a single layer array printing proceeds in a linear fashion in a raster-scan-like mode. In multilayer arrays printing proceeds in a matrix of "building blocks", where a base matrix is deposited in the first run, and subsequent runs deposit the same matrix at a certain offset distance from the previous deposited matrix, until the film uniformly covers the target surface (Figure 8). Tekin et al. reported that a multilayer array printing mode that used a mixture of a high boiling point solvent (acetophenone) and a low-boiling point solvent (isopropyl acetate) allowed for the formation of a highly homogenous film of polystryrene. ${ }^{[16]}$ This ink system was used as a model ink for studying the impact of printing mode (Figure 8). However, Halder et al. found that the use of a multilayer printing mode to deposit a P3HT:PCBM system with a previously deployed o-DCB-mesitylene solvent mixture led to highly inhomogenous films with a pronounced coffee-ring effect and 
resulted in short-circuits in the devices. Even increasing the concentration of the solute from 1.25 to $10.0 \mathrm{~g} / \mathrm{L}$ did not improve device performance. The author did not identify that this could be due to the use of high RR P3HT:PCBM (98\%), which was already shown to be incompatible with o-DCB: mesitylene mixture reported Hoth et. al. ${ }^{[14]}$ Optical images revealed a "stacked coin" structure, which must have resulted from long delays occurring in depositing adjacent drops in multiple array mode, such that the already deposited drops had dried at the edges, inhibiting drops merging upon completion of printing. On the other hand, single-array mode using CB as a solvent with a solute concentration of $10 \mathrm{~g} / \mathrm{L}$ led to more uniform films and a device performance of $1.26 \%$. However, coffee-ring lines were still observed. Thus, unlike Tekin's IJP of a polystyrene model system where multiarray mode led to an extremely homogenous film, the deposition of high a concentration P3HT:PCBM ink using a single array mode was found to give better films, highlighting the complexities of printing blend materials compared to single polymer systems (Figure 8). Ideally, the use of hazardous and chlorinated solvents should be avoided if IJP is to be implemented on a commercial scale. However, this effort is complicated by the fact that the use of chlorinated solvents is often necessary to give the highest efficiency devices. This is demonstrated in a study by Lange et al. in $2013,{ }^{[120]}$ where the use of chlorinated and non-chlorinated solvents was contrasted during the fabrication of a series of OSCs using a device structure of Glass/ITO/PEDOT:PSS/PFDTBTP:PCBM(IJP)/LiF-Al The chlorine-free solvent system based on anisole and tetralin delivered efficiencies of $2.7 \%$, in comparison to the PCE $3.5 \%$ that was achieved when the active layers were printed from chlorinated solvents. However, PFDTBTP and other polymers with similar structures were proven 
to be good candidates for the industrial-scale manufacturing of OSCs, as the use of hazardous chlorinated solvents were not needed to achieve acceptable performances. Non-halogenated solvent systems were further explored by Eggenhuisen et al. ${ }^{[121]}$ They used IJP of four consecutive layers; PEDOT:PSS as part of the front electrode, $\mathrm{ZnO}$ nanoparticles as the ETL, P3HT:PCBM as the photo-active layer, and another layer of PEDOT:PSS as the HTL - all deposited from non-halogenated solvents. The $\mathrm{ZnO}$ nanoparticles were dispersed in a veratrole:o-xylene mixture, while the P3HT:PCBM ink was prepared in a mixture of o-xylene:indan:tetraline $(1: 1: 1 \mathrm{v} / \mathrm{v} / \mathrm{v})$. The printed PEDOT:PSS, combined with the $\mathrm{ZnO}$ layer superimposed on lithographic printed $\mathrm{Mo} / \mathrm{Al} / \mathrm{Mo}$ grids, showed no performance loss as compared to a device incorporating ITO with a spin-coated $\mathrm{ZnO}$ layer. Furthermore, only minor performance losses occurred with IJP of the photo-active layer using a nonhalogenated solvents mixture when compared to P3HT:PCBM thin film spin coated from CB. Solar cells with an active area of $1 \mathrm{~cm}^{2}$ and maximum power point of 2.0 $\mathrm{mW} / \mathrm{cm}^{2}$, as well as a large area module with a $92 \mathrm{~cm}^{2}$ active area with an efficiency of $0.98 \%$, were fabricated with four and three inkje-printed layers, respectively. The IV characteristics of the module were partially explained by modelled resistive losses in the front and back electrode. Eggenhuisen's work showed that IJP can be used for the deposition of multiple active layers within the OSC stack and that the use of nonhalogenated solvents is feasible, without significant performance losses.

\subsubsection{Back Electrode}

The back electrode is the last deposited layer required to complete the device. Especially for small laboratory-scale devices, back electrodes are almost exclusively processed by evaporation, except for a few instances in which screen printing has been used. ${ }^{[95,122]}$ However, vacuum-based methods such as evaporation represent a hurdle 
for commercialization in the upscaling process, as they are throughput limiting steps in an otherwise fast R2R production line. Screen printing, on the other hand, uses a commercially-available screen-printable Ag paste that comprises Ag flakes in a carrier solvent. While screen printing can be fast, the solvent from this ink is reported to cause damage to the underlying layers. ${ }^{[33,123]}$ This is often circumvented by increasing the thickness of the underlying layer immediately below the back electrode and using a UV curable Ag paste. These materials can minimise the problem, but is seldom eliminate it completely. ${ }^{[124]}$ Additionally, screen printed Ag flakes are used in $5 \mu \mathrm{m}$ thick layers, incurring large material wastage.

IJP represents an alternative vacuum-free processing method that can significantly improve upon the processing speed of evaporation, and also avoids the challenges faced with screen printing. The first usage of an IJP Ag ink as a back electrode followed by a baking process was demonstrated by Eom et al. in 2008. ${ }^{[125]}$ The OSC was fabricated in a normal architecture with a configuration of Glass/ITO/PEDOT:PSS/P3HT:PCBM/ZnO/Ag(IJP). It was found that the $\mathrm{ZnO}$ film acted as a buffer layer between the hydrophobic P3HT:PCBM layer and the hydrophilic Ag cathode. The efficiency of this device improved with the $\mathrm{ZnO}$ annealing temperature increasing from $130{ }^{\circ} \mathrm{C}(0.150 \%)$ to $150{ }^{\circ} \mathrm{C}(0.209 \%)$. Nevertheless, the devices still shorted, likely the result of cracking in the $\mathrm{ZnO}$ film leading to the Ag electrode diffusing into the device, as found in several studies where $\mathrm{ZnO}$ is processed on top of the active layer. ${ }^{[13,96]}$

Franker et al. reported a similar endeavour, with an all-solution processed OSC with a conventional device structure of Glass/ITO/PEDOT:PSS/P3HT:PCBM/PFN(or $\mathrm{ZnO}) / \mathrm{Ag}(\mathrm{IJP}) .{ }^{[13]}$ In their study, Franeker et al. demonstrated the difference between two ETLs, ZnO and PFN. The ZnO ETL led to crack formation in the Ag layer during 
the drying and sintering process, due to the stress imposed by solvent evaporation and the difference in the coefficients of thermal expansion of the two layers. Crack formation was avoided by substituting $\mathrm{ZnO}$ with $\mathrm{PFN}$, giving the best performance of $1.8 \mathrm{~mW} / \mathrm{cm}^{2}$, which was nevertheless lower than with an evaporated electrode. Subsequently, ITO was replaced with a composite electrode (Ag-grid and HCPEDOT:PSS) and a higher device performance was achieved, with the best allsolution processed devices reaching a PCE of $1.94 \%$. By replacing $\mathrm{ZnO}$ with PFN, normal OSCs with inkjet printed back electrodes gave a PCE of $1.81 \%$, which was nonetheless lower compared to a evaporated back electrode $(2.97 \%)$ on a laboratoryscale device with an area of $0.09 \mathrm{~cm}^{2}$.

The application of IJP to a Ag electrode in an inverted device structure was reported by Angmo et al. ${ }^{[123]}$ Inkjet printed Ag back electrodes were compared with screen printed and evaporated analogues in large-area $1 \mathrm{~cm}^{2}$ OSCs with the structure Glass/ITO/ZnO/P3HT:PCBM/PEDOT:PSS/Ag(IJP) (Figure 9). With an $800 \mathrm{~nm}$ thick PEDOT:PSS (Orgacon ELP-5015, Agfa) layer, IJP of back electrodes resulted in a similar device performance to those containing evaporated back electrodes. Laser beam induced current (LBIC) imaging revealed no solvent diffusion into the device, unlike in screen-printed back electrode cells where solvents from the ink have penetrated into the device, damaging the active layer. Different printing patterns (full layer and grid) were further investigated and revealed that the use of full-layer back electrodes results in a $25 \%$ increase in PCE compared to grid patterns. However, a full-layer back electrode requires a greater consumption of printing materials and becomes non-transparent. Galagan et al. extended this work by exploring different types of PEDOT:PSS and their thicknesses over a large series of devices, with the back electrodes made by either IJP Ag grids or screen-printing a UV curable Ag 
paste. ${ }^{[126]}$ Devices with the same structure of

Glass/ITO/ZnO/P3HT:PCBM/PEDOT:PSS/Ag(IJP) were fabricated. With both inkjetprinted full area and grid electrodes with PEDOT:PSS (Orgacon ELP-5015, Agfa) as used by Angmo et al., the reproducibility of the device performance with different PEDOT:PSS thicknesses decreased with decreasing PEDOT:PSS layer thickness from 1200 to $200 \mathrm{~nm}$. This is primarily due to a large number of defects (holes and pinholes) present in the PEDOT:PSS layer with a decrease in layer thickness. Moreover, the penetration of solvents from the Ag ink through the PEDOT:PSS layer increased with a decrease in PEDOT:PSS layer thickness. With the use of water-based PEDOT:PSS (S305), a 40 nm PEDOT:PSS film could be deposited onto an inkjetprinted Ag grid, giving efficient semi-transparent solar cells with PCEs similar to those observed in devices incorporating a $1200 \mathrm{~nm}$ thick ELP 5015 PEDOT:PSS layer. Research on IJP Ag nanowires (NWs) as a top electrode for OSCs with a typical device structure of Glass/ITO/ZnO/P3HT:PC ${ }_{61} \mathrm{BM} / \mathrm{PEDOT}: \mathrm{PSS} / \mathrm{MoO} 3 / \mathrm{Ag}$ NW (IJP) was reported by Lu et al. ${ }^{[127]}$ The best performance based on this OSC was achieved when the top electrode was fabricated by 7 consecutive printing runs, resulting in a $\mathrm{PCE}=2.71 \%, \mathrm{~V}_{\mathrm{oc}}=0.60 \mathrm{~V}, \mathrm{~J}_{\mathrm{sc}}=8.44 \mathrm{~mA} / \mathrm{cm}^{2}, \mathrm{FF}=54 \%$. Indeed, both FF and $\mathrm{J}_{\mathrm{SC}}$ were found to increase with an increase in printing runs $(3,5$ and 7$)$, which could be partially attributed to the improved conductivity of the Ag NW network. Furthermore, the solvent effect on the top of anode buffer layer during the printing of the Ag NW was found to be the main reason for the decrease of device performance, as the solvent effect can decrease the charge carrier injection selectivity and lead to an increased charge recombination rate at the anode buffer layer/Ag NW interface.

The use of Ag NW networks as both the top and bottom electrodes permits the fabrication of semi-transparent OSCs. These electrodes were explored by Maisch et 
al., ${ }^{[128]}$ who reported devices with a Glass/Ag

NW(IJP)/ZnO/PV2000:PCBM/PEDOT:PSS/Ag NW(IJP) structure. An alcohol-based Ag NW ink formulation with a high boiling point component was used, with the printed Ag NW having an average length of 10's of mm without any pretreatment. A PCE of $4.3 \%$ for $1 \mathrm{~cm}^{2}$ devices was achieved with $\mathrm{V}_{\mathrm{oc}}=0.76 \mathrm{~V}, \mathrm{~J}_{\mathrm{sc}}=10.7 \mathrm{~mA} / \mathrm{cm}^{2}, \mathrm{FF}=$ $52.8 \%$. This remains the highest reported efficiency for OSCs with inkjet-printed Ag NW for both front and back electrodes. In this study, a non-aqueous ink helped prevent nozzle blockage and also allowed printing on water sensitive substrates, demonstrating its potential application to PEDOT:PSS and perovskites active layers.

\subsection{All Functional Layers}

While many studies have used IJP for the deposition of one or more layers as discussed in the previous sections, IJP is potentially suitable for complete OSCs fabrication. Jung et al. demonstrated the fabrication of all-inkjet-printed, all-airprocessed OSCs with the structure PEDOT:PSS/ PCDTBT:PC $70 \mathrm{BM} / \mathrm{ZnO} / \mathrm{Ag}$, where PCDTBT is a lower band-gap, higher efficiency polymer than P3HT. ${ }^{[118]}$ Firstly, OSCs with the structure PEDOT:PSS/PCDTBT:PCBM/Al were fabricated by tailoring the solvent of the active blend to achieve optimum printability and morphology. A solvent composition comprising CB:MT:CF $(5: 4: 1 \mathrm{v} / \mathrm{v} / \mathrm{v})$ gave a device with 5\% efficiency. To replace aluminium with an inkjet printed Ag electrode enabling all-inkjet printed devices under ambient conditions, ETL ZnO was inkjet printed below the Ag layer. With $\mathrm{ZnO} \mathrm{NPs}$, an average PCE of $2 \%$ was achieved.

Eggenhuisen et al. extended Jung's work from a laboratory study to an industriallycompatible demonstration of all-inkjet-printed devices. ${ }^{[12,129]}$ They highlighted limitations in Jung's approach, including the use of high resistance PEDOT:PSS as a front electrode, which is not feasible for large-area devices, and the use of chlorinated 
solvent mixtures. Eggenhuisen et al. increased the PCE for all-inkjet-printed large area devices by printing lower resistance electrodes, and also printed all the layers from non-chlorinated solvents. Furthermore, they also utilized multiple-nozzle industrial print-heads and demonstrated freedom of shapes and designs.

Investigations into all-inkjet printed OSCs in an inverted structure began with an inkjet-printed front electrode of Ag/PEDOT:PSS/ZnO, which gave a performance of $2.3 \%$, comparable to a similar cell with an ITO front electrode (2.4\%). Subsequently, a back electrode of PEDOT:PSS superimposed by Ag grids was also inkjet printed. PEDOT:PSS (Orgacon S315) was used as it was found to prevent penetration of the solvents from the Ag ink, and resulted in device with a PCE of comparable to an analogues evaporated back electrodes. ${ }^{[123,126]}$ The next step aimed to inkjet print a photoactive layer using one of two active materials, $\mathrm{P} 3 \mathrm{HT}: \mathrm{PC}_{60} \mathrm{BM}$ or ActivInk ${ }^{\circledR}$ PV2000 (Polyera corporation). Eventually, all-inkjet-printed devices comprising of the six inkjet printed layers were fabricated in the device structure Ag(IJP)/PEDOT:PSS(IJP)/ZnO(IJP)/photoactive layer(IJP)/PEDOT:PSS(IJP)/Aglayer(IJP). Here, HC-PEDOT:PSS, ZnO nanoparticles, the photo-active layer and PEDOT were inkjet printed using only non-halogenated solvents on an industrial printing head with 512 nozzles (360 DPI, $3.5 \mathrm{~cm}$ wide). Notable performances of $1.7 \%$ and 4.1\% were achieved for P3HT:PCBM and PV2000 blends, respectively. Furthermore, in order to demonstrate the full freedom of design offered by IJP, a fullyinkjet-printed OSC in the shape of a Christmas tree was also prepared (Figure 10).

\section{Application of Inkjet Printing to Perovskite Solar Cell Fabrication}

Despite rapid achievement of high efficiency, PeSCs faced several challenges which includes improving poor stability, increasing reproducibility during fabrication particularly during scaling manufacturing to industrial levels, ${ }^{[130,131]}$ demonstrating 
fabrication under completely vacuum-free conditions, and reducing the high production costs associated with high-cost materials such as spiro-OMeTAD ${ }^{[132,133]}$ Strategies such as identifying alternative materials, adopting new configurations, and finding new deposition methods have been used to overcome these obstacles. The inherent properties of IJP which includes its efficient use of materials, highly controlled deposition, and operation under ambient conditions makes it an attractive tool for translating PeSC fabrication from = laboratory scale to mass production. However, although IJP has already been widely applied in the study of OSCs, ${ }^{[130,134]}$ its application to fabricating PeSCs remain sparse. ${ }^{[131,134]}$ This can be attributed to PeSCs being a relatively nascent technology with the research to date being mainly focused on laboratory-scale devices without further consideration for scale-up. Despite this, as significant advancements are reported in solving materials, stability and film formation issues in lab scale devices, interest is now turning to large-scale processing. ${ }^{[135]}$

The first application of IJP to planar PeSC fabrication was reported by Wei et al. in 2014. ${ }^{[134]}$ To fabricate metal-electrode-free PeSC, two procedures were compared. Firstly, a mixed ink comprising carbon and $\mathrm{CH}_{3} \mathrm{NH}_{3} \mathrm{I}$ was inkjet printed on top of a $\mathrm{PbI}_{2}$ layer. After heating for one hour, a planar $\mathrm{PeSC}$ was formed as $\mathrm{PbI}_{2}$ was converted into the photoactive $\mathrm{CH}_{3} \mathrm{NH}_{3} \mathrm{PbI}_{3}$ layer. Secondly, a reference planar PeSC with only an IJP carbon ink was also fabricated on top of a $\mathrm{PbI}_{2}$ layer which was subsequently converted to perovskite by immersion into a $\mathrm{CH}_{3} \mathrm{NH}_{3} \mathrm{I}$ solution to obtain the final device. In comparison to this reference device, the former approach comprising of the mixed ink of carbon and $\mathrm{CH}_{3} \mathrm{NH}_{3} \mathrm{I}$ ink led to better-defined crystallinity in the $\mathrm{CH}_{3} \mathrm{NH}_{3} \mathrm{PbI}_{3}$ thin film and an improvement of the quality of interface. Simultaneous in-situ chemical transformation and the carbon electrode 
deposition led to the significantly improved Carbon $/ \mathrm{CH}_{3} \mathrm{NH}_{3} \mathrm{PbI}_{3}$ interface. JV results showed high performance in solar cells prepared by IJP using a mixed carbon and $\mathrm{CH}_{3} \mathrm{NH}_{3} \mathrm{I}$ ink (PCE: $\left.11.60 \%, \mathrm{~V}_{\text {oc }}: 0.95 \mathrm{~V}, \mathrm{~J}_{\mathrm{sc}}: 17.20 \mathrm{mAcm}^{-2}, \mathrm{FF}: 0.71\right)$. In comparison, the reference devices showed a PCE:8.51\%, $\mathrm{V}_{\mathrm{oc}}: 0.90 \mathrm{~V}, \mathrm{~J}_{\mathrm{sc}}: 15.00$ $\left.\mathrm{mAcm}^{-2}, \mathrm{FF}=0.63\right)$.

Li et al. ${ }^{[130]}$ successfully employed IJP to fabricate a $\mathrm{MAPbI}_{3}$ perovskite film on mesoporous $\mathrm{TiO}_{2}$. The role of the printing table temperature and ink composition were investigated. Ink was prepared by mixing $\mathrm{MAI}$ and $\mathrm{PbI}_{2}$ in $\gamma$-butyrolacetone. The printing table temperature $\left(25,40,50\right.$ and $\left.60^{\circ} \mathrm{C}\right)$ had a strong influence on the film morphology. A temperature of $50{ }^{\circ} \mathrm{C}$ was found to be most suitable for forming larger crystals with high surface coverage resulting in a PCE of $7.9 \%$. The PCE dropped however to $7.3 \%$ which was attributed to pin-holes and high roughness. Thus, MACl, which has been shown to improve perovskite morphology, was added to the ink. Precursor inks comprising $(1-\mathrm{x}): 1: \mathrm{x}(\mathrm{x}=0-0.9)$ molar ratios of $\mathrm{PbI}_{2}, \mathrm{MAI}$ and MACl, respectively, were inkjet printed. A composition of 0.4:1:0.6 resulted in high reproducibility along with the highest performance of PCE: $12.3 \%, \mathrm{~V}_{\mathrm{oc}}: 0.91 \mathrm{~V}$, $\mathrm{J}_{\mathrm{sc}}: 19.55 \mathrm{mAcm}^{-2}$ and FF: $69 \%$. This efficiency was higher than the highest value reported for mesoporous PeSCs prepared by a single step perovskite deposition with spin-coating.

Hashmi et al. further reported on an all printable, ambient-processed, HTL-free mesoporous PeSCs. ${ }^{[136]}$ The device structure comprised Glass/FTO/TiO $/ 2 / \mathrm{ZrO}_{2} / \mathrm{MAPbI}_{3} / \mathrm{Carbon}$. $\mathrm{TiO}_{2}, \mathrm{ZrO}_{2}$ and carbon were screen printed consecutively. Finally, the matrix was infiltrated with $\mathrm{MAPbI}_{3}$ precursor ink by IJP. The perovskite precursor was based on a mixture of $\mathrm{PbI}_{2}$ and MAI with 5-ammonium valeric acid iodide (5-AVAI) as an additive. 5-AVAI is reported to work as a 
templating agent improving the crystalline network and charge-carrier lifetime of $\mathrm{CH}_{3} \mathrm{NH}_{3} \mathrm{PbI}_{3}$. Additionally, this additive enables preventing the inkjet nozzles from clogging by slowing-down perovskite crystal growth. Highly reproducible and stable devices were achieved with the highest PCE of $7.83 \%$ under forward bias scan and $8.74 \%$ under reverse bias scan. The devices were tested under 1 sun illumination at 35 ${ }^{\circ} \mathrm{C}$ without any encapsulation and were found to be exceptionally stable. After 1046 hours of continuous illumination, the devices performance dropped insignificantly from $6.7 \pm 0.3 \%$ to $6.4 \pm 0.3 \%$. No lead iodide formation was observed in XRD images confirming that no degradation had occurred in the perovskite film. While no explanation was given for the improved stability as $\mathrm{MAPbI}_{3}$ has very poor stability against moisture, the hydrophobicitity of carbon coupled with $\mathrm{MAPbI}_{3}$ being embedded in the carbon scaffold would have contributed to the stability. In a subsequent study, Hashimi et al. further studied long-term stability of these devices under constant 1.5 sun ultraviolet light (UV) exposure with the use of an epoxy which was directly applied on top of the carbon layer. ${ }^{[137]} \mathrm{UV}$ is a strong degradation agent in DSSCs and OPVs which lead to chain scission in the organic materials. Devices were kept under open circuit conditions with $45 \%$ relative humidity and a temperature of 40 ${ }^{\circ} \mathrm{C}$. The sealed devices displayed no degradation even after 1002 hours of constant UV aging.

The structural and PV properties of perovskites can also be tuned by varying the composition of the cations in the photoactive layer. Using a desktop multi-channel IJP technique, Monojit Bag et al. creatively tuned the composition of the perovskite layer for optimal performance and stability by in situ mixing of cations (MA and FA) from separate ink cartridges using RGB color codes of the multichannel inkjet printer. ${ }^{[131]}$ Devices in the $p-i-n$ structure were fabricated. The ratio of optimal MA:FA ratio was 
2:1 which gave the highest PCE for this study of $11.1 \%\left(\mathrm{~V}_{\mathrm{oc}}: 0.87 \mathrm{~V}, \mathrm{~J}_{\mathrm{sc}}: 18.77\right.$ $\mathrm{mAcm}^{-2}$, FF: 0.68; Figure 11).

Furthermore, Mathies et al. employed a multipass inkjet printed for fabrication of PeSCs in the n-i-p structure with $\mathrm{MAPbI}_{3}$-based active layers ${ }^{[138]}$ The precursor ink consisted of $0.7 \mathrm{M}$ $\mathrm{MAPbI}_{3}$ (MAI: $\mathrm{PbI}_{2}$ in 1:1 ratio) in a mixture of gammabutyrolactone (GBL) and dimethyl sulfoxide (DMSO). GBL serves as a high boiling point solvent whereas DMSO positively affects crystallization by forming adduct with $\mathrm{PbI}_{2}$. The inkjet printed devices were compared with spin-coated devices. The spin-coated device employed an anti-solvent quenching step during spin-coating with the use of toluene to enable pinhole-free perovskite layer. Since this quenching step could not be adapted to IJP, a vacuum-annealing step after the deposition of precursor ink was found essential. The number of printing passes (sublayers) and drop spacing were investigated. Three sublayers and a drop spacing of $45 \mu \mathrm{m}$ led to a PCE of $11.3 \%$. In comparison, spin-coated devices led to a PCE of $12.8 \%$ under the same environmental condition $\left(22^{\circ} \mathrm{C}, 45 \%\right.$ relative humidity).

\section{Challenges and Outlook}

Inkjet printing, traditionally used in the graphics and publishing industries, has proven to be an effective manufacturing technique for printed electronics in general and solution-based printable solar cells in particular. In OSCs, IJP has been explored widely in both laboratory settings and in semi-industrial production. These reports suggest IJP could be a viable large-scale manufacturing technique for printing of just one functional layer to up to several functional layers of a solar cell. The feasibility of IJP for printing of one or more layers depends on the end goal of the product. The complete fabrication of a device via IJP is perhaps more attractive in other electronic applications such as organic sensors, organic transistors, etc., where device area is 
small and the need for fine patterning is more restrictive than in solar cells. In fact, IJP is already deployed in the fabrication of next generation OLED production by companies such as Kateeva and LG. Nonetheless, complete solar cell fabrication with IJP may equally be applicable for niche applications in solar cells such as aesthetically pleasing and artistic solar cells or for the printing of small area solar cells for lowpower based applications such as the internet-of-things.

While IJP of all layers in OSCs have been demonstrated, its greatest potential lies in over other printing methods lies in the vacuum-free deposition of both front and back electrodes in the form of metal grids/ITO is an expensive front electrode material and its brittle nature not only restricts flexibility in the final product but causes severe limitations in the production and handling of flexible substrates in R2R production. The inkjet printed metal grids offer excellent flexibility and are more cost-effective as less material is consumed in their production compared to a continuous thin film of ITO. Additionally, IJP enables high resolution printing and control over detrimental topological features, particularly spikes, owing to its non-contact method of printing. Such spikes are likely to be prevalent in other forms of contact-based printing such as screen printing, gravure, or flexographic printing. Spikes cause electrical shorts in solution-processed thin film solar cells where the active layer thickness - the barrier between front and back electrode - is generally below $500 \mathrm{~nm}$.

In contrast, the biggest challenge of using IJP lies the early development of inks and the time it takes for optimization of printing parameters. While rarely reported, success of IJP depends on an interplay of a complex set of parameters such as droplet generating voltage waveform, drop spacing and volume, surface characteristics of the substrate, environmental conditions during printing, ink characteristics and the 
deposition temperature. Particularly, the waveform and contact angle of the ink is rarely reported which severely limit the implications of these work to other groups. Thus, immense amount of work goes into reaching an optimized printing condition in IJP which needs to be repeated all over again for a new set of inks. Nonetheless, the intensive research into IJP of OSCs have led to a wealth of knowledge regarding ink formulations and printing conditions for all functional materials as evidenced by the demonstration of all inkjet printed and functional OSCs in the shape of a Christmas tree.

In contrast to OSCs, IJP is only beginning to be explored in PeSC fabrications. However, the approaches thus far are diverse. The usefulness of IJP as a perovskite precursor infiltration tool in mesoporous structures has shown excellent results. Dropby-drop deposition characteristic of IJP offers excellent control allowing precise optimization of pore-filling in mesoporous structures. Further ink development have shown multiple functional materials (carbon electrode and perovskite precursors) can be printed in one-step, thus simplifying production and saving cost. Additionally, IJP has been successful in planar n-i-p and p-i-n devices to some extent. Generally, perovskite film formation in planar devices employ an additional quenching step, either with the use of fast blowing of nitrogen gas or dropping an anti-solvent immediately after the deposition of the perovskite ink. Replicating these quenching approaches in planar devices with the use of IJP may represent additional challenges which would need instrument modification or further ink development that do not rely on these quenching approaches. So far, vacuum-storage step right after printing has been shown to circumvent this shortcoming. Any vacuum-steps are not feasible and realistic solutions need to be sought. Thus far, IJP in PeSCs is only focused on the 
perovskite ink. While IJP of some of the other functional materials can be directly adapted from OSCs, some needs to be developed specifically for PeSCs. Particularly, it can be envisioned that the printing of perovskite layer itself and superimposing layers would require the generation of new inks for IJP. Inorganic-organic hybrid perovskites are not as forgiving as polymer blends to the changes in ink chemistry and the formation of defect-free uniform films, particularly in planar structures, remain challenging. Additionally, Ag is not stable for use in PeSCs due to the reaction with the halides present in the perovskites. Thus, new ink developments are needed to tackle these challenges associated with film formation, stability, and reproducibility, if IJP is to find broad application in PeSC fabrication.

In all, whether used as a sole fabrication method for multilayer processing or used in combination with other fabrication methods, IJP brings unique advantages not offered by other fabrication methods. The extent of its application and the feasibility of it's use in both PeSCs and OSCs depends on the end product.

\section{Acknowledgements}

We acknowledge support from Chinese Government's Fundamental Research Funds for the Central Universities (2016-JL-002), CSIRO's OCE Post-doctoral fellowship, Australian Centre for Advanced Photovoltaics (ACAP), and Glass and Technology Research Institute of Shahe, China. 


\section{Notes and references}

$\$$ Abbreviations are summarized in Table 1 .

[1] B. P. (British Pertroleum), Historical Data Workbook. Statistical Review of World Energy., British Petroleum (BP), 2016.

[2] S. B. Darling, F. You, RSC Adv. 2013, 3, 17633.

[3] F. C. Krebs, N. Espinosa, M. Hösel, R. R. Søndergaard, M. Jørgensen, M. C. Scharber, 2013, 1 .

[4] D. Angmo, T. T. Larsen-Olsen, M. Jørgensen, R. R. Søndergaard, F. C. Krebs, $A d v$. Energy Mater. 2013, 3, 172.

[5] M. Hösel, D. Angmo, R. R. Søndergaard, G. A. dos Reis Benatto, J. E. Carlé, M. Jørgensen, F. C. Krebs, Adv. Sci. 2014, 1, 1400002.

[6] W. Zhao, S. Li, H. Yao, S. Zhang, Y. Zhang, B. Yang, J. Hou, J. Am. Chem. Soc. 2017, 139, 7148 .

[7] X. Gu, Y. Zhou, K. Gu, T. Kurosawa, Y. Guo, Y. Li, H. Lin, B. C. Schroeder, H. Yan, F. Molina-Lopez, C. J. Tassone, C. Wang, S. C. B. Mannsfeld, H. Yan, D. Zhao, M. F. Toney, Z. Bao, Adv. Energy Mater. 2017, 1602742.

[8] K. Yoshikawa, H. Kawasaki, W. Yoshida, T. Irie, K. Konishi, K. Nakano, T. Uto, D. Adachi, M. Kanematsu, H. Uzu, K. Yamamoto, Nat. Energy 2017, 2, 17032.

[9] W. S. Yang, B.-W. Park, E. H. Jung, N. J. Jeon, Y. C. Kim, D. U. Lee, S. S. Shin, J. Seo, E. K. Kim, J. H. Noh, S. Il Seok, Science (80-. ). 2017, 356, 1376 LP.

[10] A. Kojima, K. Teshima, Y. Shirai, T. Miyasaka, J. Am. Chem. Soc. 2009, 131, 6050.

[11] F. C. Krebs, Sol. Energy Mater. Sol. Cells 2009, 93, 394.

[12] R. R. Sondergaard, M. Hosel, F. C. Krebs, J. Polym. Sci. Part B Polym. Phys. 2013, 51,16 .

[13] J. J. van Franeker, W. P. Voorthuijzen, H. Gorter, K. H. Hendriks, R. A. J. Janssen, A. Hadipour, R. Andriessen, Y. Galagan, Sol. Energy Mater. Sol. Cells 2013, 117, 267.

[14] M. Singh, H. M. Haverinen, P. Dhagat, G. E. Jabbour, Adv. Mater. 2010, 22, 673.

[15] B. J. de Gans, P. C. Duineveld, U. S. Schubert, Adv. Mater. (Weinheim, Ger. 2004, 16, 203.

[16] E. Tekin, B.-J. de Gans, U. S. Schubert, J. Mater. Chem. 2004, 14, 2627.

[17] E. Tekin, P. J. Smith, U. S. Schubert, Soft Matter 2008, 4, 703.

[18] T. Kawase, T. Shimoda, C. Newsome, H. Sirringhaus, R. H. Friend, Thin Solid Films 
2003, 438-439, 279.

[19] B. Derby, Annu. Rev. Mater. Res. 2010, 40, 395.

[20] Z. Zhan, J. An, Y. Wei, V. T. Tran, H. Du, Nanoscale 2017, 9, 965.

[21] L. Wu, Z. Dong, F. Li, H. Zhou, Y. Song, Adv. Opt. Mater. 2016, 4, 1915.

[22] Y. Y. Sun, Y. J. Zhang, Q. Liang, Y. Zhang, H. J. Chi, Y. Shi, D. N. Fang, Rsc Adv. 2013, 3, 11925.

[23] M. T. Plateau, 2017, 5982.

[24] J. Plateau, Experimental and Theoretical Statics of Liquids Subject to Molecular Forces Only, 1873.

[25] Lord Rayleigh, Proc. London Math. Soc. 1878, s1-10, 4.

[26] Kelvin, L, Electric Telegraph Recorder, 1870, 109,688.

[27] Elmqvist R, Measuring Instrument of the Recording Type, 1951, 2566443.

[28] B. Derby, Annu. Rev. Mater. Res. 2010, 40, 395.

[29] R. G. Sweet, Fluid Droplet Recorder, 1971.

[30] O. A. Basaran, H. Gao, B. P. P, Annu. Rev. Fluid Mech. 2013, 45, 85.

[31] N. Reis, C. Ainsley, B. Derby, J. Appl. Phys. 2005, 97, 94903.

[32] J. E. Fromm, IBM J. Res. Dev. 1984, 28, 322.

[33] D. Soltman, V. Subramanian, and V. Subramanian, Langmuir 2008, 24, 2224.

[34] R. Holtzman, Nat. Publ. Gr. 2016, 1.

[35] P. G. Saffman, S. G. Taylor, Society 1958, 245, 312.

[36] J. H. Heo, M. H. Lee, H. J. Han, B. R. Patil, J. S. Yu, S. H. Im, J. Mater. Chem. A 2016, 4, 1572.

[37] F. C. Krebs, N. Espinosa, M. Hösel, R. R. Søndergaard, M. Jørgensen, Adv. Mater. 2014, 26, 29.

[38] M. Kaltenbrunner, G. Adam, E. D. Głowacki, M. Drack, R. Schwödiauer, L. Leonat, D. H. Apaydin, H. Groiss, M. C. Scharber, M. S. White, N. S. Sariciftci, S. Bauer, Nat. Mater. 2015, 14, 1032.

[39] Appl. Phys. Lett. 2006, 89, 233517.

[40] T. Kuwabara, T. Nakayama, K. Uozumi, T. Yamaguchi, K. Takahashi, Sol. Energy Mater. Sol. Cells 2008, 92, 1476.

[41] M. S. White, D. C. Olson, S. E. Shaheen, N. Kopidakis, D. S. Ginley, Appl. Phys. Lett. 2006, $89,143517$.

[42] A. K. K. Kyaw, X. W. Sun, C. Y. Jiang, G. Q. Lo, D. W. Zhao, D. L. Kwong, Appl. 
Phys. Lett. 2008, 93, 221107.

[43] Z. Yin, J. Wei, Q. Zheng, Adv. Sci. 2016, 3, DOI 10.1002/advs.201500362.

[44] K. Mahmood, S. Sarwar, M. T. Mehran, RSC Adv. 2017, 7, 17044.

[45] W. Yan, S. Ye, Y. Li, W. Sun, H. Rao, Z. Liu, Z. Bian, C. Huang, Adv. ENERGY Mater. 2016, 6, DOI 10.1002/aenm.201600474.

[46] Z. H. Bakr, Q. Wali, A. Fakharuddin, L. Schmidt-Mende, T. M. Brown, R. Jose, NANO ENERGY 2017, 34, 271.

[47] L. Calio, S. Kazim, M. Graetzel, S. Ahmad, Angew. CHEMIE-INTERNATIONAL Ed. 2016, 55, 14522.

[48] J. Nelson, Mater. Today 2011, 14, 462.

[49] C. J. Brabec, S. Gowrisanker, J. J. M. Halls, D. Laird, S. Jia, S. P. Williams, Adv. Mater. 2010, 22, 3839.

[50] J. J. M. HALLS, C. A. WALSH, N. C. GREENHAM, E. A. MARSEGLIA, R. H. FRIEND, S. C. MORATTI, A. B. HOLMES, Nature 1995, 376, 498.

[51] B. A. Gregg, M. C. Hanna, J. Appl. Phys. 2003, 93, 3605.

[52] G. Li, V. Shrotriya, J. Huang, Y. Yao, T. Moriarty, K. Emery, Y. Yang, Nat Mater 2005, 4, 864 .

[53] W. Ma, C. Yang, X. Gong, K. Lee, A. J. Heeger, Adv. Funct. Mater. 2005, 15, 1617.

[54] M. Jørgensen, K. Norrman, S. A. Gevorgyan, T. Tromholt, B. Andreasen, F. C. Krebs, Adv. Mater. 2012, 24, 580.

[55] A. K. Chilvery, A. K. Batra, B. Yang, K. Xiao, P. Guggilla, M. D. Aggarwal, R. Surabhi, R. B. Lal, J. R. Currie, B. G. Penn, J. Photonics Energy 2015, 5, 57402.

[56] L. E. Polander, P. Pahner, M. Schwarze, M. Saalfrank, C. Koerner, K. Leo, APL Mater. 2014, 2, 81503.

[57] Q.-K. Wang, R.-B. Wang, P.-F. Shen, C. Li, Y.-Q. Li, L.-J. Liu, S. Duhm, J.-X. Tang, Adv. Mater. Interfaces 2015, 2, 1400528.

[58] M. Zhang, H. Yu, M. Lyu, Q. Wang, J.-H. Yun, L. Wang, Chem. Commun. 2014, 50, 11727.

[59] S. Lv, S. Pang, Y. Zhou, N. P. Padture, H. Hu, L. Wang, X. Zhou, H. Zhu, L. Zhang, C. Huang, G. Cui, Phys. Chem. Chem. Phys. 2014, 16, 19206.

[60] N. Pellet, P. Gao, G. Gregori, T.-Y. Yang, M. K. Nazeeruddin, J. Maier, M. Grätzel, Angew. Chemie Int. Ed. 2014, 53, 3151.

[61] J. H. Noh, S. H. Im, J. H. Heo, T. N. Mandal, S. Il Seok, Nano Lett. 2013, 13, 1764.

[62] N. G. Park, Mater. Today 2015, 18, 65. 
[63] A. K. Chilvery, A. K. Batra, B. Yang, K. Xiao, P. Guggilla, M. D. Aggarwal, R. Surabhi, R. B. Lal, J. R. Currie, B. G. Penn, J. Photonics Energy 2015, 5, 57402.

[64] Z. Song, S. C. Watthage, A. B. Phillips, M. J. Heben, J. Photonics Energy 2016, 6, 22001.

[65] H.-S. Kim, C.-R. Lee, J.-H. Im, K.-B. Lee, T. Moehl, A. Marchioro, S.-J. Moon, R. Humphry-Baker, J.-H. Yum, J. E. Moser, M. Grätzel, N.-G. Park, Sci. Rep. 2012, 2, 591.

[66] J. J. Choi, X. Yang, Z. M. Norman, S. J. L. Billinge, J. S. Owen, Nano Lett. 2014, 14, 127.

[67] T. Leijtens, G. E. Eperon, S. Pathak, A. Abate, M. M. Lee, H. J. Snaith, Nat. Commun. 2013, 4, 2885.

[68] T. Leijtens, B. Lauber, G. E. Eperon, S. D. Stranks, H. J. Snaith, J. Phys. Chem. Lett. 2014, 5, 1096.

[69] G. E. Eperon, V. M. Burlakov, P. Docampo, A. Goriely, H. J. Snaith, Adv. Funct. Mater. 2014, 24, 151.

[70] W. S. Yang, B.-W. Park, E. H. Jung, N. J. Jeon, Y. C. Kim, D. U. Lee, S. S. Shin, J. Seo, E. K. Kim, J. H. Noh, S. Il Seok, Science (80-. ). 2017, 356, 1376.

[71] M. M. Lee, J. Teuscher, T. Miyasaka, T. N. Murakami, H. J. Snaith, Science (80-. ). 2012, 338, 643 LP.

[72] M. Liu, M. B. Johnston, H. J. Snaith, Nature 20139, 501, 395.

[73] Z. Huanping, C. Qi, L. Gang, L. Song, S. Tze-bing, D. Hsin-Sheng, H. Ziruo, Y. Jingbi, L. Yongsheng, Y. Yang, Science (80-. ). 2014, 345, 542.

[74] D. Liu, T. L. Kelly, Nat Phot. 2014, 8, 133.

[75] C. Zuo, H. J. Bolink, H. Han, J. Huang, D. Cahen, L. Ding, Adv. Sci. 2016, 3, 1500324.

[76] J.-Y. Jeng, Y.-F. Chiang, M.-H. Lee, S.-R. Peng, T.-F. Guo, P. Chen, T.-C. Wen, Adv. Mater. 2013, 25, 3727.

[77] Q. Dong, Y. Yuan, Y. Shao, Y. Fang, Q. Wang, J. Huang, Energy Environ. Sci. 2015, $8,2464$.

[78] P. Docampo, J. M. Ball, M. Darwich, G. E. Eperon, H. J. Snaith, Nat. Commun. 2013, 4,2761 .

[79] L. Meng, J. You, T. F. Guo, Y. Yang, Acc. Chem. Res. 2016, 49, 155.

[80] K. Norrman, A. Ghanbari-Siahkali, N. B. Larsen, Annu. Reports Sect. “C” (Physical Chem. 2005, 101, 174. 
[81] R. Mens, P. Adriaensens, L. Lutsen, A. Swinnen, S. Bertho, B. Ruttens, J. D’Haen, J. Manca, T. Cleij, D. Vanderzande, J. Gelan, J. Polym. Sci. Part A Polym. Chem. 2008, $46,138$.

[82] F. C. Krebs, M. Jørgensen, K. Norrman, O. Hagemann, J. Alstrup, T. D. Nielsen, J. Fyenbo, K. Larsen, J. Kristensen, Sol. Energy Mater. Sol. Cells 2009, 93, 422.

[83] J.-S. Yu, I. Kim, J.-S. Kim, J. Jo, T. T. Larsen-Olsen, R. R. Sondergaard, M. Hosel, D. Angmo, M. Jorgensen, F. C. Krebs, Nanoscale 2012, 4, 6032.

[84] M. M. Voigt, R. C. I. MacKenzie, S. P. King, C. P. Yau, P. Atienzar, J. Dane, P. E. Keivanidis, I. Zadrazil, D. D. C. Bradley, J. Nelson, Sol. Energy Mater. Sol. Cells 2012, 105, 77 .

[85] M. M. Voigt, R. C. I. MacKenzie, C. P. Yau, P. Atienzar, J. Dane, P. E. Keivanidis, D. D. C. Bradley, J. Nelson, Sol. Energy Mater. Sol. Cells 2011, 95, 731.

[86] P. Kopola, T. Aernouts, R. Sliz, S. Guillerez, M. Ylikunnari, D. Cheyns, M. V??lim??ki, M. Tuomikoski, J. Hast, G. Jabbour, R. Myllyl??, A. Maaninen, Sol. Energy Mater. Sol. Cells 2011, 95, 1344.

[87] P. Kopola, T. Aernouts, S. Guillerez, H. Jin, M. Tuomikoski, A. Maaninen, J. Hast, Sol. Energy Mater. Sol. Cells 2010, 94, 1673.

[88] D. Vak, H. Weerasinghe, J. Ramamurthy, J. Subbiah, M. Brown, D. J. Jones, Sol. Energy Mater. Sol. Cells 2016, 149, 154.

[89] D. K. Mohamad, J. Griffin, C. Bracher, A. T. Barrows, D. G. Lidzey, Adv. Energy Mater. 2016, 6, 1600994.

[90] A. Barrows, A. Pearson, C. Kwak, A. Dunbar, A. Buckley, D. Lidzey, Energy Environ. Sci. 2014, 7, 1 .

[91] C. N. Hoth, S. A. Choulis, P. Schilinsky, C. J. Brabec, Adv. Mater. 2007, 19, 3973.

[92] T. Aernouts, T. Aleksandrov, C. Girotto, J. Genoe, J. Poortmans, Appl. Phys. Lett. 2008, 92,3 .

[93] C. J. M. Emmott, A. Urbina, J. Nelson, Sol. Energy Mater. Sol. Cells 2012, 97, 14.

[94] N. Espinosa, R. García-Valverde, A. Urbina, F. C. Krebs, Sol. Energy Mater. Sol. Cells 2011, 95, 1293.

[95] F. C. Krebs, Org. Electron. 2009, 10, 761.

[96] T. T. Larsen-Olsen, T. R. Andersen, B. Andreasen, A. P. L. Böttiger, E. Bundgaard, K. Norrman, J. W. Andreasen, M. Jørgensen, F. C. Krebs, Sol. Energy Mater. Sol. Cells 2012, 97, 43.

[97] K. Ellmer, Nat Phot. 2012, 6, 809. 
[98] F. C. Krebs, T. Tromholt, M. Jorgensen, Nanoscale 2010, 2, 873.

[99] Y. Zhou, F. Li, S. Barrau, W. Tian, O. Inganäs, F. Zhang, Sol. Energy Mater. Sol. Cells 2009, 93, 497.

[100] S. K. Hau, H.-L. Yip, J. Zou, A. K.-Y. Jen, Org. Electron. 2009, 10, 1401.

[101] Y.-M. Chang, L. Wang, W.-F. Su, Org. Electron. 2008, 9, 968.

[102] Y. Zhou, H. Cheun, S. Choi, W. J. Potscavage Jr., C. Fuentes-Hemandez, B. Kippelen, Appl. Phys. Lett. 2010, 97, 153304.

[103] Y. Galagan, B. Zimmermann, E. W. C. Coenen, M. Jørgensen, D. M. Tanenbaum, F. C. Krebs, H. Gorter, S. Sabik, L. H. Slooff, S. C. Veenstra, J. M. Kroon, R. Andriessen, Adv. Energy Mater. 2012, 2, 103.

[104] A. Cheknane, Prog. Photovoltaics Res. Appl. 2011, 19, 155.

[105] M. Neophytou, F. Hermerschmidt, A. Savva, E. George, C. A., Appl. Phys. Lett. 2012, 101, 193302.

[106] Y.-C. Huang, F.-H. Hsu, H.-C. Cha, C.-M. Chuang, C.-S. Tsao, C.-Y. Chen, Org. Electron. 2013, 14, 2809.

[107] M. Neophytou, E. Georgiou, M. M. Fyrillas, S. A. Choulis, Sol. Energy Mater. Sol. Cells 2014, 122, 1.

[108] Y. Galagan, E. W. C. Coenen, R. Abbel, T. J. van Lammeren, S. Sabik, M. Barink, E. R. Meinders, R. Andriessen, P. W. M. Blom, Org. Electron. 2013, 14, 38.

[109] S. H. Eom, S. Senthilarasu, P. Uthirakumar, S. C. Yoon, J. Lim, C. Lee, H. S. Lim, J. Lee, S.-H. Lee, Org. Electron. 2009, 10, 536.

[110] K. X. Steirer, J. J. Berry, M. O. Reese, M. F. A. M. van Hest, A. Miedaner, M. W. Liberatore, R. T. Collins, D. S. Ginley, Thin Solid Films 2009, 517, 2781.

[111] Z. Xiong, C. Liu, Org. Electron. 2012, 13, 1532.

[112] T. M. Eggenhuisen, Y. Galagan, a. F. K. V. Biezemans, T. M. W. L. Slaats, W. P. Voorthuijzen, S. Kommeren, S. Shanmugam, J. P. Teunissen, a. Hadipour, W. J. H. Verhees, S. C. Veenstra, M. J. J. Coenen, J. Gilot, R. Andriessen, W. a. Groen, J. Mater. Chem. A 2015, 3, 7255.

[113] C. N. Hoth, P. Schilinsky, S. A. Choulis, C. J. Brabec, Nano Lett. 2008, 8, 2806.

[114] C. N. Hoth, S. A. Choulis, P. Schilinsky, C. J. Brabec, J. Mater. Chem. 2009, 19, 5398.

[115] A. Lange, M. Wegener, C. Boeffel, B. Fischer, A. Wedel, D. Neher, Sol. Energy Mater. Sol. Cells 2010, 94, 1816.

[116] A. Teichler, R. Eckardt, S. Hoeppener, C. Friebe, J. Perelaer, A. Senes, M. Morana, C. J. Brabec, U. S. Schubert, Adv. Energy Mater. 2011, 1, 105. 
[117] S. H. Eom, H. Park, S. H. Mujawar, S. C. Yoon, S.-S. Kim, S.-I. Na, S.-J. Kang, D. Khim, D.-Y. Kim, S.-H. Lee, Org. Electron. 2010, 11, 1516.

[118] S. Jung, A. Sou, K. Banger, D.-H. Ko, P. C. Y. Chow, C. R. McNeill, H. Sirringhaus, Adv. Energy Mater. 2014, 4, 1400432.

[119] A. Haldar, K.-S. Liao, S. A. Curran, J. Mater. Res. 2012, 27, 2079.

[120] A. Lange, W. Schindler, M. Wegener, K. Fostiropoulos, S. Janietz, Sol. Energy Mater. Sol. Cells 2013, 109, 104.

[121] T. M. Eggenhuisen, Y. Galagan, E. W. C. Coenen, W. P. Voorthuijzen, M. W. L. Slaats, S. A. Kommeren, S. Shanmuganam, M. J. J. Coenen, R. Andriessen, W. A. Groen, Sol. Energy Mater. Sol. Cells 2015, 134, 364.

[122] M. Manceau, D. Angmo, M. Jørgensen, F. C. Krebs, Org. Electron. 2011, 12, 566.

[123] D. Angmo, J. Sweelssen, R. Andriessen, Y. Galagan, F. C. Krebs, Adv. Energy Mater. 2013, 3, 1230.

[124] F. C. Krebs, R. Søndergaard, M. Jørgensen, Sol. Energy Mater. Sol. Cells 2011, 95, 1348 .

[125] S. H. Eom, S. Senthilarasu, P. Uthirakumar, C.-H. Hong, Y.-S. Lee, J. Lim, S. C. Yoon, C. Lee, S.-H. Lee, Sol. Energy Mater. Sol. Cells 2008, 92, 564.

[126] Y. Galagan, S. Shanmugam, J. P. Teunissen, T. M. Eggenhuisen, A. F. K. V. Biezemans, T. Van Gijseghem, W. A. Groen, R. Andriessen, Sol. Energy Mater. Sol. Cells 2014, 130, 163.

[127] H. Lu, J. Lin, N. Wu, S. Nie, Q. Luo, C. Ma, Z. Cui, Appl. Phys. Lett. 2015, 106, 93302.

[128] P. Maisch, K. C. Tam, L. Lucera, F. W. Fecher, H.-J. Egelhaaf, H. Scheiber, E. Maier, C. J. Brabec, 2016, 9942, 99420R.

[129] T. M. Eggenhuisen, Y. Galagan, A. Biezemans, M. Coenen, J. Gilot, P. Groen, R. Andriessen, 2014 IEEE 40th Photovolt. Spec. Conf. 2014, 2842.

[130] S.-G. Li, K.-J. Jiang, M.-J. Su, X.-P. Cui, J.-H. Huang, Q.-Q. Zhang, X.-Q. Zhou, L.M. Yang, Y.-L. Song, J. Mater. Chem. A 2015, 3, 9092.

[131] M. Bag, Z. Jiang, L. A. Renna, S. P. Jeong, V. M. Rotello, D. Venkataraman, Mater. Lett. 2016, 164, 472.

[132] Y. Wu, A. Islam, X. Yang, C. Qin, J. Liu, K. Zhang, W. Peng, L. Han, Energy Environ. Sci. 2014, 7, 2934.

[133] J. Liu, Y. Wu, C. Qin, X. Yang, T. Yasuda, A. Islam, K. Zhang, W. Peng, W. Chen, L. Han, Energy Environ. Sci. 2014, 7, 2963. 
[134] Z. Wei, H. Chen, K. Yan, S. Yang, Angew. Chemie - Int. Ed. 2014, 53, 13239.

[135] D. V. Angmo, M. Gao, Organic-Inorganic Hybrid Perovskite Solar Cells with Scalable and Roll-to-Roll Compatible Printing/Coating Processes, John Wiley \& Sons, 2017.

[136] S. G. Hashmi, D. Martineau, X. Li, M. Ozkan, A. Tiihonen, M. I. Dar, T. Sarikka, S. M. Zakeeruddin, J. Paltakari, P. D. Lund, M. Grätzel, Adv. Mater. Technol. 2017, 2, 1600183.

[137] S. G. Hashmi, A. Tiihonen, D. Martineau, M. Ozkan, P. Vivo, K. Kaunisto, V. Ulla, S. M. Zakeeruddin, M. Grätzel, J. Mater. Chem. A 2017, 5, 4797.

[138] F. Mathies, T. Abzieher, A. Hochstuhl, K. Glaser, A. Colsmann, U. W. Paetzold, G. Hernandez-Sosa, U. U. Lemmer, A. Quintilla, D. Rueda, A. Quintilla, U. U. Lemmer, J. Mater. Chem. A 2016, 4, 994209.

[139] H. Tan, A. Jain, O. Voznyy, X. Lan, M. Yuan, B. Zhang, Y. Zhao, F. Fan, P. Li, L. N. Quan, Y. Zhao, Z. Lu, Z. Yang, S. Hoogland, E. H. Sargent, 2017, 726, 722.

[140] Y. Galagan, E. W. C. Coenen, S. Sabik, H. H. Gorter, M. Barink, S. C. Veenstra, J. M. Kroon, R. Andriessen, P. W. M. Blom, Sol. Energy Mater. Sol. Cells 2012, 104, 32.

[141] P. Maisch, K. C. Tam, L. Lucera, H.-J. Egelhaaf, H. Scheiber, E. Maier, C. J. Brabec, Org. Electron. 2016, 38, 139. 


\section{Figure Captions}

Figure 1 Key milestones in the development of inkjet printing.

Figure 2 Schematic diagram of inkjet printing methods.

Figure 3 DoD printability window with respect to ink properties. Reprinted with permission from ref. ${ }^{[28]}$. Copyright (C) 2010, Annual Reviews.

Figure 4 Common device structures in organic solar cells and perovskite solar cells.

Figure 5 Semi-industrial R2R-produced Ag grids for application as transparent electrodes in organic solar cells. [a] Inkjet printed Ag grids (middle) compared with thermally imprinted and filled Ag grids (left) and flexography printed grids (right). [b] Transmission spectra of resultant Ag grids on flexible PET substrates. [c] Schematic diagram of final solar cell structure. Reprinted with permission from ref. ${ }^{[83]}$. Copyright (C) 2012, Royal Society of Chemistry.

Figure 6 [a] Effect of drop spacing on an inkjet printed line; (1) individual drops, (2) scalloped, (3) uniform, (4) bulging, and (5) stacked coins. Drop spacing decreases from left to right. [b] Cross section line profiles and 3D projections of single drops printed at different temperatures as measured by an optical profilometer. Reprinted with permission from ref. ${ }^{[33]}$. Copyright (C) 2008, American Chemical Society

Figure 7 AFM images of an inkjet printed P3HT:PCBM blend deposited from [a] tetralene and $[\mathrm{b}]$ an o-DCB:mesitylene solvent mixture. Solvents have a dramatic influence on BHJ film quality. [c] The solar cell structure the P3HT:PCBM blend was incorporated into and [d] their $\mathrm{J}-\mathrm{V}$ characteristics measured under $1000 \mathrm{~W} \cdot \mathrm{m}^{-2}$ AM1.5G. Reprinted with permission from ref. ${ }^{[11]}$. Copyright (C) 2007, WILEYVCH Verlag GmbH \& Co.

Figure 8 [a] Schematic representation of IJP printing modes; (left) multi-array and (right) single array. [b] 2D derivation of optical images of P3HT:PCBM films printed in different modes using different concentrations. Optical images of films printed in [c] multi-array and [d] single array modes. Multi-array mode led to pronounced coffee ring effects. [e] Confocal scanning microscopy images and the corresponding cross section line profiles of polystyrene films printed in single array mode from a butyl acetate solution. Most of the polymer is deposited at the edges. Films printed in multi-array mode using [f] 10:90 w/w methyl benzoate/ethyl acetate and [g] 5:95 w/w acetophenone/isopropyl acetate solvent mixtures, demonstrating improvements in uniformity when using mixed solvent systems. Reprinted with permission from ref. ${ }^{[33]}$ and ${ }^{[17]}$. [a-d] Copyright (C) 2012. Materials 
Research Society 2012. [e-f] Copyright (C) 2012. Materials Research Society 2012. Copyright (C) 2012, Royal Society of Chemistry.

Figure 9 [a]. Schematic of the full-layer and grid designs used to inkjet print back electrodes for organic solar cells. [b] LBIC maps of current generating areas, highlighting the difference in current harvesting in devices that employed different processing methods for the back electrode; (left) evaporated, (middle) inkjet printed, and (right) screen printed. Solvents from screen printed Ag damage the underlying photoactive layer, while the reflection from the inkjet printed lines enhance current collection. Scale bar is $200 \mu \mathrm{m}$. [c] Photovoltaic properties characterized under $1000 \mathrm{~W} \mathrm{~cm}^{-2}$ AM1.5G. Reprinted with permission from ref. ${ }^{[123]}$. Copyright $(\mathrm{C}$ 2013, WILEY-VCH Verlag GmbH \& Co.

Figure 10 Progress towards all-inkjet printed OSCs. [a] Schematic representation of the layers in a fully inkjet printed OSC and [b] photograph of the actual device. J-V curves recorded under $1000 \mathrm{~W} \mathrm{~cm}^{-2} \mathrm{AM} 1.5 \mathrm{G}$ of [c] laboratory-scale devices $(0.038$ $\mathrm{cm}^{2}$ active area) with inkjet printed high efficiency organic blend P2000 which gave $7 \%$ efficiency and [c] large-area adevices $\left(1 \mathrm{~cm}^{2}\right.$ active area) with up to 6 inkjet printed layers. [e] Freedom-of-design demonstration. (left) Digital motif of a Christmas tree shaped organic solar cell and (right) actual printed device. [f] J-V curve of the Christmas tree shaped organic solar cell. Reprinted with permission from ref. ${ }^{[112]}$. Copyright (C) 2015, Royal Society of Chemistry.

Figure 11 SEM images of inkjet printed perovskite films using MAI:FAI precursor ratios of [a] 1:0, [b] 2:1, [c] 1:1, and [d] 0:1 ratio. [e] J-V curve of a perovskite solar cell incorporating an inkjet printed MAI:FAI thin film recorded under $1000 \mathrm{~W} \mathrm{~cm}^{-2}$ AM1.5G. [f] Optical images and [g] powder X-ray diffraction (PXRD) patterns of perovskite films at different MAI:FAI ratios. A 2:1 MAI:FAI ratio was found to be optimum for inkjet printing, leading to the greatest conversion of $\mathrm{PbI}_{2}$ into perovskite. Reprinted with permission from ref. ${ }^{[131]}$. Copyright (C) 2015, Elsevier. 


\section{Figures}

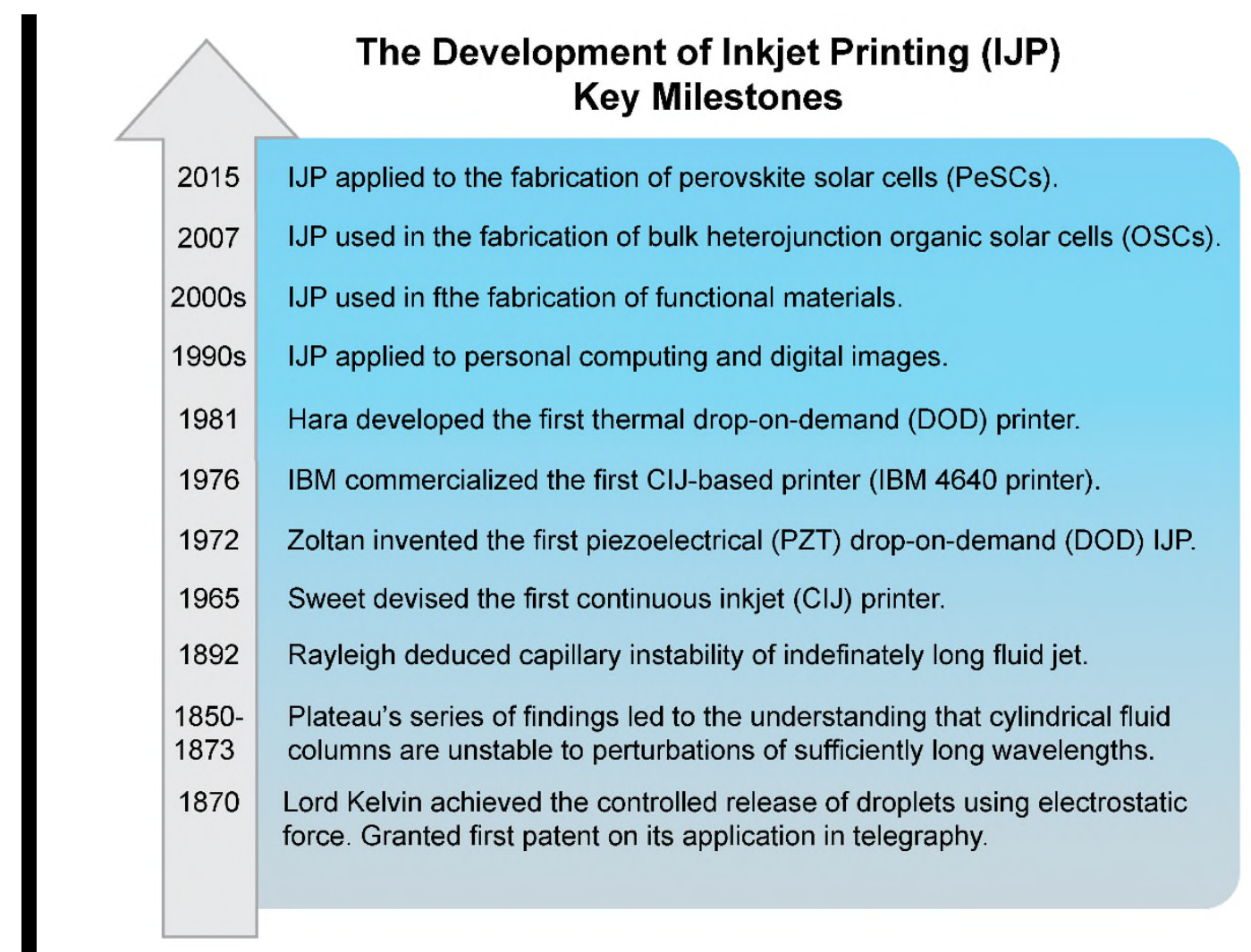

Figure 1 


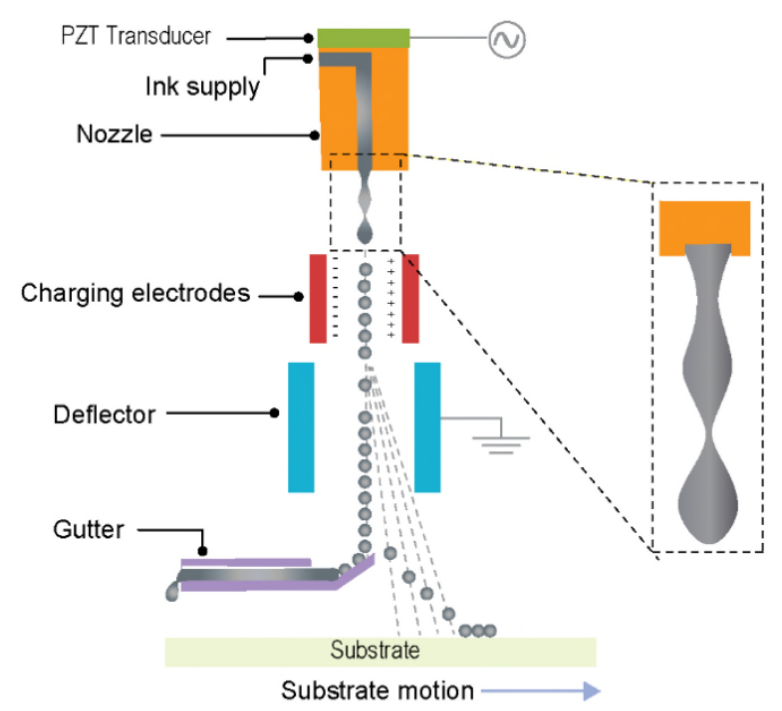

Continuous Inkjet (CIJ) Printing

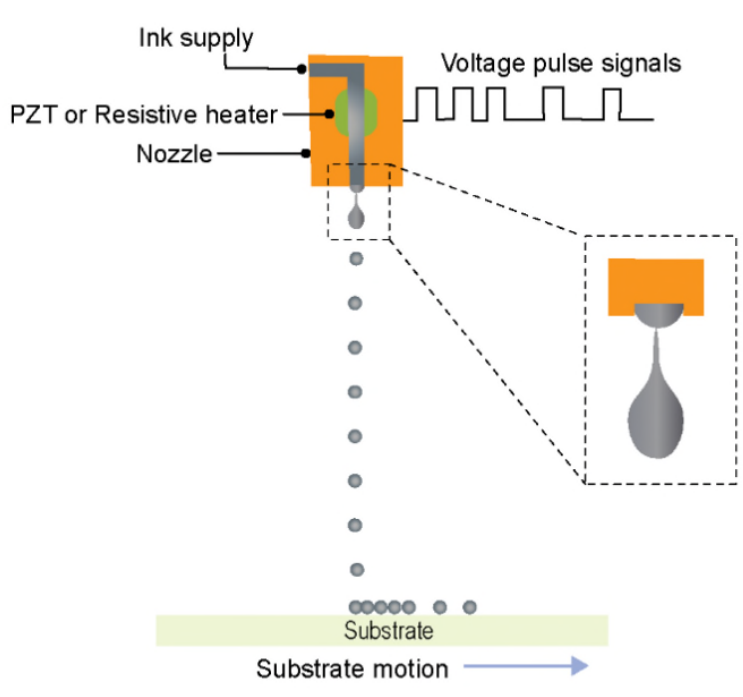

Drop-on-Demand (DoD) Inkjet Printing

Figure 2

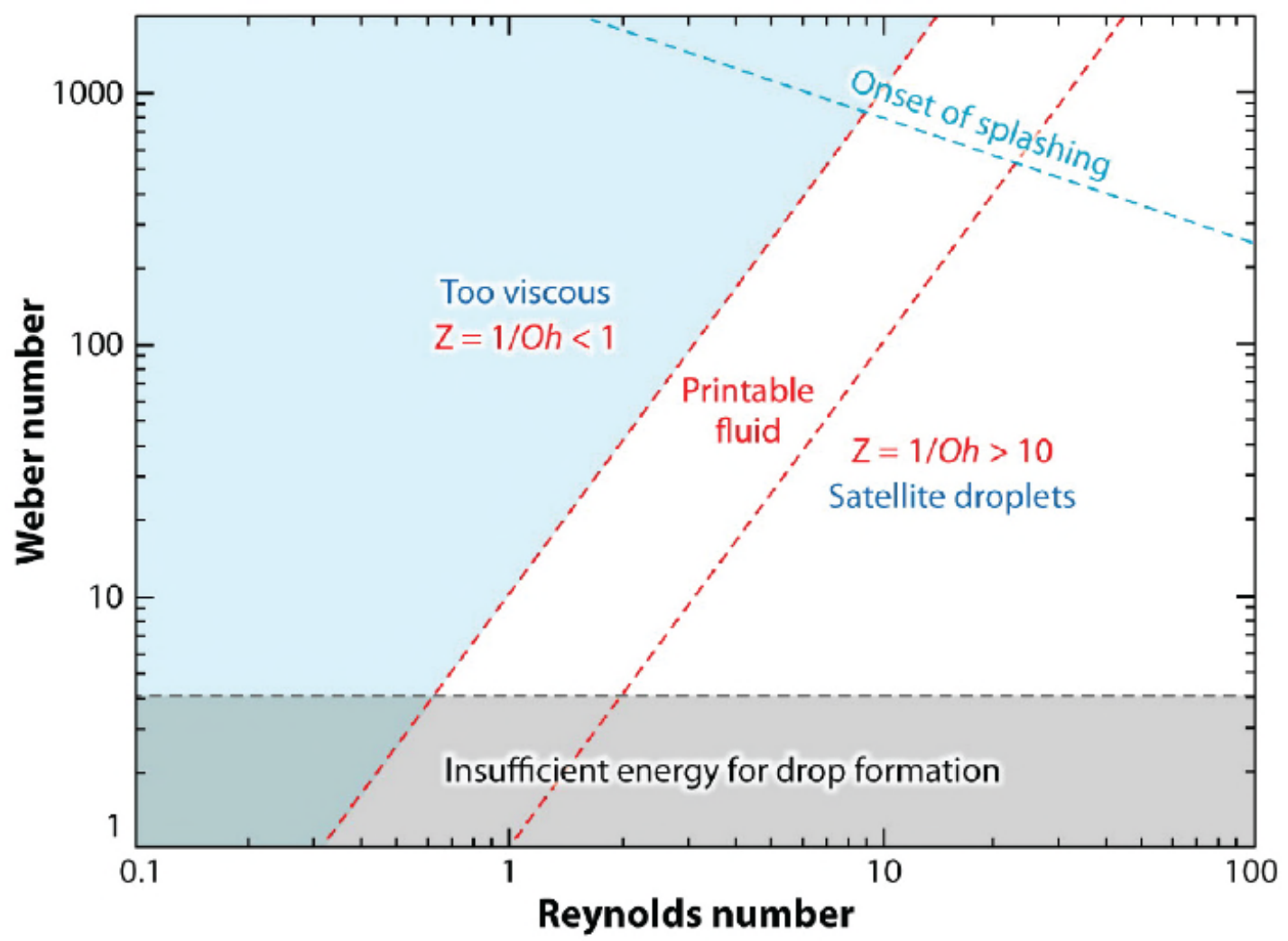

Figure 3 
Organic Solar Cells

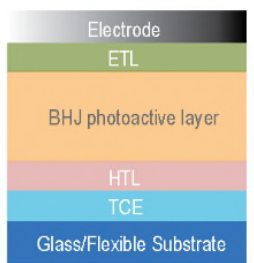

Normal

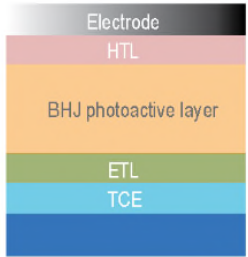

Inverted

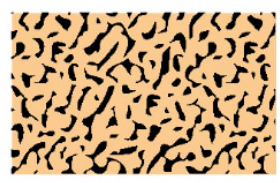

Perovskite Solar Cells
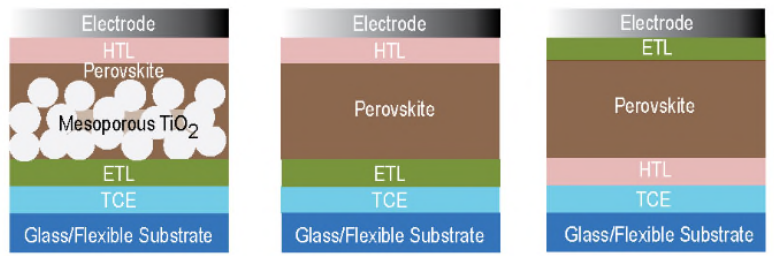

Mesoporous structure (n-i-p)

$$
\text { (n-i-p) }
$$

Inverted planar (p-i-n)

Figure 4

[a]
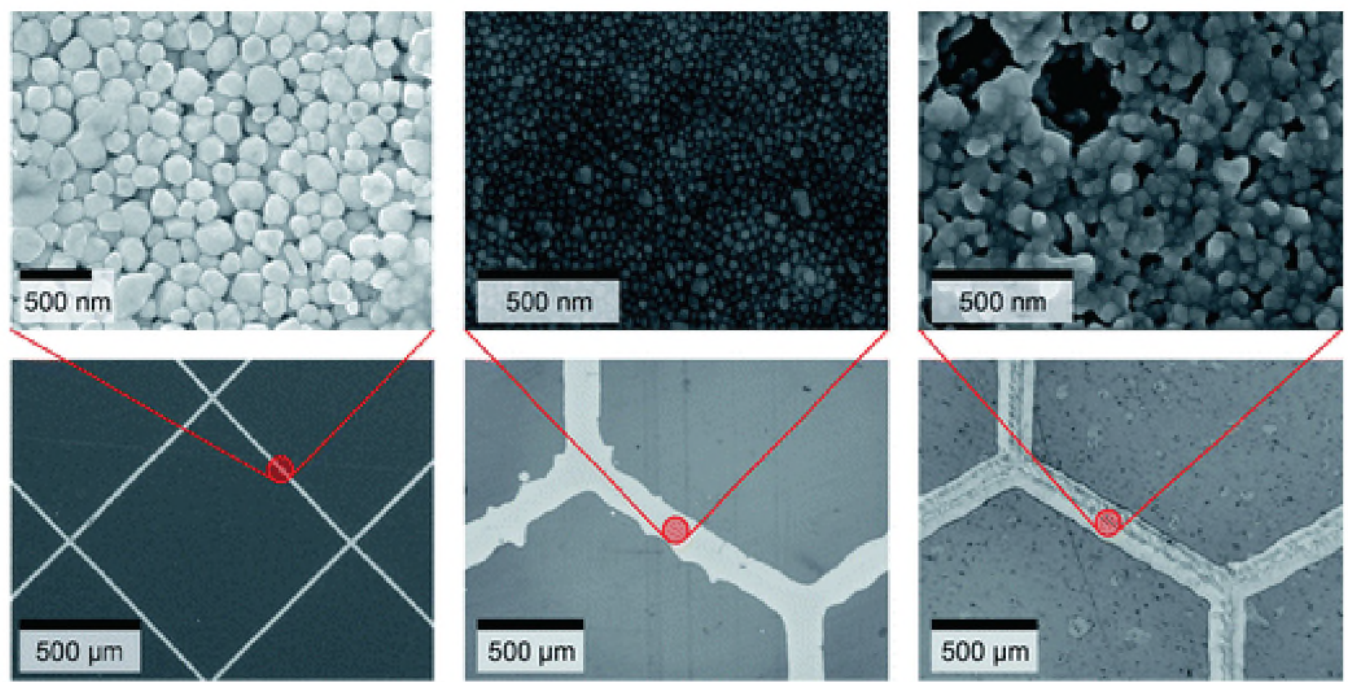

[b]

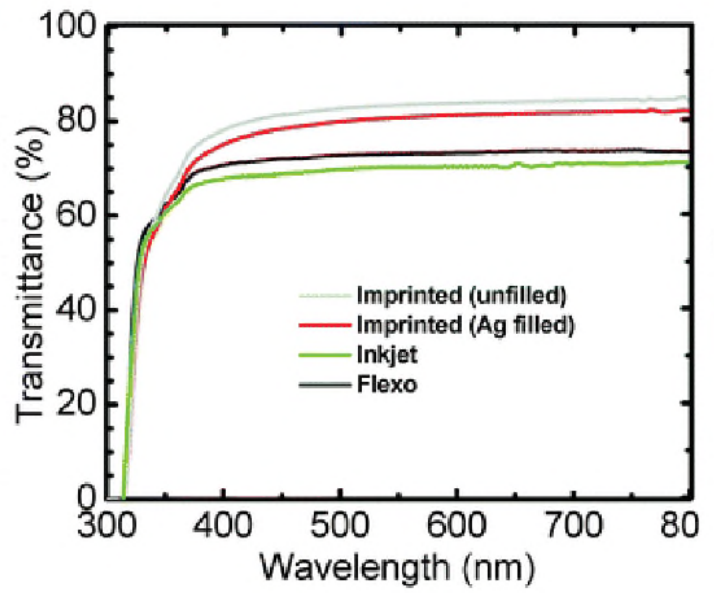

[c]

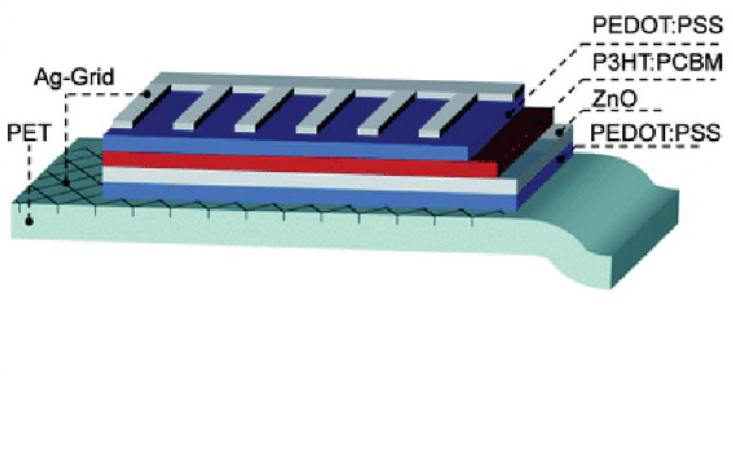

Figure 5 
[a]

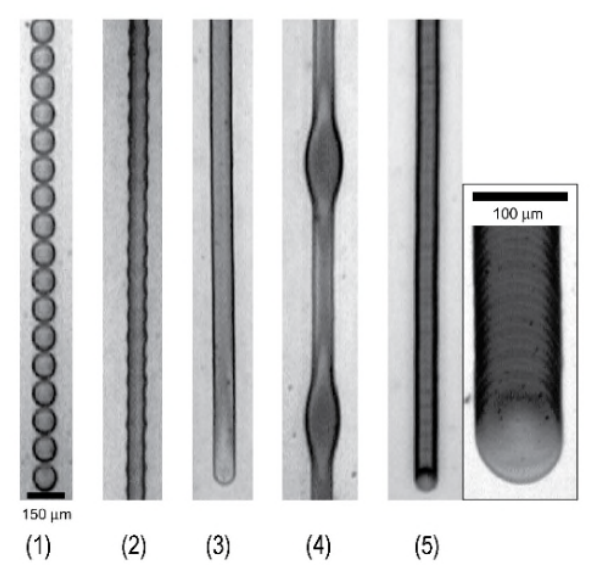

[b]
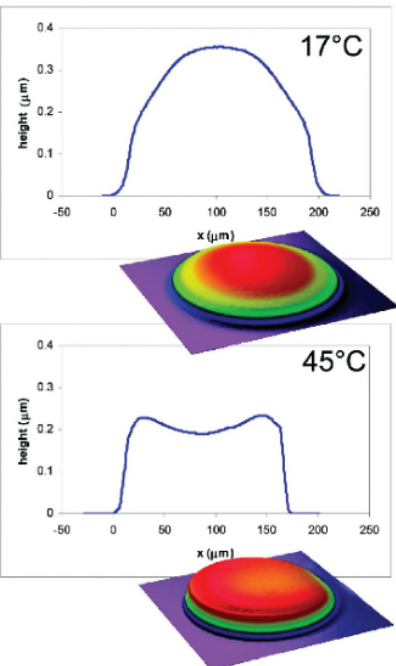
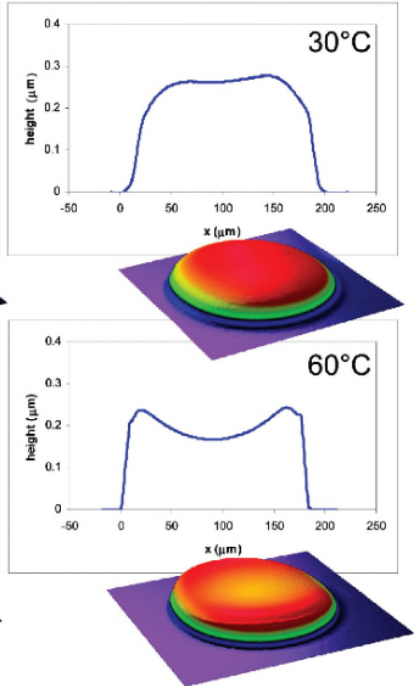

Figure6

[a]

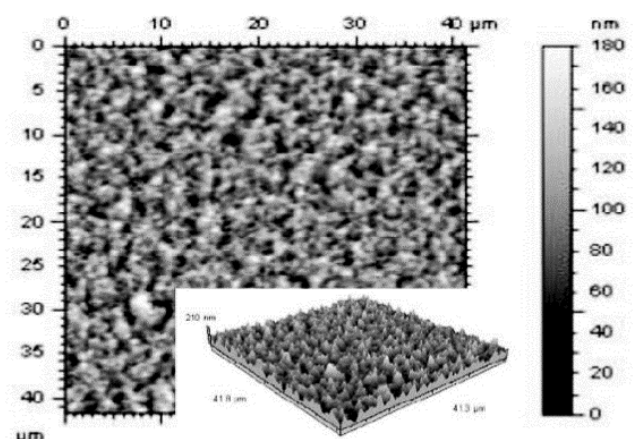

${ }_{n \rightarrow m} \wedge$

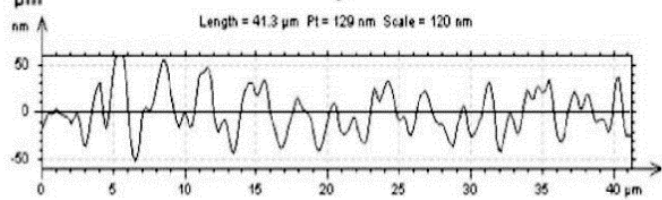

[c]

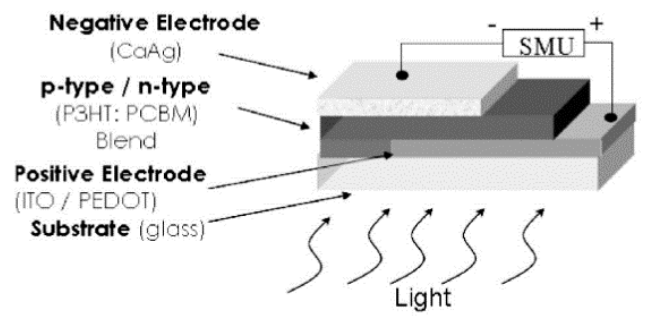

[b]
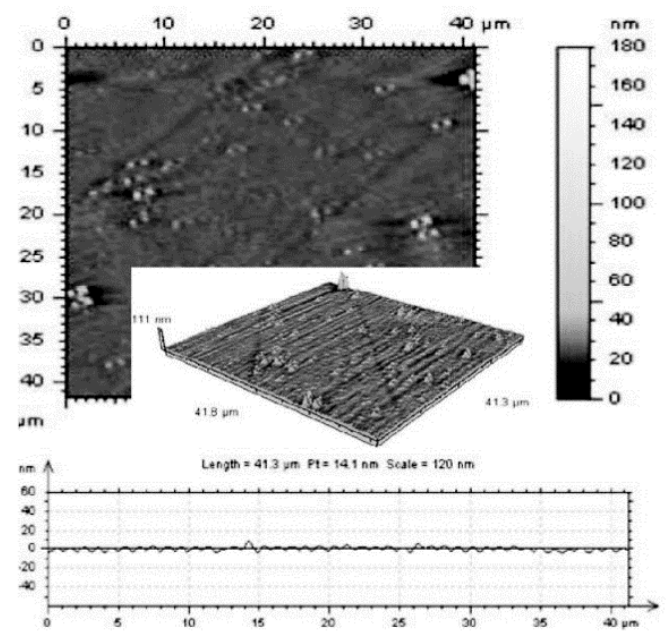

[d]

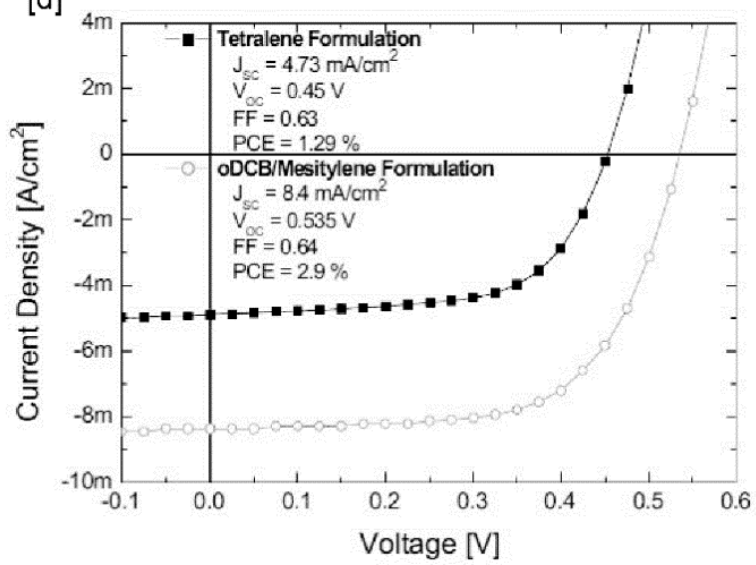

Figure 7 
[a] Multi-array

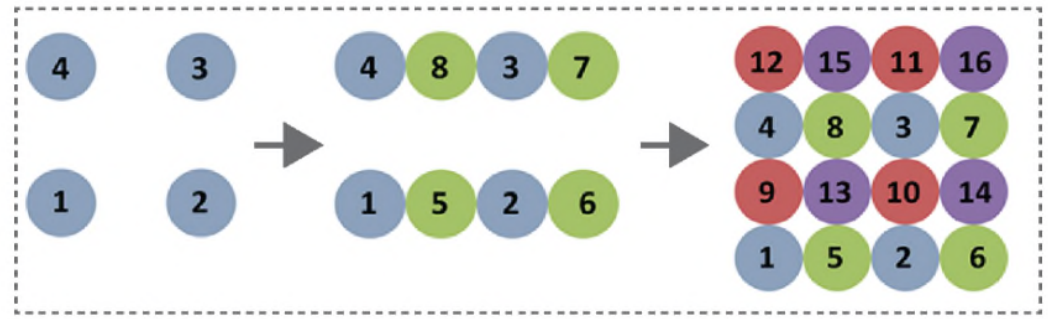

$1 6 \longdiv { 1 5 } 1 4,13$

$9 \longdiv { 1 0 }, 11,12$

$8 \longdiv { 7 } 6 \sqrt { 3 }$

$1 \longdiv { 2 } \quad 3 \quad 4$

[b]

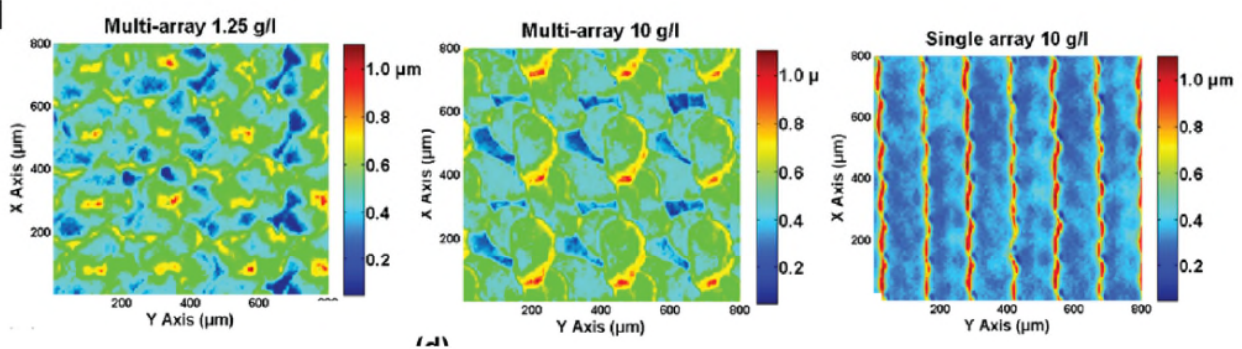

[c]

[d]
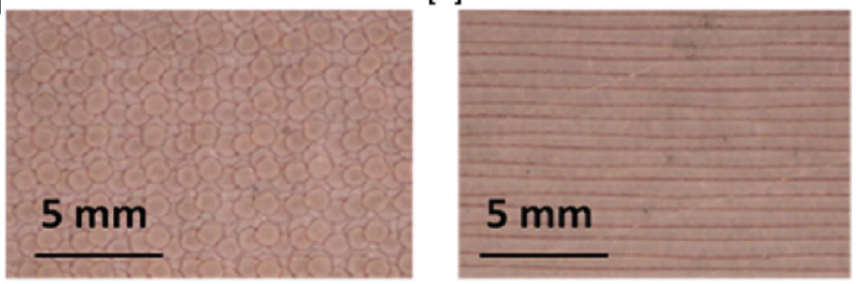

[e]
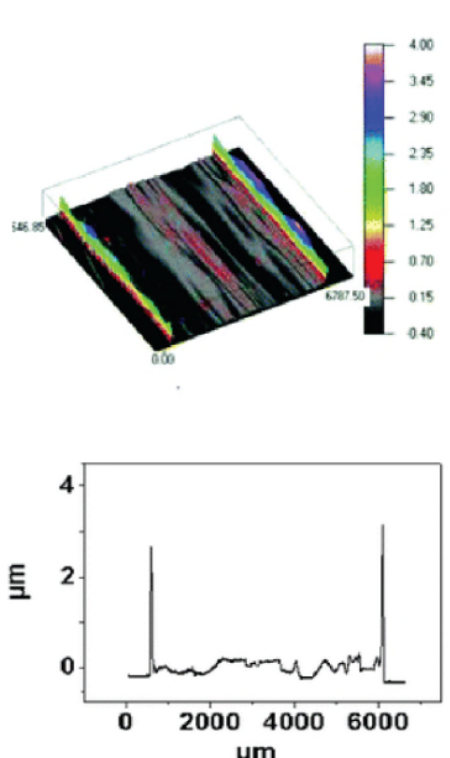

[f]
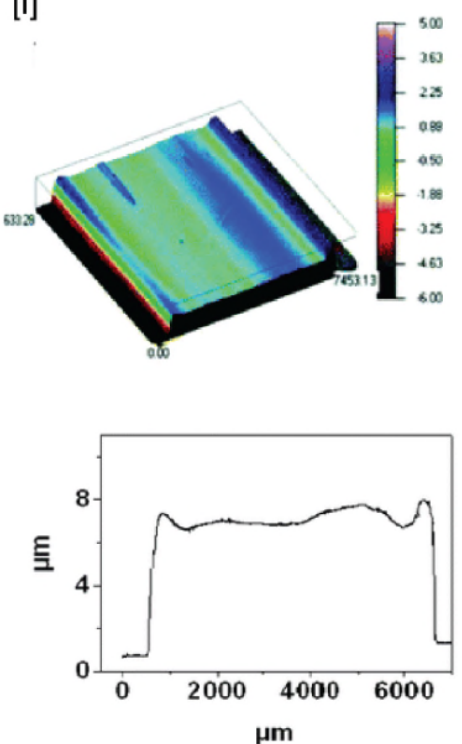
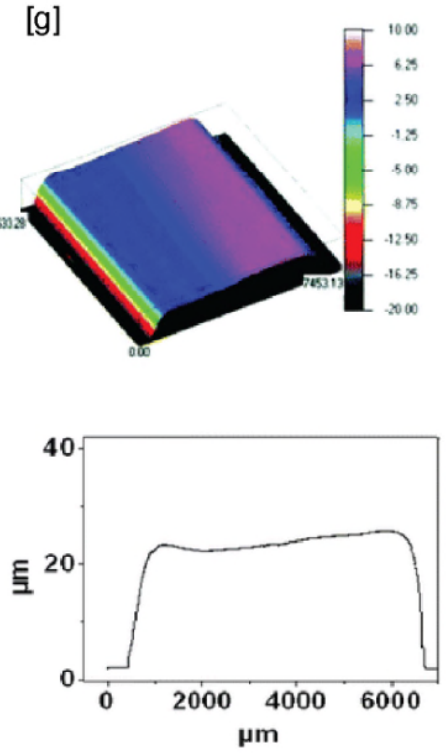

Figure 8 
[a]

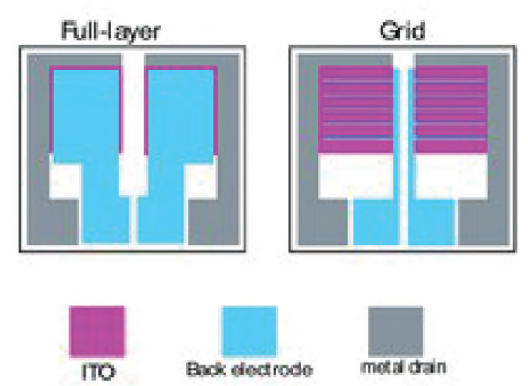

[b]

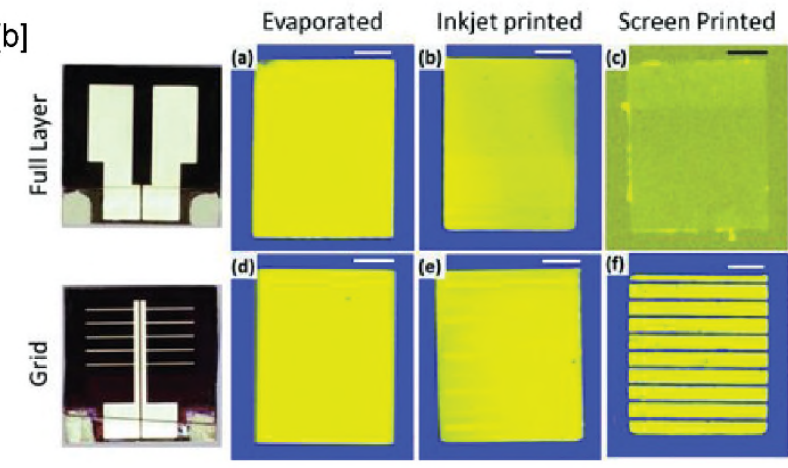

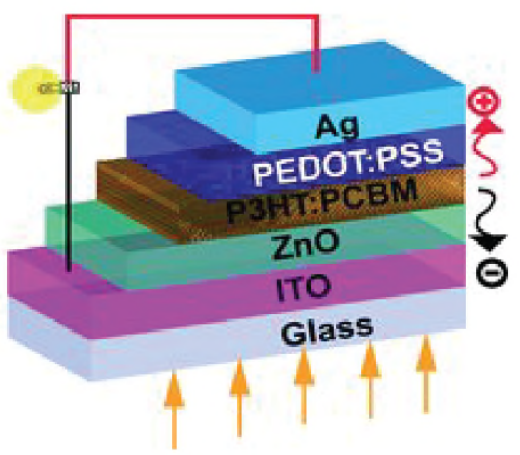

[c]

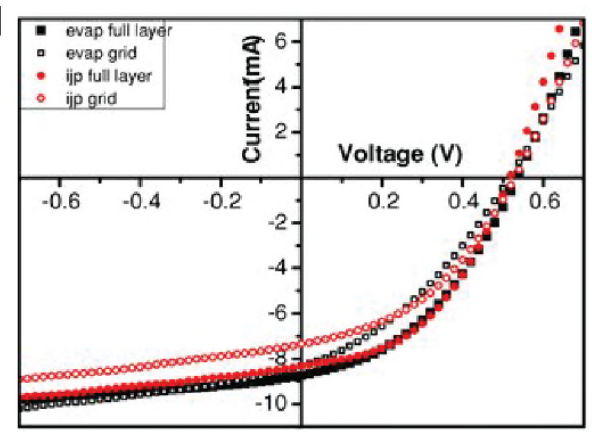

Figure 9 
[a]

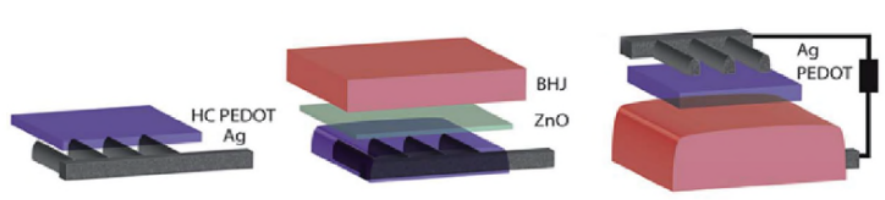

[b]

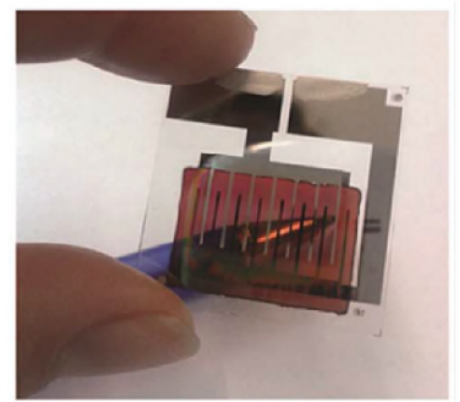

[c]

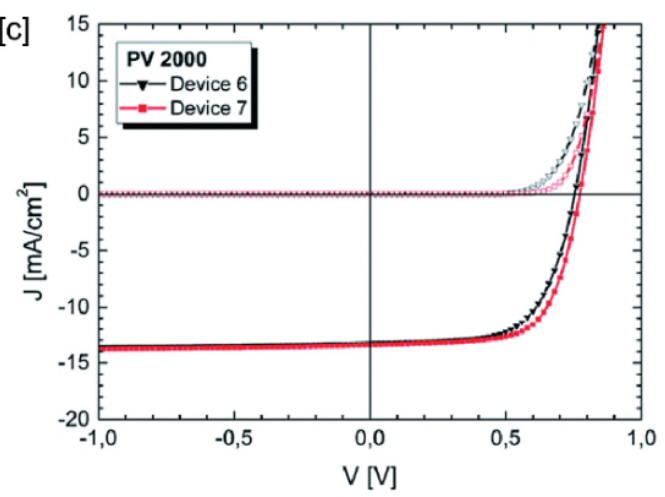

[e]

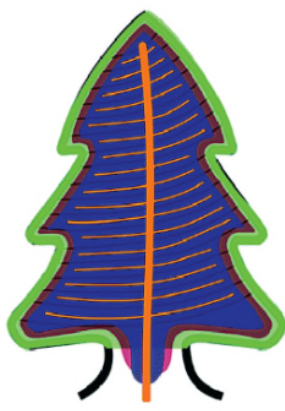

FrontAg UPHCPEDOT IIPZnO

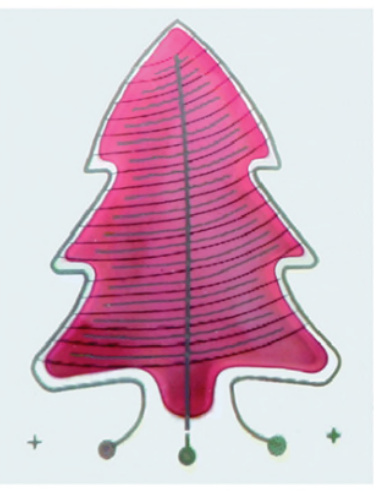

[d]
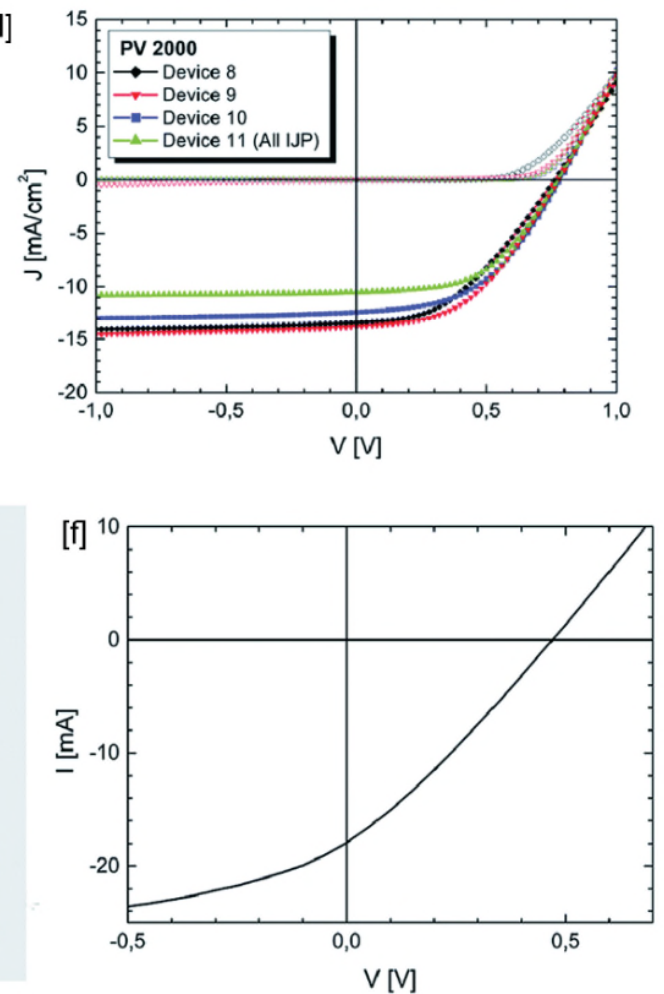

Figure 10 

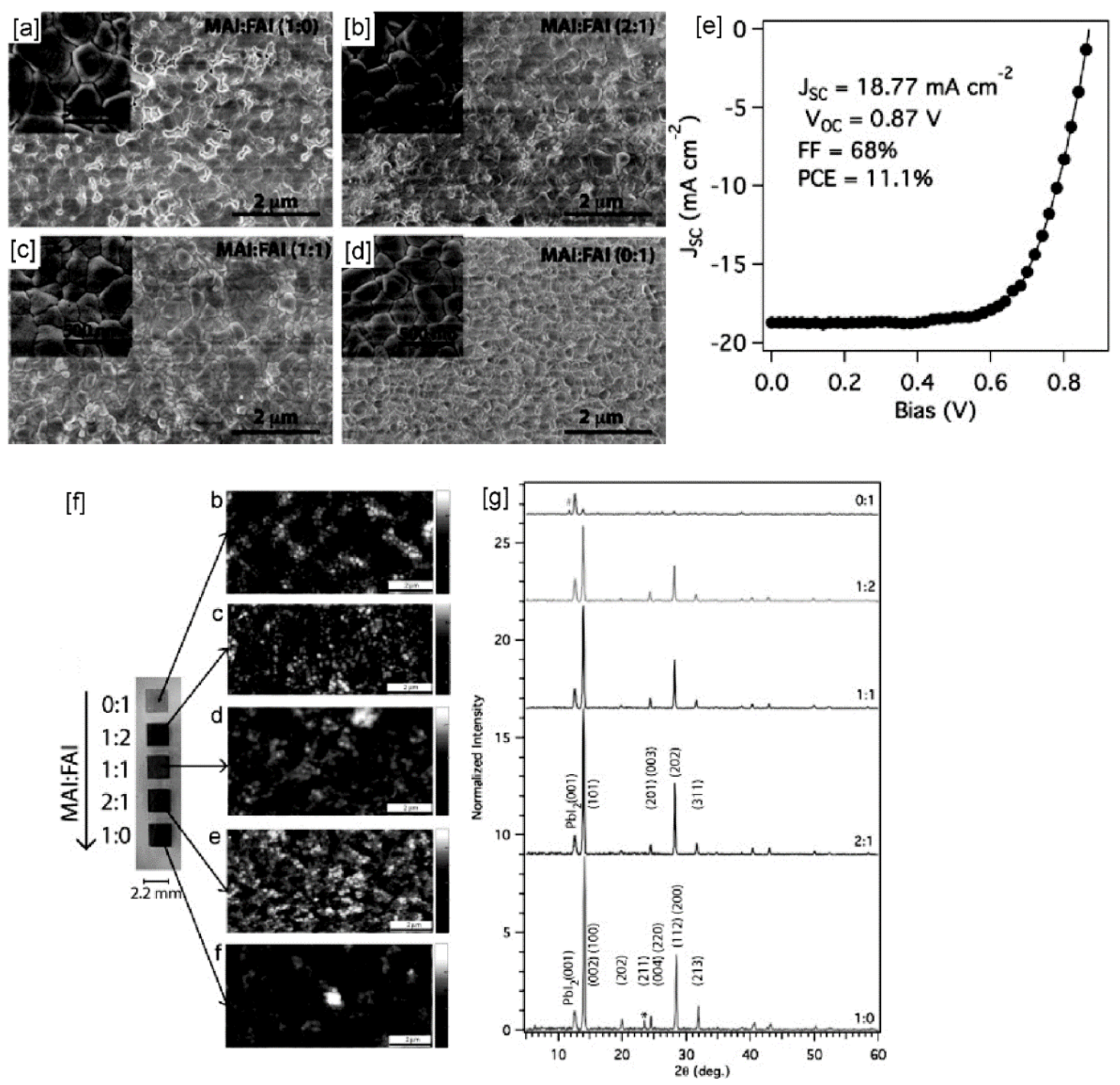

Figure 11 


\section{Tables}

Table 1 List of abbreviations used in this article.

\begin{tabular}{|c|c|}
\hline AM 1.5 & Air mass 1.5 \\
\hline IJP & Inkjet printing \\
\hline GW & Gigawatt \\
\hline SP & Screen printing \\
\hline PV & Photovoltaic \\
\hline PCE & Power conversion efficiency \\
\hline DPI & Dots-per-inch \\
\hline MPP & Maximum power point \\
\hline OSC & Organic solar cell \\
\hline PeSC & Perovskite solar cell \\
\hline R2R & Roll-to-roll \\
\hline PET & Polyethylene terephthalate \\
\hline PEN & Polyethyle nenaphthalate \\
\hline ITO & Indium tin oxide \\
\hline TCE & Transparent conducting electrode \\
\hline ETL & Electrode transport layer \\
\hline HTL & Hole transport layer \\
\hline DSSC & Dye-sensitized solar cell \\
\hline Mp- & Mesoporous \\
\hline $\mathrm{V}_{\mathrm{oc}}$ & open-circuit voltage \\
\hline $\mathrm{I}_{\mathrm{sc}}$ & Short-circuit current \\
\hline $\mathrm{J}_{\mathrm{sc}}$ & Short-circuit current density \\
\hline $\mathrm{FF}$ & Fill factor \\
\hline CIJ & Continuous inkjet printing \\
\hline LBIC & Laser beam induced current \\
\hline TIJ & Thermal inkjet printing \\
\hline DOD & Drop-on-demand \\
\hline PZT & Piezoelectric transducer \\
\hline MA & Methylammonium \\
\hline FA & Formamidinium \\
\hline $\begin{array}{l}\text { PEDOT:PS } \\
\mathrm{S}\end{array}$ & Poly(3,4-ethylenedioxythiophene):poly(styrenesulfonate) \\
\hline P3HT & Poly(3-hexylthiophene) \\
\hline PCBM & Fullerene derivative [6,6]-phenyl-C61-butyric acid methyl ester \\
\hline $\mathrm{BCP}$ & Bathocuproine \\
\hline EGBE & Ethylene glycol butyl ether \\
\hline o-DCB & ortho-Dichlorobenzene \\
\hline RR & Regioregularity \\
\hline QD & Quantum dot \\
\hline ODT & 1,8-octanedithiol \\
\hline Cl-naph & 1-chloronaphthalene \\
\hline $\mathrm{CB}$ & Chlorobenzene \\
\hline $\mathrm{CF}$ & Chloroform \\
\hline MT & Mesitylene \\
\hline TCB & Trichlorobenzene \\
\hline
\end{tabular}




\begin{tabular}{|l|l|}
\hline HC- & Highly conductive \\
\hline Ag NW & Sliver nanowire \\
\hline PCPDTBT & $\begin{array}{l}\text { Poly[2,6-(4,4-bis-(2-ethylhexyl)-4H-cyclopenta[2,1-b;3,4- } \\
\text { b']dithiophene)-alt-4,7(2,1,3-benzothiadiazole)] }\end{array}$ \\
\hline PSBTBT & $\begin{array}{l}\text { Poly[(4,4'-bis-(2-ethylhexyl)-dithieno(3,2-b;2',3'-d)silole]-2,6- } \\
\text { diyl-alt-(2,1,3 benzothiadiazole)-4,7-diyl] }\end{array}$ \\
\hline NP & nanoparticle \\
\hline b.p. & Boiling point \\
\hline
\end{tabular}


Table 2 Comprehensive list of inkjet printed layers incorporated into OSCs. Key parameters relating to IJP are summarized All cells characterized under $1000 \mathrm{~W} \mathrm{~cm}^{-2} \mathrm{AM} 1.5 \mathrm{G}$.

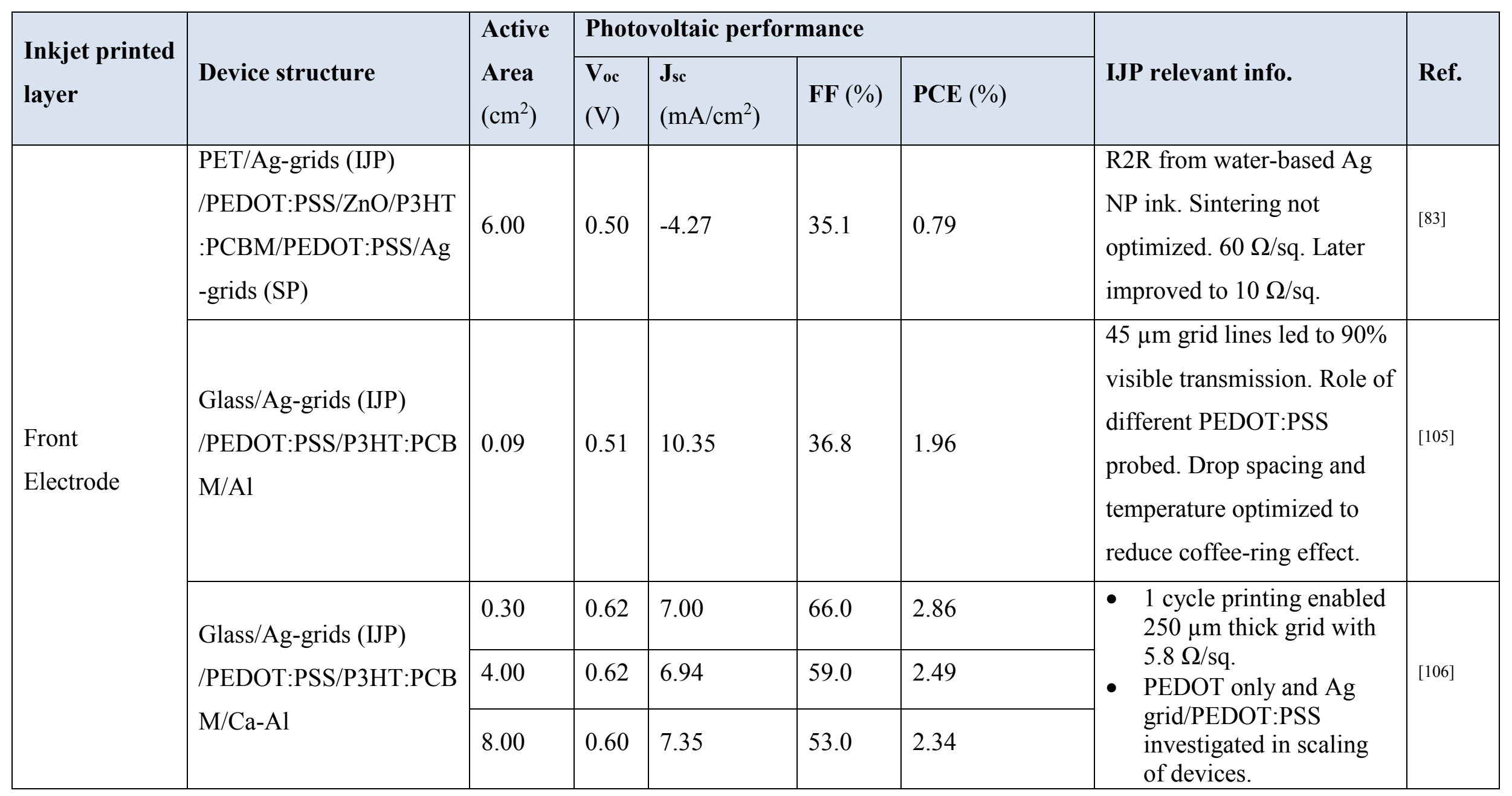




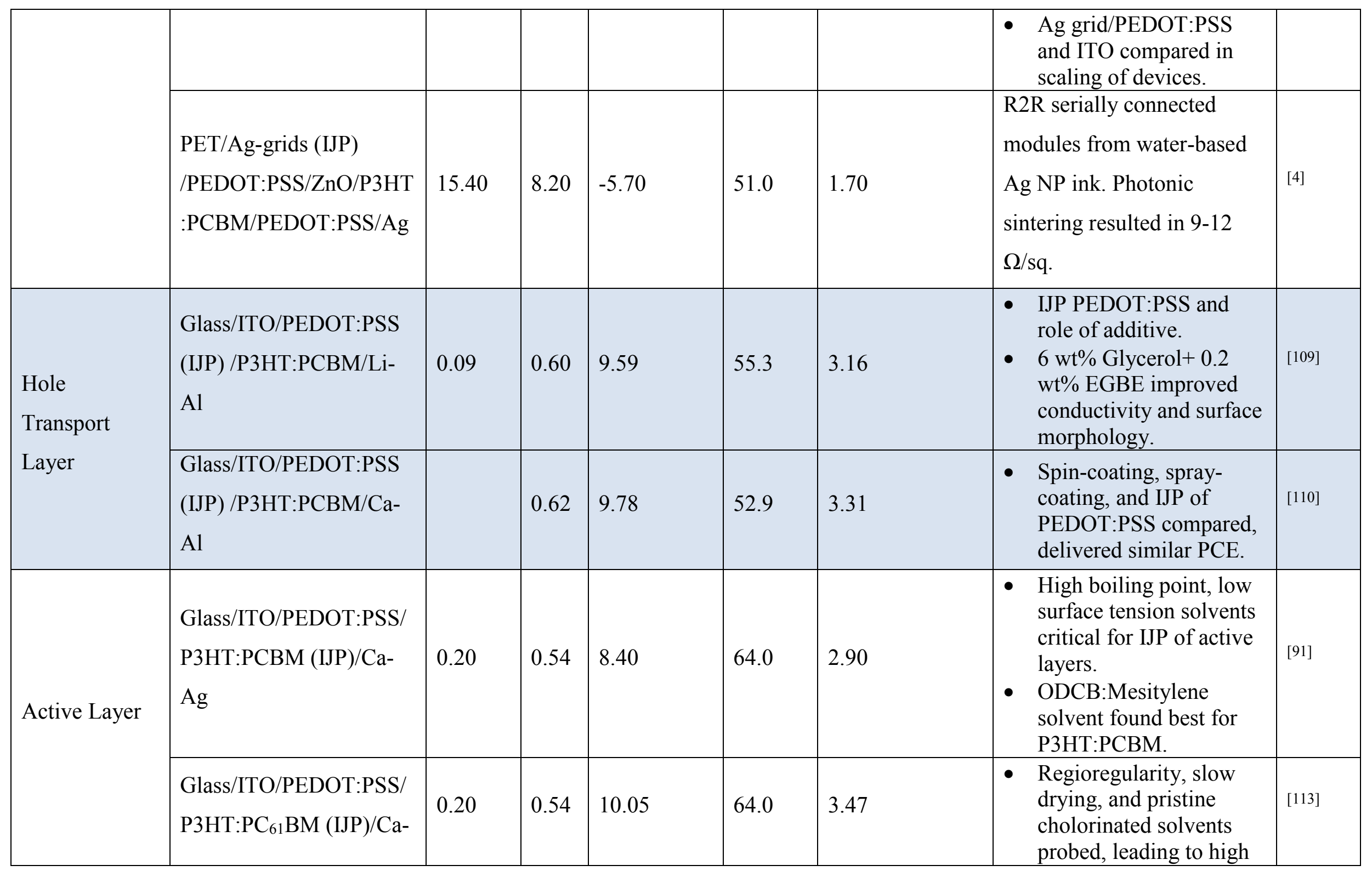




\begin{tabular}{|c|c|c|c|c|c|c|c|}
\hline $\mathrm{Ag}$ & & & & & & $\begin{array}{l}\text { efficiency P3HT:PCBM } \\
\text { cells. } \\
\text { - } \\
\text { Regioregularity of } \\
\text { P3HT:PCBM inkjet } \\
\text { printed films probed. } \\
\text { - } \text { Highly regioregular } \\
\text { (98\%) found not suitable } \\
\text { for IJP while doctor } \\
\text { blading led to high } \\
\text { efficiency. }\end{array}$ & \\
\hline $\begin{array}{l}\text { Glass/ITO/PEDOT:PSS/ } \\
\text { P3HT:PCBM (IJP)/Al }\end{array}$ & $\sim 0.03$ & 0.66 & 4.67 & 46.0 & 1.40 & $\begin{array}{l}\text { Ink viscosity and surface } \\
\text { wetting impact highlighted. }\end{array}$ & [92] \\
\hline $\begin{array}{l}\text { Glass/ITO/PEDOT:PSS/ } \\
\text { P3HT:PCBM (IJP)/Ca- } \\
\text { Ag }\end{array}$ & 0.02 & 0.54 & 10.10 & 64.0 & 3.50 & $\begin{array}{l}\text { Regioregularity of } \\
\text { P3HT:PCBM in inkjet } \\
\text { printed films probed. } \\
\text { - Highly regioregular } \\
\text { (98\%) found not suitable } \\
\text { for IJP. }\end{array}$ & [114] \\
\hline $\begin{array}{l}\text { Glass/ITO/PEDOT:PSS } \\
\text { (IJP)/P3HT:PCBM } \\
\text { (IJP)/Al }\end{array}$ & & 0.51 & 8.94 & 34.0 & 1.54 & \multirow{2}{*}{$\begin{array}{l}\text { PEDOT:PSS modified } \\
\text { with } 25 \mathrm{wt} \% \text { IPA:25 } \\
\text { wt } \% \text { EG. } \\
\text { CB and trichlorobenzene } \\
\text { found optimal for } \\
\text { P3HT:PCBM IJP. }\end{array}$} & \multirow[b]{2}{*}{ [115] } \\
\hline $\begin{array}{l}\text { Glass/ITO/PEDOT:PSS } \\
\text { (Spin- } \\
\text { coated)/P3HT:PCBM } \\
\text { (IJP)/Al }\end{array}$ & 0.16 & 0.57 & 9.34 & 45.0 & 2.40 & & \\
\hline Glass/ITO/PEDOT:PSS/ & & 0.67 & 5.29 & 39.0 & 1.48 & $\begin{array}{l}\text { Combinatorial IJP for } \\
\text { fabrication of thin film }\end{array}$ & [116] \\
\hline
\end{tabular}




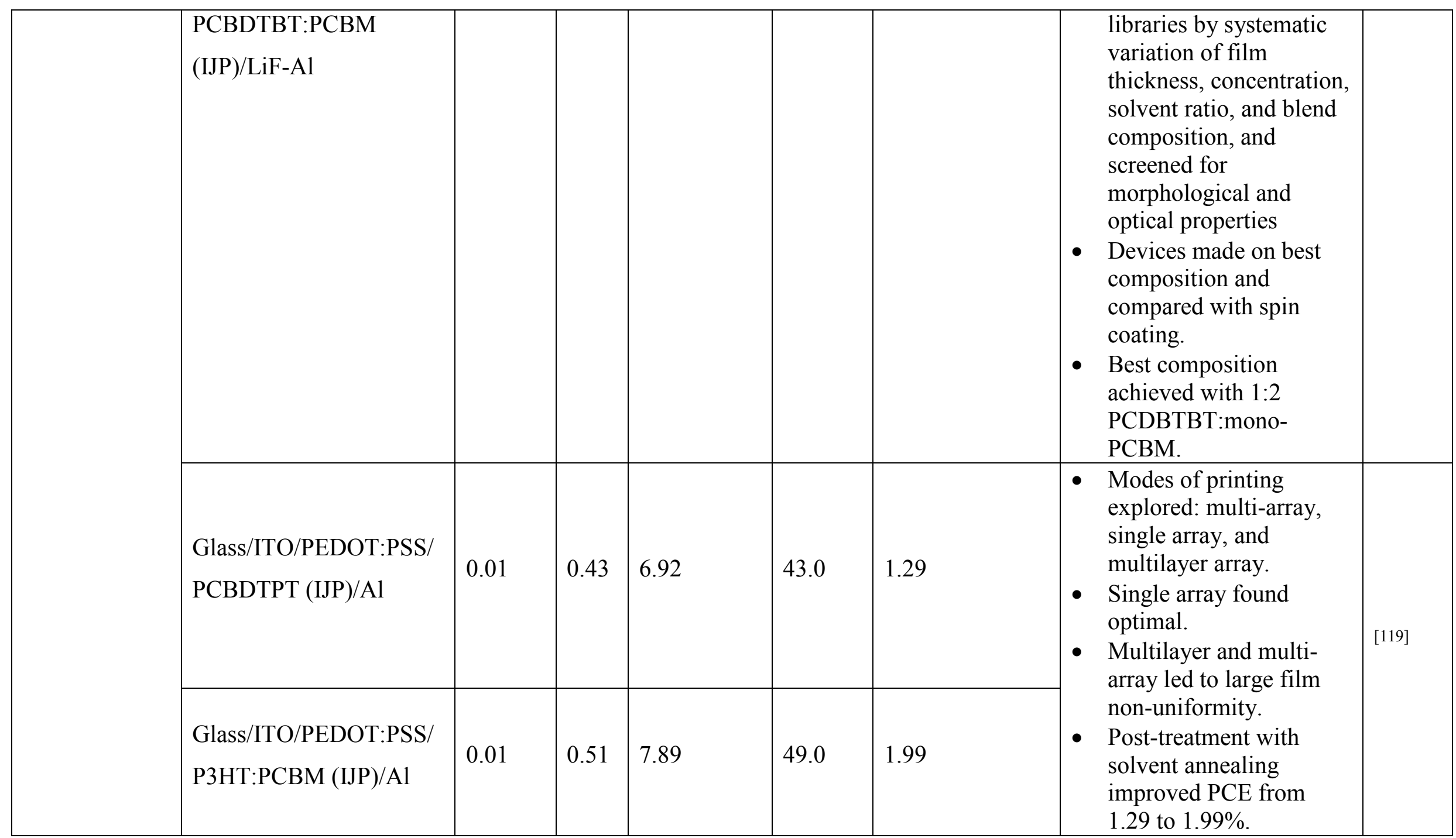




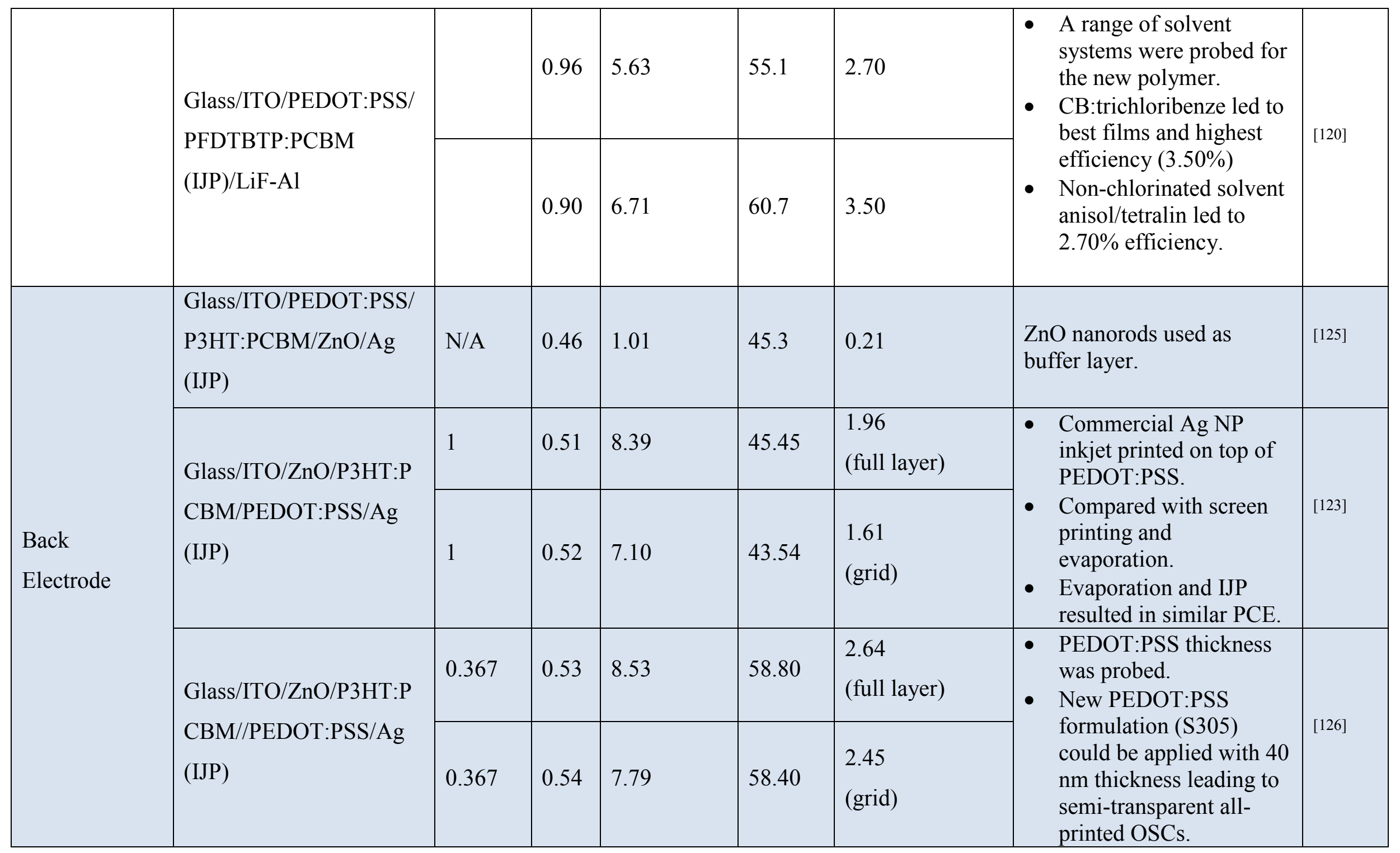




\begin{tabular}{|c|c|c|c|c|c|c|c|c|}
\hline & $\begin{array}{l}\text { Glass/ITO/ZnO/P3HT:P } \\
\text { C }_{61} \mathrm{BM} / / \mathrm{PEDOT}: \mathrm{PSS}: \mathrm{Mo} \\
\mathrm{O}_{3} / \mathrm{Ag} \text { NW (IJP) }\end{array}$ & & 0.60 & 8.44 & 54.00 & 2.71 & $\begin{array}{ll}\text { - } & \text { Printed Ag NW } \\
\text { - } & \text { Multiple passes (7) } \\
& \text { needed. }\end{array}$ & [127] \\
\hline \multirow{3}{*}{$\begin{array}{l}\text { Front } \\
\text { Electrode \& } \\
\text { Hole } \\
\text { Transport } \\
\text { Layer }\end{array}$} & $\begin{array}{l}\text { Glass/Ag-grids } \\
\text { (IJP)/PEDOT:PSS (IJP) } \\
\text { /P3HT:PCBM/LiF-Al }\end{array}$ & 0.09 & 0.50 & 6.51 & 42.2 & $\begin{array}{l}1.38 \\
\text { (flash sintering) }\end{array}$ & $\begin{array}{l}6 \mathrm{~s} \text { of flash sintering }(1000 \\
\mathrm{W}) \text { led to similar } \\
\text { efficiencies as } 6 \mathrm{hrs} \text { of oven } \\
\text { sintering }\left(130^{\circ} \mathrm{C}\right) \text {. }\end{array}$ & {$[108]$} \\
\hline & $\begin{array}{l}\text { Glass/Ag-grids } \\
\text { (IJP)/PEDOT:PSS (IJP) } \\
\text { /P3HT:PCBM/LiF-Al }\end{array}$ & 4 & 0.50 & 6.37 & 48.0 & 1.54 & \multirow{2}{*}{$\begin{array}{l}\text { - IJP height and width of } \\
\text { Ag grids were analyzed } \\
\text { and modelled. } \\
\text { - Busbar impact was } \\
\text { probed. } \\
\text { - Flexible substrate and } \\
\text { glass substrates } \\
\text { compared. Ag grid led }\end{array}$} & \multirow[t]{2}{*}[140]{} \\
\hline & $\begin{array}{l}\text { Flexible foil/Ag-grids } \\
\text { (IJP) /PEDOT:PSS (IJP) }\end{array}$ & 4 & 0.50 & 6.15 & 48.0 & 1.48 & & \\
\hline
\end{tabular}




\begin{tabular}{|c|c|c|c|c|c|c|c|c|}
\hline & /P3HT:PCBM/LiF-Al & & & & & & $\begin{array}{l}\text { to similar PCE } \\
\text { irrespective of the } \\
\text { substrate, whereas ITO } \\
\text { led to drop in efficiency } \\
\text { on flexible substrates } \\
\text { due to high sheet } \\
\text { resistance. }\end{array}$ & \\
\hline \multirow[t]{2}{*}{$\begin{array}{l}\text { Hole } \\
\text { Transport } \\
\text { Layer \& } \\
\text { Active Layer }\end{array}$} & $\begin{array}{l}\text { Glass/ITO/PEDOT:PSS } \\
\text { (IJP)/P3HT:PCBM } \\
\text { (IJP)/LiF-Al }\end{array}$ & 0.09 & 0.63 & 10.68 & 55.3 & 3.71 & $\begin{array}{l}\text { Additives for } \\
\text { PEDOT:PSS and } \\
\text { P3HT:PCBM probed. } \\
\text { PEDOT:PSS in } \\
\text { glycerol:EGBE. } \\
\text { CB with 5\% ODT } \\
\text { solvent for } \\
\text { P3HT:PCBM. }\end{array}$ & [117] \\
\hline & $\begin{array}{l}\text { Glass/ITO/PEDOT:PSS } \\
\text { (IJP)/PCDTBT:PC } 70 \mathrm{BM} \\
\text { (IJP)/Al }\end{array}$ & 0.5 & 0.89 & 9.95 & 56.8 & 5.07 & $\begin{array}{l}\text { CB:MT:CF (5:4:1) } \\
\text { solvent mixture needed. } \\
5 \mathrm{wt} \% \text { DMSO and } 0.1 \% \\
\text { fluoro surfactant added } \\
\text { to PEDOT:PSS. }\end{array}$ & [118] \\
\hline \multirow[t]{2}{*}{$\begin{array}{l}\text { Front \& Back } \\
\text { Electrodes }\end{array}$} & $\begin{array}{l}\text { Glass/Ag-grids (IJP) } \\
\text { /PEDOT:PSS/P3HT:PCB } \\
\text { M/PFN/Ag (IJP) }\end{array}$ & & 0.50 & 6.40 & 63.0 & 1.94 & $\begin{array}{l}\text { First successfully all- } \\
\text { printed devices. } \\
\text { ZnO led to cracks in Ag } \\
\text { film. Thus, substituted } \\
\text { with PFN. } \\
\text { - Efficiency lower than } \\
\text { evaporated Ag back } \\
\text { electrodes. }\end{array}$ & [13] \\
\hline & $\begin{array}{l}\text { Glass/Ag } \\
\text { NW(IJP)/ZnO/PV2000:P }\end{array}$ & 1.00 & 0.76 & 10.70 & 52.8 & 4.30 & $\begin{array}{l}\text { Silver ink diluted with } \\
\text { pentanol to achieve } \\
\text { good printing. }\end{array}$ & [141] \\
\hline
\end{tabular}




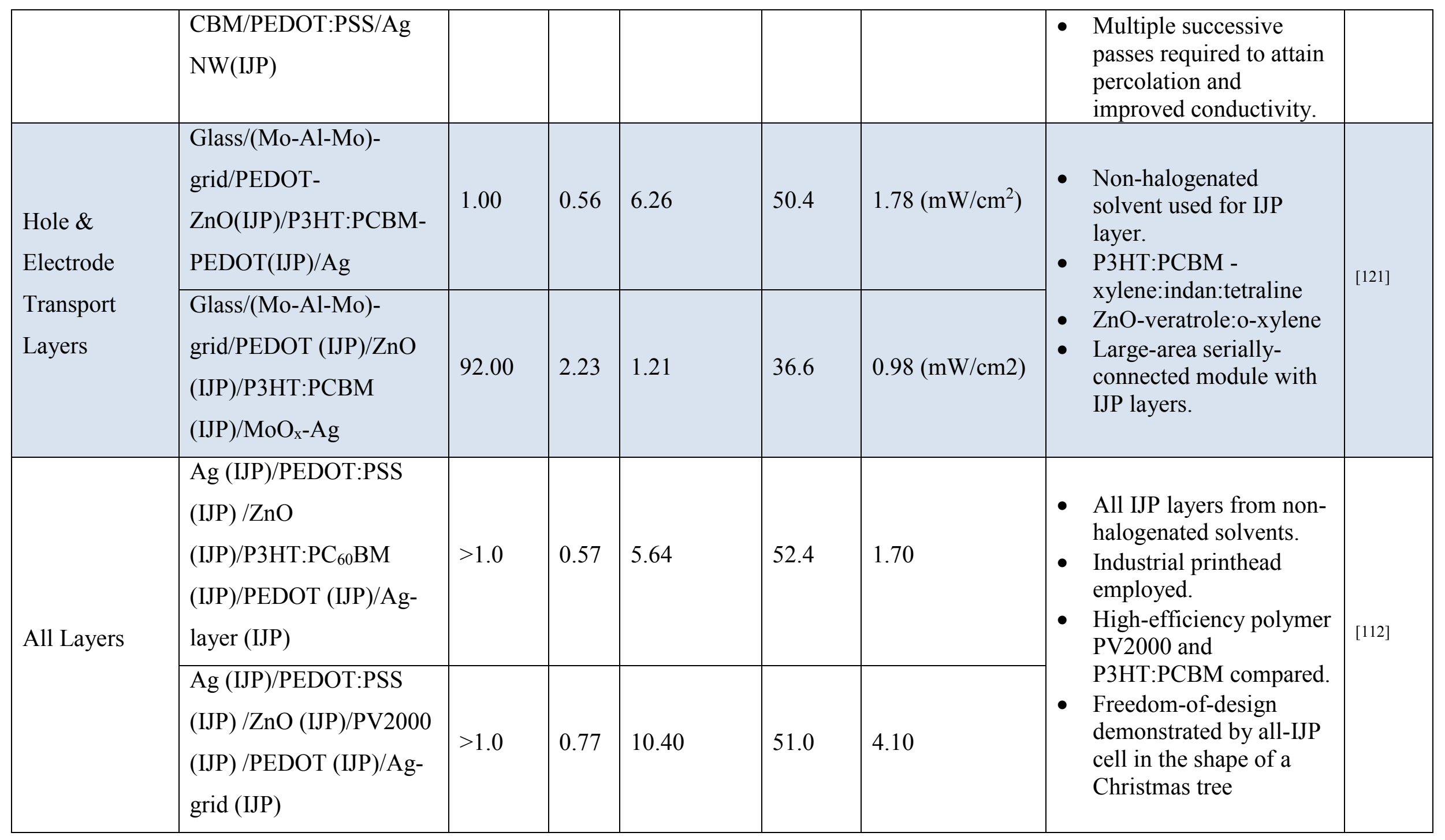




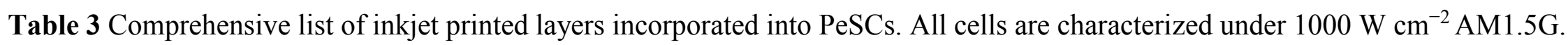

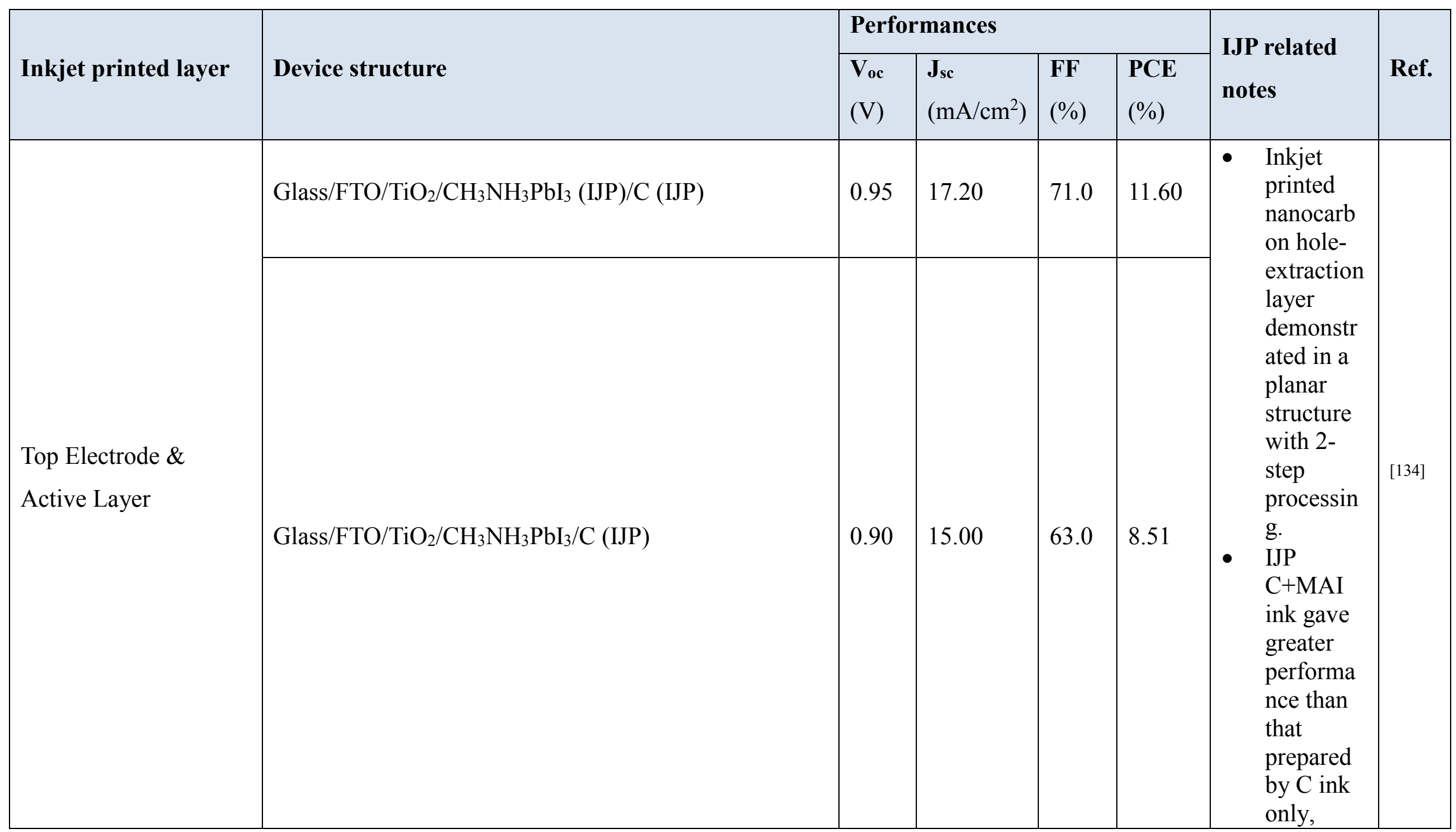




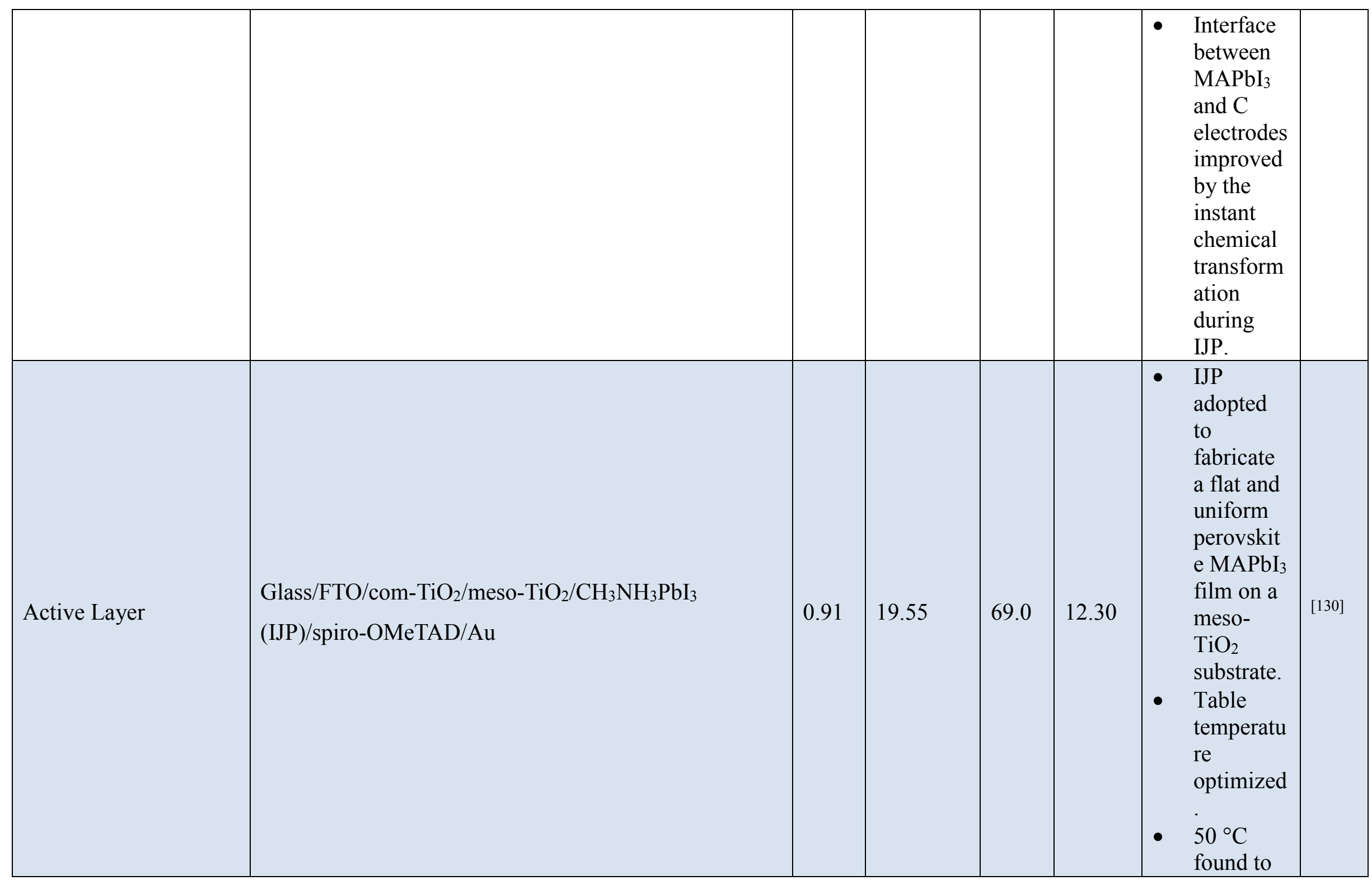




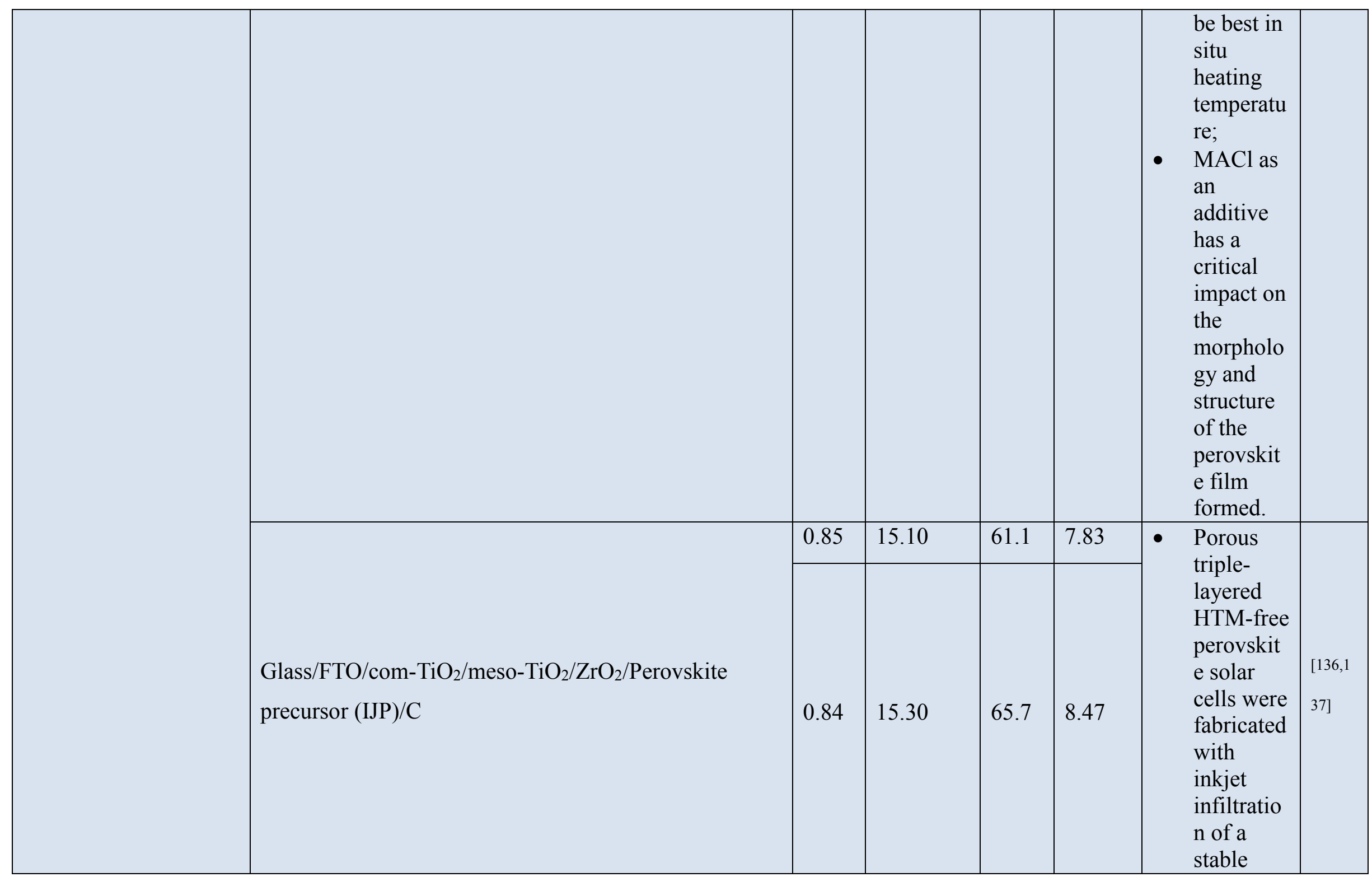




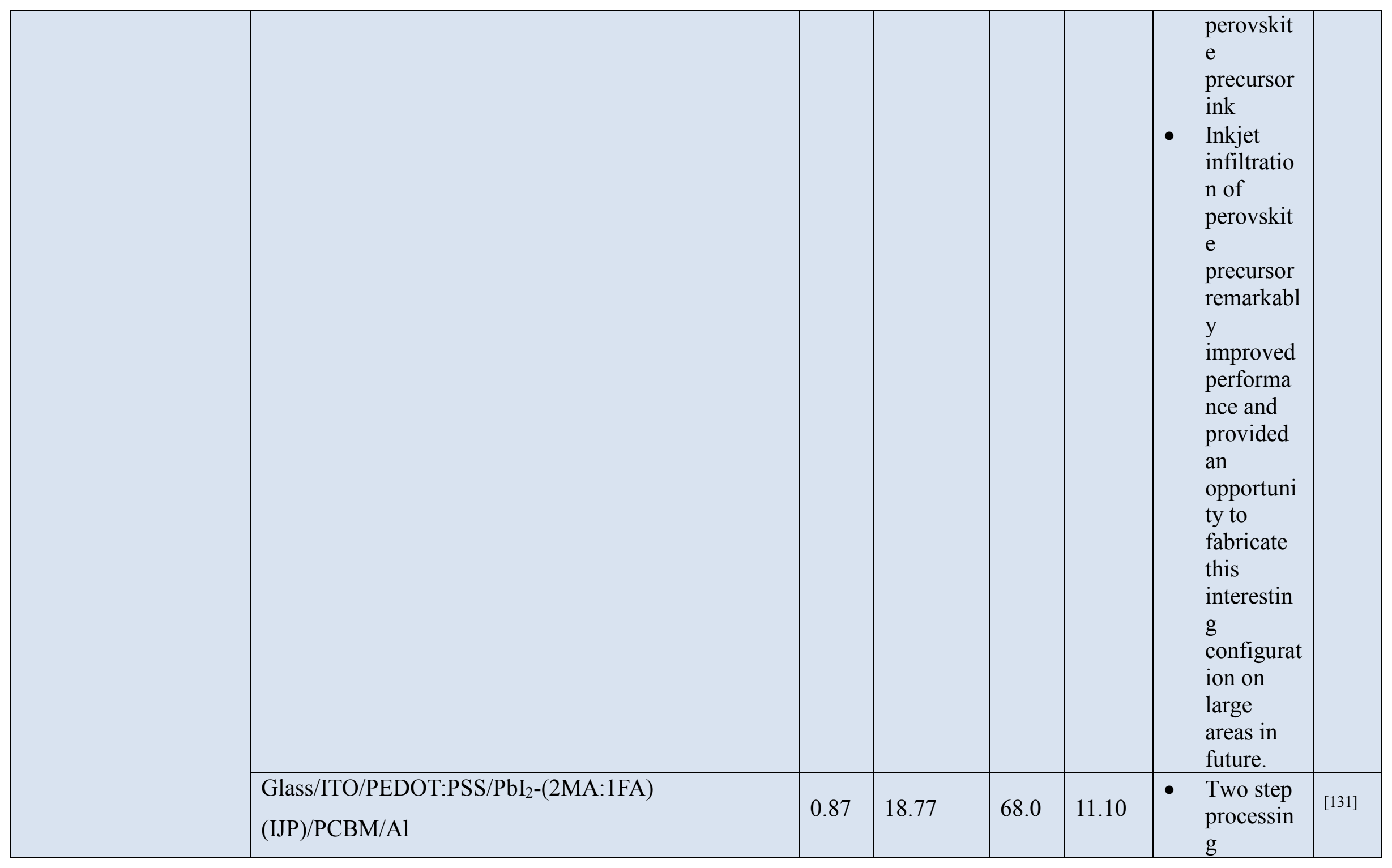




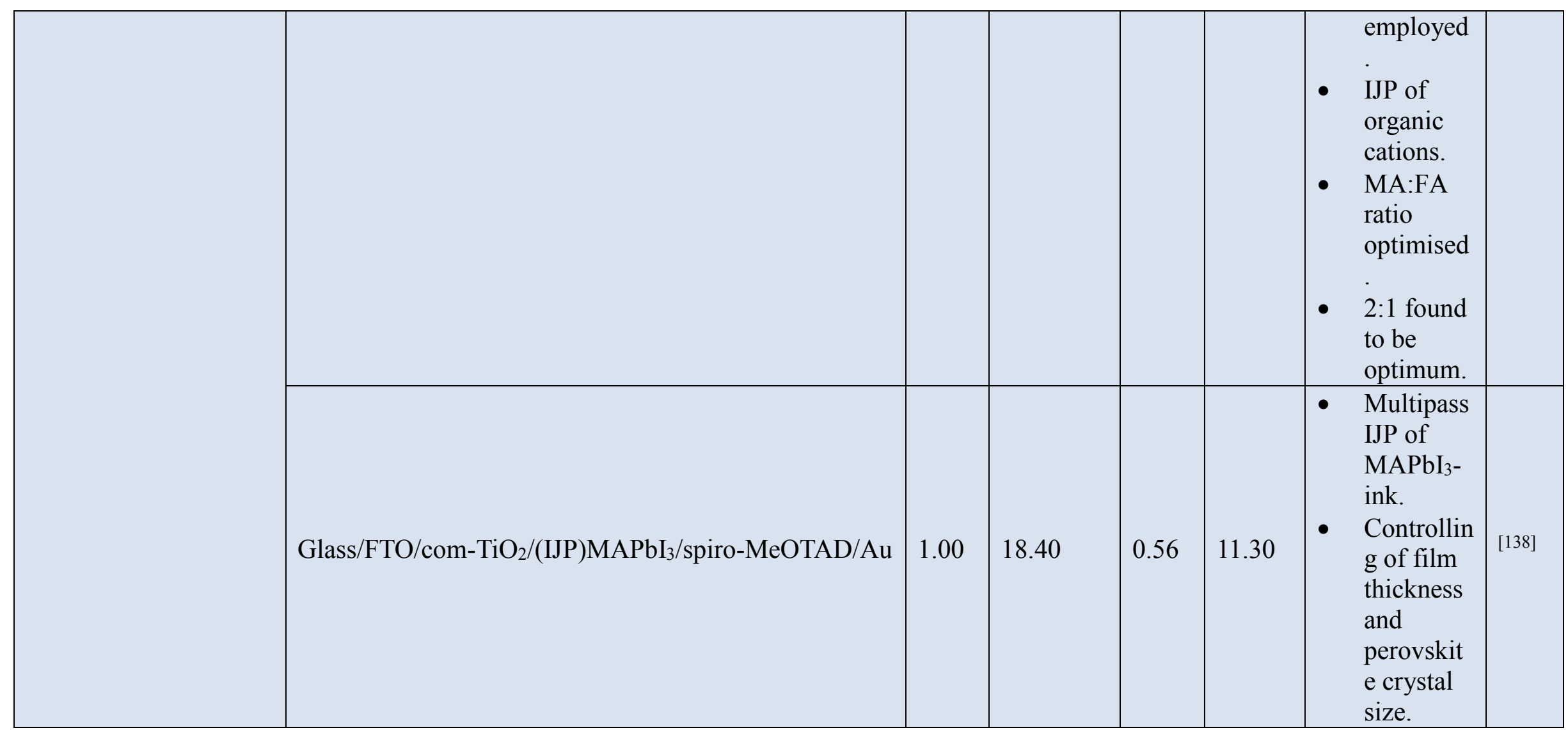


Table 4. A comparison between the physical properties of thermally imprinted and silver filled, inkjet printed, and flexographically printed Ag grids used as transparent conducting electrodes, and the semi-industrial scale production methods used to produce them (shaded rows). Our comments are listed in the last column. Reproduced with permission from ref. ${ }^{[83]}$. Copyright $\mathbb{C}$ 2012, Royal Society of Chemistry. 


\begin{tabular}{|c|c|c|c|c|}
\hline & $\begin{array}{l}\text { Thermally } \\
\text { Imprinted }\end{array}$ & Inkjet printed & $\begin{array}{l}\text { Flexographic } \\
\text { printed }\end{array}$ & Our comments \\
\hline Speed $\left[\mathrm{m} \mathrm{min}^{-1}\right]$ & $0.48^{\mathrm{a}}$ & 2 & 25 & Speed in production is limited by oven length. \\
\hline $\begin{array}{l}\text { Maximum possible speed } \\
{\left[\mathrm{m} \mathrm{min}^{-1}\right]}\end{array}$ & $6^{\mathrm{a}}$ & 75 & 200 & \\
\hline Number of steps & 2 & 1 & 1 & \\
\hline Ink type & Nanoparticles & Nanoparticles & Nanoparticles & \\
\hline Water as solvent & Yes & Yes & Yes & \\
\hline Cost of master & Medium & Free (Digital) & Low & \\
\hline Freedom-of-design & Medium & High & Medium & $\begin{array}{l}\text { While all methods will allow } 2 \mathrm{D} \text { freedom-of- } \\
\text { design, IJP offers faster turnover as no physical } \\
\text { production of a master is required, thus designs } \\
\text { can be made/change without delay. }\end{array}$ \\
\hline Technical yield & High & High & High & \\
\hline Resolution $[\mu \mathrm{m}]$ & 16 & 100 & 100 & \\
\hline $\begin{array}{l}\text { Maximum resolution achievable } \\
{[\mu \mathrm{m}]^{\mathrm{c}}}\end{array}$ & 8 & 32 & 32 & \\
\hline Printed height [nm] & $0 \pm 25$ & $200 \pm 100$ & $200 \pm 150$ & \\
\hline
\end{tabular}




\begin{tabular}{|c|c|c|c|c|}
\hline Spikes [nm] & 20 & 50 & 1000 & \\
\hline Sheet resistance $\left[\Omega \square^{-11}\right]$ & 10 & 60 & 11 & $\begin{array}{l}\text { IJP inks contain stabilizers and require longer } \\
\text { drying times. In this article, drying time for IJP } \\
\text { inks was } 2 \text { min. Thus, conductivity can be } \\
\text { improved by increasing drying/sintering time }{ }^{[4]} \\
\text { which is easily accomplishable industrial setting } \\
\text { with longer drying length (longer oven). }\end{array}$ \\
\hline \multicolumn{5}{|c|}{$\begin{array}{l}\text { a The thermally imprinted grid is prepared in two consecutive steps - imprinting of the pattern on the substrate followed by filling with silver. } \\
\text { The speed was } 0.96 \mathrm{~m} \mathrm{~min}^{-1} \text { in both steps. The maximum achievable speed is } 12 \mathrm{~m} \mathrm{~min}^{-1} \text { if carried out in an inline process. If the imprinting } \\
\text { and silver filling is carried out in two discrete steps the maximum achievable speed is } 6 \mathrm{~m} \mathrm{~min}^{-1} \text {. The optical transmission includes reflection } \\
\text { losses and substrate absorption. } \\
{ }^{\mathrm{c}} \text { The value in brackets is the highest resolution currently achievable, defined as the minimum width of a discretely printed line. } \\
\text { d The flexoprinted grid lines presented spikes with a height of up to } 400 \text { microns. }\end{array}$} \\
\hline
\end{tabular}


2017-09-27

\title{
Perovskite and organic solar cells
}

fabricated by inkjet printing: progress and prospects

\author{
Peng, Xiaojin
}

Wiley

Peng, Xiaojin, Yuan, Jian, Shen, Shirley et al., Perovskite and organic solar cells fabricated by inkjet printing: progress and prospects. Advanced Functional Materials, Volume 27, Issue 41, November 3, 2017, article number 1703704

https://doi.org/10.1002/adfm.201703704

Downloaded from Cranfield Library Services E-Repository 